\title{
Electrokinetic Decontamination of Concrete
}

\author{
Final Report \\ August 3, 1993 - September 15, 1996
}

\section{RECEIVED \\ NOV 031997 \\ OSTI}

Work Performed Under Contract No.: DE-AC21-93MC30162

For

U.S. Department of Energy

Office of Environmental Management

Office of Technology Development

1000 Independence Avenue

Washington, DC 20585
U.S. Department of Energy

Office of Fossil Energy

Federal Energy Technology Center

Morgantown Site

P.O. Box 880

Morgantown, West Virginia 26507-0880

BSTRIBUTION OF THIS DOCUMENT IS UNUMTES

By

ISOTRON Corporation

13152 Chef Menteur Highway

New Orleans, Louisiana 70129

MASTER 


\section{Disclaimer}

This report was prepared as an account of work sponsored by an agency of the United States Government. Neither the United States Government nor any agency thereof, nor any of their employees, makes any warranty, express or implied, or assumes any legal liability or responsibility for the accuracy, completeness, or usefulness of any information, apparatus, product, or process disclosed, or represents that its use would not infringe privately owned rights. Reference herein to any specific commercial product, process, or service by trade name, trademark, manufacturer, or otherwise does not necessarily constitute or imply its endorsement, recommendation, or favoring by the United States Government or any agency thereof. The views and opinions of authors expressed herein do not necessarily state or reflect those of the United States Government or any agency thereof. 


\section{DISCLAIMER}

Portions of this document may be illegible electronic image products. Images are produced from the best available original document. 


\begin{abstract}
The ELECTROSORB " $\mathrm{C}$ " process is an electrokinetic process for decontaminating concrete. ELECTROSORB "C" uses a carpet-like extraction pad which is placed on the contaminated concrete surface. An electrolyte solution is circulated from a supporting module. This module keeps the electrolyte solution clean.

The work is advancing through the engineering development stage with steady progress toward a full scale demonstration unit which will be ready for incorporation in the DOE Large Scale Demonstration Program by Summer 1997.

A demonstration was carried out at the Mound Facility in Miamisburg, Ohio, in June 1996. Third party verification by EG\&G verified the effectiveness of the process. Results of this work and the developmental work that proceeded are described herein.
\end{abstract}




\section{TABLE OF CONTENTS}

LIST OF FIGURES $\ldots \ldots \ldots \ldots \ldots \ldots \ldots \ldots \ldots \ldots \ldots \ldots \ldots \ldots \ldots \ldots \ldots \ldots \ldots \ldots$

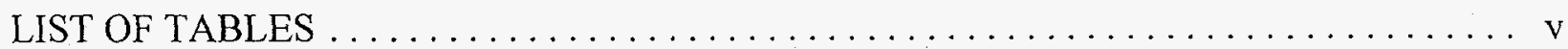

ACKNOWLEDGMENTS $\ldots \ldots \ldots \ldots \ldots \ldots \ldots \ldots \ldots \ldots \ldots \ldots \ldots \ldots \ldots$ vi

EXECUTIVE SUMMARY $\ldots \ldots \ldots \ldots \ldots \ldots \ldots \ldots \ldots \ldots \ldots \ldots \ldots$ vii

1. INTRODUCTION $\ldots \ldots \ldots \ldots \ldots \ldots \ldots \ldots \ldots \ldots \ldots \ldots \ldots \ldots \ldots \ldots$

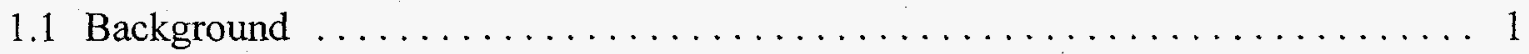

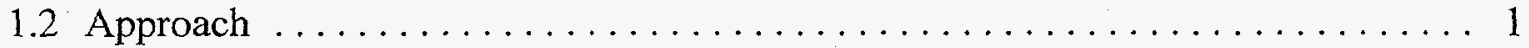

1.3 Milestones $\ldots \ldots \ldots \ldots \ldots \ldots \ldots \ldots \ldots \ldots \ldots \ldots \ldots \ldots \ldots \ldots \ldots$

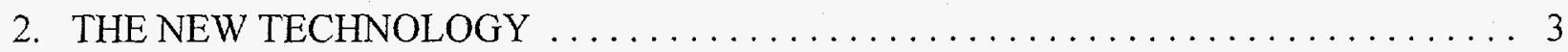

2.1 Brief Description of Technology $\ldots \ldots \ldots \ldots \ldots \ldots \ldots \ldots \ldots \ldots \ldots \ldots \ldots \ldots \ldots \ldots$

2.2 Summary of Technical Accomplishments in the Field Demo . . . . . . . . . . . 4

2.3 Technical Advantages over Baseline/Alternate Innovative Technologies . . . . . . . 5

2.4 Readiness for Commercial Application . . . . . . . . . . . . . . . . 6

3. ECONOMICS $\ldots \ldots \ldots \ldots \ldots \ldots \ldots \ldots \ldots \ldots \ldots \ldots \ldots \ldots \ldots \ldots \ldots$

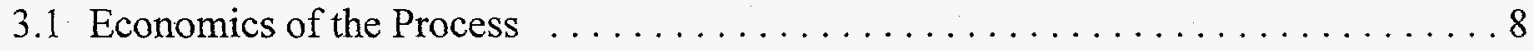

3.2 Cost Benefits over Baseline Technologies $\ldots \ldots \ldots \ldots \ldots \ldots \ldots \ldots \ldots \ldots \ldots$

3.3 Cost for Technology Development $\ldots \ldots \ldots \ldots \ldots \ldots \ldots \ldots \ldots \ldots \ldots \ldots$

4. SAFETY, ENVIRONMENTAL PROTECTION AND RISK $\ldots \ldots \ldots \ldots \ldots \ldots \ldots \ldots$

5. REGULATORY/PERMITTING $\ldots \ldots \ldots \ldots \ldots \ldots \ldots \ldots \ldots \ldots \ldots \ldots \ldots$

6. STAKEHOLDER ISSUES $\ldots \ldots \ldots \ldots \ldots \ldots \ldots \ldots \ldots \ldots \ldots \ldots \ldots \ldots \ldots \ldots \ldots \ldots \ldots \ldots$

7. COMMERCIAL VIABILITY $\ldots \ldots \ldots \ldots \ldots \ldots \ldots \ldots \ldots \ldots \ldots \ldots \ldots \ldots \ldots$

7.1 Current Status of the Technology in Meeting Technical Challenges . . . . . . 11

7.2 Final Product Concept and Scopes of Process Optimization and Improvement . . . . . . . . . . . . . . . . . . . . . . 12

7.3 Patent and License Agreements . . . . . . . . . . . . . . . . . . 12

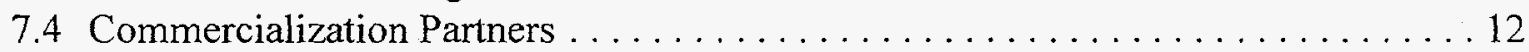

7.5 Plan for Technology Transfer to the End-User $\ldots \ldots \ldots \ldots \ldots \ldots \ldots \ldots \ldots \ldots \ldots$

\section{APPENDIX}

Process Chemistry and Operating Parameters of the ELECTROSORB ${ }^{\circledR}$ "C" Electrokinetic Extraction Technology . . . . . . . . . . . . . . . . . . . . . . . . 1-28 


\section{LIST OF FIGURES}

Figure

Page

1 Scenario No. 1: Total Cost per Sq. Ft. of Concrete $\ldots \ldots \ldots \ldots \ldots \ldots$

2 Scenario No. 2: Total Cost per Sq. Ft. of Concrete ................. 9

3 Scenario No. 3: Total Cost per Sq. Ft. of Concrete . . . . . . . . . . . . . 10

\section{APPENDIX}

A1 ELECTROSORB ${ }^{\circledR}$ "C" Process Concept $\ldots \ldots \ldots \ldots \ldots \ldots \ldots \ldots \ldots \ldots$

A2 A Schematic of the ELECTROSORB ${ }^{\circledR}$ "C" Process Demonstrated at the Mound Facility . . . . . . . . . . . . . . . . . . 2

A3 Exposed Concrete Surface in Tests 1 through $4 \ldots \ldots \ldots \ldots \ldots$

A4 Thorium Extraction Vs. Treatment Time in Test $1 \ldots \ldots \ldots \ldots \ldots$

A5 Thorium Extraction Vs. Treatment Time in Test $2 \ldots \ldots \ldots \ldots \ldots \ldots \ldots$

A6 Thorium Extraction Vs. Treatment Time in Test $3 \ldots \ldots \ldots \ldots \ldots$

A7 Thorium Extraction $V_{s}$. Treatment Time in Test $4 \ldots \ldots \ldots \ldots \ldots \ldots \ldots$

A8 Normalized Thorium and Calcium Extraction Rates in Tests 1 through $4 \ldots \ldots 10$

A9 Possible Mechanisms for Heterogeneous Chemical Reactions . . . . . . . . 13

A10 Relative Thorium and Calcium Extraction Under Varying Current . . . . . . 15

A11 Exposed Concrete Surface in Tests 5 and $6 \ldots \ldots \ldots \ldots \ldots \ldots$

A12 Thorium Extraction Vs. Treatment Time in Tests 5 and $6 \ldots \ldots \ldots$

A13-1 Radiation Count in the Test 5 Area before Treatment . . . . . . . . . . . 22

A13-2 Radiation Count in the Test 5 Area after Treatment . . . . . . . . . . . . . 22

A14-1 Radiation Count in the Test 6 Area before Treatment . . . . . . . . . . . 23

A14-2 Radiation Count in the Test 6 Area after Treatment . . . . . . . . . . . . . 23

A15 Locations of Tests 5 and 6 Areas on the Radiation Level Grid . . . . . . . . . 24

A16 Process Scheme for Secondary Waste Minimization $\ldots \ldots \ldots \ldots \ldots \ldots$

Photo A1 Process Hardware Operated during the Mound Facility Demonstration ......... 3

Photo A2 Mound Facility Demonstration Floor Conditions . . . . . . . . . . . . . 4 


\section{LIST OF TABLES}

Table

Page

1 Comparison of Projected Secondary Waste Volume for

ELECTROSORB ${ }^{\circledR}$ Process versus Baseline Technologies

\section{APPENDIX}

A1 Operating Conditions for Tests 1 through $4 \ldots \ldots \ldots \ldots \ldots \ldots$

A2 Thorium and Calcium Extraction in Tests 1 through $4 \ldots \ldots \ldots \ldots \ldots$

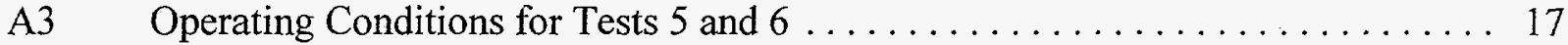

A4 Thorium and Calcium Extraction in Tests 5 and $6 \ldots \ldots \ldots \ldots \ldots$ 


\section{ACKNOWLEDGMENTS}

The authors thank the program managers for their support. The effort of Program Technical Manger, Jagdish Malhotra is especially recognized for the guidance given to the program. The overall program integration and management effort of Paul Hart and Steve Bossart of METC staff is sincerely appreciated. Also, the role of D\&D Program Manager, Jerry Hyde is acknowledged, especially for organizing this technology development opportunity.

The authors also acknowledge contribution of Dr. Yuri Kharkats of the A.N. Frumkin Institute of Electrochemistry in Moscow, to the theoretical modeling, and to Dr. Konstantin Popov of the Institute of Chemical Reagents and High Pure Substances in Moscow, for his contribution in the area of complexant theory. 


\section{EXECU'TIVE SUMMARY}

The U.S. Department of Energy has identified the decontamination of concrete as one of its primary problem areas that must be addressed in its Decontamination and Decommissioning Program.

The DOE estimates the magnitude of this problem at 200 million square feet of radionuclide contaminated concrete.

The cost of decontamination of concrete varies considerably with the site specific considerations. Nevertheless, the "average estimates" point to figures in range of tens of dollars per square foot.

The problem of waste disposal of concrete rubble and debris is yet another high priority item in the Decontamination and Decommissioning Program.

In response to these problems, ISOTRON ${ }^{\circledR}$ Corporation has presented a technology which can provide a novel approach to this problem. This approach provides benefits as follows:

- The process provides favorable economics (generally in range of $50 \%$ of the presently available).

- The process is "user friendly", considering the fact that the process is confined within an enclosure, thus insuring against airborne releases.

- The process is semiautomatic in the sense that the worker is not required to attend the process (minimizing worker exposure time within a rad zone).

- The process does not damage the concrete surface, thus facilitating reuse of the surface.

- The process minimizes the volume of secondary waste generated during decontamination.

- The process achieves a solid waste form.

In the course of bringing this technology through the Phase I demonstration phase, ISOTRON ${ }^{\circledR}$ scientists have succeeded in accomplishing some breakthroughs which will be important for DOE.

1. ISOTRON ${ }^{\circledR}$ 's electrolyte recycle technique using cold vapor distillation and solidification with proprietary oil field cement can have significant impact on other problem wastes which DOE encounters.

2. The process for electrokinetically cleaning concrete rubble was demonstrated during this work. This can provide DOE with an important tool in its toolbox.

3. The demonstration of the electrokinetic enhanced dissolution of contaminants using state of the art complexant technologies and the potential for continuously recycling the electrolyte solution 
during the decontamination scenario will provide DOE's D\&D contractors with an easy to use process which requires limited volume of working solutions and which will reach cleanup levels which were heretofore unattainable.

The following conclusions can be derived from the Phase I work:

A. The ELECTROSORB "C" electrokinetic extraction process presents a highly effective process for cleaning concrete.

B. The process can remove contaminants which are deep in concrete inasmuch as the "electromobile" contaminants, such as cesium and strontium which are likely to travel to such depths, are also responsive to the electric transport.

C. The process can be made semiautomatic, thus freeing workers from extended "hands-on" activities and prolonged "stay time" in a rad zone.

D. Assuming certain engineering work, the process can be made ready for evaluation in DOE's large scale demonstration program. 


\section{INTRODUCTION}

\subsection{BACKGROUND}

As a consequence of weapons production activities which occurred over the past 50 years, the U.S. Department of Energy has accumulated more than 200 million square feet of contaminated concrete. This problem compels the development of an efficient technology for concrete decontamination.

In response to this need, ISOTRON ${ }^{\circledR}$ proposed the application of an electrokinetic transport mechanism to extract contaminants from concrete.

ISOTRON ${ }^{\mathbb{Q}}$ 's work with electrokinetic decontamination of soil provided that foundation for this work with concrete. This constituted the background needed to apply the technology to concrete. Unknown to ISOTRON ${ }^{\circledR}$ scientists, there was underway an investigative effort into electrokinetics by Dr. Bill Bostick of Oak Ridge’s K-25. This was summarized in Report № K/TCD-1054 issued in March 1993.

As of the end of 1992, the DOE's Decontamination and Decommissioning Focus Group advertized for innovative new approaches for soil decontamination, by means of a PRDA. ISOTRON ${ }^{\circledR}$ responded with a proposal to apply this electrokinetic extraction technique to concrete, and received a contract award.

\subsection{APPROACH}

The work which started in Summer of 1993 provided for a comprehensive study of the mechanisms which would control the process. ISOTRON ${ }^{\circledR}$ scientists concluded that the process must address not only electrokinetic transport of the contaminants through the concrete, but also the solubilization of the contaminants which had been sorbed on the internals of the concrete matrix or which had precipitated in the matrix due to its high $\mathrm{pH}$.

It became obvious that the solubilization aspect would be the controlling issue and that the success of the electrokinetic extraction process would be determined by the ability to find a highly effective solubilization mechanism which could be delivered to the concrete in the presence of its high $\mathrm{pH}$.

\subsection{MILESTONES}

During the second half of 1993, the work on solubilization chemistry in the laboratory was carried out in parallel with the preparation for small scale extraction demonstration at the DOE's Oak Ridge K-25 Site. This site provided excellent site support accommodations, due to its designation as a Center for Environmental Technologies. Early in the program, ISOTRON ${ }^{\circledR}$ and METC identified Vault № 15-A of the K-25 "U" Building as a preferred location for evaluating the electrokinetic process. This vault had been used for storage of fissile materials. During 1952 ad 1961 , reactor returns were converted from uranium oxide to $\mathrm{UF}_{6}$ in $\mathrm{K}-1131$, and the ash materials resulting from 
this conversion were stored and transferred from one container to another resulting in leaks and spills within this vault.

By end of November 1993, ISOTRON ${ }^{\circledR}$ completed the first on-site electrokinetic extraction of contaminants from the Vault 15-A floors.

Analytical work related to solubilization chemistry revealed a need for improved accuracy and, in early 1994, an Ion Conductive Plasma device was provided to ISOTRON ${ }^{\circledR}$ by DOE.

Following the advice of METC program technical manager and scientific collaborators from Oak Ridge National Laboratory, ISOTRON ${ }^{\circledR}$ placed emphasis on the electrokinetic decontamination of concrete debris. This work was carried out during the first six months of 1994. The results were successful. The results were reported to METC in program review meeting held in Morgantown, WV, November 15-19, 1994. See Technical Report № 061594 "Electrokinetic Extraction of Radionuclides from Concrete". During this same period, ISOTRON ${ }^{\oplus}$ scientists were able to show the feasibility of extracting contaminants using a "carpet like" extraction pad.

During the second half of 1994, ISOTRON ${ }^{\circledR}$ scientists' work focused on preparing for and carrying out a second field study. The on-site activity was performed over a two-week interval using a trailer mounted instrumentation and power supply package. This setup permitted ISOTRON ${ }^{\circledR}$ to establish an optimum electrokinetic extraction regime. This work also focused on the solubilizer chemistry, polarity and grounding methodology. This work is reported in program Report № 061594 dated June 15, 1994, "Electrokinetic Extraction of Radionuclides from Concrete (Complexants Carbonate, Citrate, Chloride)". This work demonstrated in the potential of the process to extract contaminants from deep in concrete.

During the first six months of 1995 , ISOTRON ${ }^{\circledR}$ scientists advanced the surface extraction pad design and returned to the Vault 15-A with a redesigned instrumentation package and the advanced pad. Again, the on-site program lasted for two weeks. The results showed extraction of up to two grams of uranium from a four square foot floor area. The results of this work were reported to METC in ISOTRON ${ }^{\circledR}$ report dated June 15 (Revision 02), "Results of Third In-Situ Jest at K-25 Site (Oak Ridge, Tennessee), April 24-28, 1995".

In June 1995, members of ISOTRON ${ }^{\circledast}$ staff traveled to Morgantown to present the positive results of the work and to request permission to advance the scope of work to allow construction of a 24 square foot extraction pad and a supporting module which would allow for the development of a scaled-up process which would clearly show the operational feasibility of this new process. In August 1995, Morgantown's staff authorized this activity, namely, a vacuum assisted SEEC pad (Surface Electrokinetic Extraction Pad) and its companion electrolyte recycle module.

By Fall of 1995 , ISOTRON ${ }^{\circledR}$ was proceeding with hardware development as well as coordination with K-25 Site plan for the field demonstration in Vault 15-A. Arrangements were made for pretest and post test characterization by a third party (Radian Corporation). 
In October 1995, ISOTRON ${ }^{\circledR}$ presented the results of its work at the Environmental Technology Development Through Industry Partnership Meeting, sponsored by EPRI (see technical paper "Electrokinetic Decontamination of Concrete").

Toward the end of 1995, a decision was made to change the host site to Mound Facility Building 21 , where the target contaminant would be thorium rather than uranium. This change was considered to be in the best interest of the Government inasmuch as it would allow additional insight into the capability of the process to deal with a range of contaminants. Furthermore, the Mound site was committed to identify an immediate follow-on application for this technology, if the demo was successful.

During the first six months of 1996, the hardware development proceeded. Functional testing was carried out during late Spring and the on-site testing was carried out over the two-week period of June 15 through June 30 . The successful results of this demonstration are reported in the following section.

On August 12, 1996, a technical briefing was presented to METC's staff who are concerned with Decontamination and Decommissioning. ISOTRON ${ }^{\circledR}$ 's positive results were tentatively verified by the preliminary report made by EG\&G staff from Mound Site. The following technical data relates to this briefing.

\section{THE NEW TECHNOLOGY}

\subsection{BRIEF DESCRIPTION OF TECHNOLOGY}

ELECTROSORB ${ }^{\circledR}$ Electrokinetic Extraction Technology, developed by ISOTRON ${ }^{\circledR}$ Corporation offers a cost-effective approach to treating contaminated concrete. The process is designed to mobilize contaminants that are deep in the concrete. Most heavy metals/radionuclides are fixed in the concrete matrix either as sorbed species or in precipitated forms. Such fixed contaminants can be extracted using this process if they are chemically solubilized. This technology utilizes highly effective metal solubilizing reagents to dissolve these otherwise immobile contaminants. (Herein these are referred to as solubilizers). A DC electric field is applied across the contaminated concrete to electrokinetically transport the solubilized contaminants from the concrete-pores to a collector placed on the concrete-surface. The process takes place inside an enclosure which is maintained at a negative pressure. Process operation under a negative pressure and the use of wet chemistry allow dust-free decontamination. Under the influence of the applied electric field, the solubilizer reagent's penetration into the concrete matrix is enhanced.

The collector is an extraction pad laid on the surface of contaminated concrete. The pad provides confinement for a planar electrode and the solubilizer solution. A DC voltage is applied between this planar electrode and the concrete rebar or a metallic ground-rod. The solubilizer solution wets the planar electrode and the concrete surface, and provides electrical continuity between the two. The extraction pad is operated under a vacuum which assists in holding the pad firmly against the 
concrete surface while at the same time preventing leakage of the solubilizer solution out of the padarea. The vacuum under the pad is also instrumental in providing return-flow of the circulating solubilizer solution from the concrete surface to a solution-circulation tank. The process is designed such that it can be operated with little attendance. This reduces the workers' health hazards that are associated with a more labor intensive process.

Other features of the process include a modest rate of chemical consumption and a reduced volume of secondary waste. This is possible because the process incorporates a mechanism for recycling the solubilizer solution. The contaminant-laden solubilizer solution is pumped through a solution cleanup module comprised of ion exchange bead columns. The contaminants are stripped out of the solubilizer solution in the resin bead columns, and the processed solution is recycled back to service. When the extraction cycle is completed, the loaded bead columns can be dewatered and sent for burial.

ISOTRON ${ }^{\circledR}$ is working on an advancement of secondary waste treatment process, which will significantly minimize the volume of waste sent for disposal. In this case, the nearly spent solubilizer solution will be fed to a vacuum-evaporation unit. The evaporator sludge will be solidified into a low-volume solid ceramic waste-form for disposal that complies with 10CFR

PART 61 burial criteria. The distillate collected in the evaporator will be reused for making the solubilizer solution.

\subsection{SUMMARY OF TECHNICAL ACCOMPLISHMENTS IN THE FIELD DEMO}

The field demonstration of concrete decon technology took place in the Building 21 site of DOE's Mound facility in Miamisburg, Ohio. This demonstration was conducted over a period of 12 days. Six separate runs of the concrete decontamination process were carried out. The technical accomplishments from this field demo can be summarized as follows.

- The effectiveness of the technology in extracting contaminants from concrete was demonstrated at full-scale, indicating the feasibility of cleanup of an entire building by employing this technology.

- The preliminary results point to the conclusion that the use of the stronger solubilizer solutions would achieve cleanup to the release level. The radiation count from the concrete floor was measured before and after each process cycle. The process was shown to reduce the radiation count to the background level. This corresponds to approximately $83 \%$ reduction in radiation count. This cleanup level will be verified by a post-treatment survey of the cleaned areas of the concrete floor. This is being done by ICF Kaiser Engineers, an independent contractor.

- The manual version of process hardware showed trouble-free operation, proving its readiness for the next step in process development. The next version will involve a more automated module. 
- The process hardware incorporated features for remote-controlling the introduction of concentrated reagents. These features demonstrated satisfactory performance.

- It was shown that the use of the stronger solubilizer solutions is not compatible with ISOTRON ${ }^{\circledR 1} \mathrm{~s}$ design predictions for resin bead volume usage. The volume of resin bead which was used was too high for an economic process. This necessitates a change in approach to secondary waste processing.

\subsection{TECHNICAL ADVANTAGES OVER BASELINE AND/OR ALTERNATE INNOVATIVE TECHNOLOGIES}

The ELECTROSORB ${ }^{\circledR}$ Electrokinetic Extraction Technology offers distinct advantages over the baseline and/or other innovative technologies. Alternative technologies can be classified under three broad categories: 1) chemical, 2) mechanical, and 3) heating. The limitations and/or drawbacks of these alternatives are some combinations of the following:

- limited to surface or shallow contamination;

- not effective for removing sorbed contaminants;

- result in airborne debris and dust problems;

- energy and/or labor intensive, especially when applied to large contaminated areas;

- high risk of personnel-exposure hazards;

- generate large volume of secondary waste (including dust, rubble, and wastewater).

The features of the ELECTROSORB ${ }^{\circledR}$ process represent a solution to these problems. The process employs electrokinetics, the electric field-driven transport phenomena, to extract contaminants from contaminated concrete. An electric field can be applied across any depth through concrete matrix. Also, electrokinetics is independent of hydraulic characteristics of a porous medium. For these reasons, this process can effectively extract contaminants from concrete, regardless of the depth of contamination and the hydraulic properties of this porous matrix.

The process uses an electrolyte solution, confined under an extraction pad, for solubilizing sorbed and/or precipitated contaminants. This feature allows extraction of immobile contaminants without creating any airborne dust problems.

The process is passive. It requires minimal operator interaction and does not use heavy equipment. Its labor demand is low and its deployment is easy. This also implies reduced exposure of workers to radiation dose.

The process's electrical energy demand is modest, in spite of the use of a continuous electrical current flux for contaminant extraction. This is a result of low electrical power delivery rate and high rate of contaminant extraction. 
The extracted contaminants are separated from the solubilizer solution and concentrated in a solid and easily disposable waste-form. This allows reuse of the solution, adding a significant cost feature in large-scale decontamination service. Secondary waste is generated, but its volume will be moderate. The waste volume advantage increases as the depth of contamination increases. The process is expected to be effective over considerable depth through the concrete matrix. Table 1 provides a comparison of projected secondary waste volume for the ELECTROSORB ${ }^{\circledR}$ process versus selected baseline technologies. The waste volume figure presented for ELECTROSORB ${ }^{\circledR}$ process applies to thorium extraction. The solubilizer reagents required for thorium extraction are quite strong. This results in etching of the concrete, which in turn results in generation of increased secondary waste volume. In this scenario, the advantage in secondary waste volume between the ELECTROSORB ${ }^{\circledast}$ process and the baseline technologies is not significant as reflected by the data presented in Table 1. However, the contaminants that have penetrated deep into the concrete are those which have less affinity for the solid phase of the concrete matrix. These contaminants can be solubilized more easily, and their solubilization need not result in etching of the concrete. In such case, the volume of the secondary waste generated by this process will be less than the same from the baseline technologies. The difference in secondary waste volume will be pronounced when the concrete floor bears fissures and cracks. In such situations, decontamination of the floor by the baseline technologies will be accompanied by removal of a large amount of the concrete.

Table 1

Comparison of Projected Secondary Waste Volume for ELECTROSORB ${ }^{\circledR}$ Process versus Baseline Technologies

\begin{tabular}{|l|l|}
\hline \multicolumn{1}{|c|}{ Technology } & \multicolumn{1}{|c|}{$\begin{array}{c}\text { Volume of Secondary Waste Generated, } \\
\mathbf{f t}^{3} / \mathbf{f t}^{2}\end{array}$} \\
\hline Scarifying & \multicolumn{1}{c}{} \\
\hline Grit Blasting $^{\mathrm{a}}$ & 0.081 \\
\hline ELECTROSORB $^{\otimes}$ (for thorium extraction) & 0.03 \\
\hline
\end{tabular}

a: Source:[1]

b: This figure is based on a waste-form comprising of loaded ion-exchange beads.

c: This figure is appropriate when waste-form is oil field cement.

\subsection{READINESS FOR COMMERCIAL APPLICATION}

This new technology is in an advanced stage of readiness for commercial application. The basic considerations for evaluating the readiness for commercialization are: process effectiveness, the functional reliability of process hardware at full-scale, and economics. The facts in support of the above conclusion are as follows. 
A prototype version of the process hardware has been operated at full scale. The ESM unit (for solution circulation and contaminant separation) showed reliable and trouble-free performance during the Mound facility-demo. Certain modifications of the hardware units have been identified, which are necessary for achieving a greater ease of operation and for a more efficient process control. The process hardware to be used in the subsequent process demonstration will incorporate these features.

One of the key factors controlling the efficacy of this technology is contaminant solubilization efficiency. ISOTRON ${ }^{\circledR}$ scientists identified solubilizing reagents that were effective for dissolving thorium from concrete matrix. The effectiveness of these reagents has been demonstrated at the Mound facility. The contaminant solubilization chemistry incorporated in this process is working to the extent that it provides confidence on the process's ability to extract contaminants.

Another factor that weighs heavily on the economics of this process is related to the secondary waste generation. ISOTRON ${ }^{\circledR}$ team has already made considerable progress in the area of secondary waste concentration and recycling of solubilizer solution. However, it is clear that further reduction of secondary waste volume must be achieved. ISOTRON ${ }^{\circledR 1} \mathrm{~s}$ approach involves application of advanced separations techniques incorporated into the existing process. The team is actively pursuing this process optimization task. It is scheduled to be completed before the next field demonstration at the K-25 site.

To summarize, certain features of this process must be optimized to achieve its potential for serving as a cost-effective and easily deployable technology for concrete decon. These optimization efforts should be completed before the next field demonstration, because the economics of the process will be positively affected. The potential benefit to DOE's D\&D effort can best be appreciated by the end-users if the process is presented in its best light. 


\subsection{ECONOMICS}

\subsection{ECONOMICS OF THE PROCESS}

Cost estimates will vary depending on many operational parameters. The Scenario No. 1 is applicable to the parameters used in the process demonstration at the Building 21 site of the Mound Facility.

\section{Figure 1}

Scenario No. 1

Total Cost per Sq. Ft. of Concrete:

$\$ 19.48$

\section{Cost Elements}

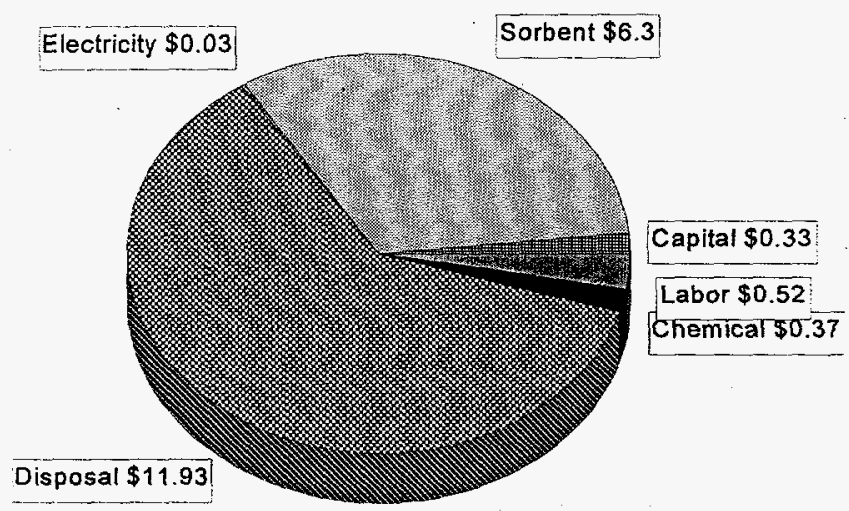

The process cost estimates presented above are based on the cleanup of $600 \mathrm{sq}$. ft. of concrete per day. The additional elements of total process cost are as follows: Thirty extraction pads, each having a footprint of $22.75 \mathrm{sq} . \mathrm{ft}$. are operated. Three solution circulation and processing modules (i.e., ten pads per module) are used. The capital cost is based on 3 years life-span for process equipment and taking 100 working days per year. Labor is based on a 2-person team at $\$ 43.75 /$ hour ( 8 hours per day). The disposal cost of the solid waste is based on the rate of $\$ 300.0 / \mathrm{ft}^{3}$. The projected sorbent cost does not assume reuse of the ion exchange beads. The electricity cost is based on the rate of $\$ 0.08 / \mathrm{kw}-\mathrm{hr}$. 
The Scenario No. 2 is applicable to the process features which incorporate a vacuum-evaporator unit and waste solidification in magnesium phosphate ceramic (originally developed by Argonne National Laboratory). The closed loop low temperature concentrator unit, having a processing capacity of 300 gallons/24 hours (manufacturer's price $\$ 55,165$ ), is used for separating the waste materials from the process water. The concentrate is solidified in the aforementioned waste-form. The waste loading capacity of the ceramic is $40 \%$ by weight. In this case, the chemical cost includes the costs of solubilizer and ceramic waste-form making chemicals. The vaporization energy is based on manufacturer's energy demand rating of $0.85 \mathrm{kw}-\mathrm{hr} / \mathrm{gallon}$.

Figure 2

Scenario No. 2

Total Cost per Sq. Ft. of Concrete:

$\$ 7.39$

\section{Cost Elements}

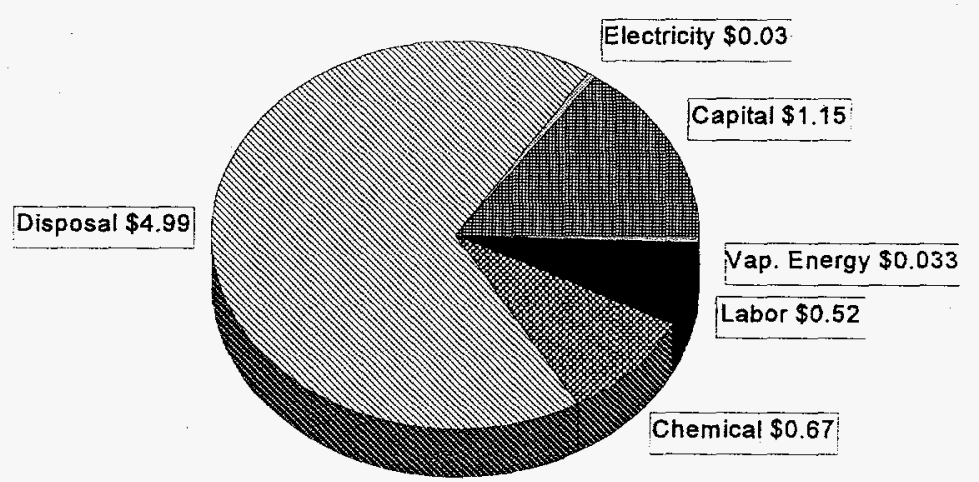


The Scenario No. 3 is nearly identical to the Scenario No. 2 except that a proprietary cement material is used for the solidification of the waste. This material allows a higher waste loading capacity $(50 \%)$ as compared to the mag-phos ceramic.

Figure 3

Scenario No. 3

Total Cost per Sq. Ft. of Concrete:

$\$ 4.91$

\section{Cost Elements}

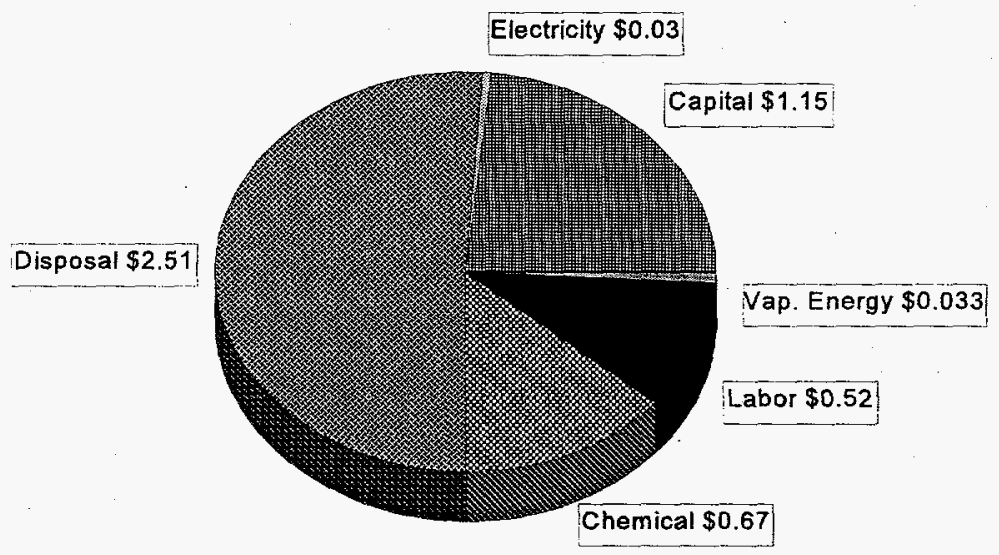

\subsection{COST BENEFITS OVER THE BASELINE TECHNOLOGIES}

The cost of the baseline technologies are as follows [1]:

Scarifier: $\$ 7.0$ to $12.6 / \mathrm{ft}^{2}$

Grit/Shot Blasting: $\$ 0.31$ to $6.65 / \mathrm{ft}^{2}$

It is not clear from the source literature whether the above costs include the cost of radioactive secondary waste disposal. The present technology is certainly cost-competitive with the baseline technologies. The Scenario No. 2 and Scenario No. 3 costs reflect savings over the baseline technologies. 


\subsection{COST FOR TECHNOLOGY DEVELOPMENT}

The budget for this technology development project is modest. Currently authorized funding permits only one prototype full scale field demonstration. A second demonstration is strategically important in order to permit incorporation of some important engineering advances. The scientific discoveries made during the course of this process development effort will have substantial impact on progress in the field of decontamination. The development of effective contaminant solubilizer systems, and solution recycling and secondary waste volume reduction techniques will offer spinoff benefits for many other decon processes.

\section{SAFETY, ENVIRONMENTAL PROTECTION AND RISK}

The ELECTROSORB ${ }^{\circledR}$ "C" Process represents a safe, dust-free, and environmentally benign approach to concrete decontamination. The extraction takes place in an enclosure maintained under a negative operating pressure. It uses wet chemistry, which is an added feature for eliminating airborne problems. The oxygen gas generated due to electrolysis at the anode is diluted by the sweep of air into the extraction pad. The discharge from vacuum pump goes to HEPA filtration unit. The final waste-form for disposal complies with 10CFR PART 61 burial criteria.

\section{REGULATORY/PERMITTING}

At this time, ISOTRON ${ }^{\circledR}$ is working with SAIC to identify needs, and to position this technology for DOE's large scale demonstration program. During these demonstrations, the regulatory criteria will be determined.

\section{STAKEHOLDER ISSUES}

The stakeholder issues are focussed on the workers involved in cleanup, the tax payers, and the onsite staff who has responsibility for regulatory compliance. The ELECTROSORB ${ }^{\circledR}$ "C" process is especially responsive to these.

\section{COMMERCIAL VIABILITY}

\subsection{CURRENT STATUS OF THE TECHNOLOGY IN MEETING TECHNICAL CHALLENGES}

The process was demonstrated at full-scale as an effective method for extracting contaminants from concrete. Process optimization work is underway to render the secondary waste in a low-volume form that is ready for disposal. The process hardware is operationally reliable. 


\subsection{FINAL PRODUCT CONCEPT AND SCOPES OF PROCESS OPTIMIZATION AND IMPROVEMENT}

The present technology in its commercial form will be a semi-automated process for rapid decontamination of concrete. The process will be applicable to both radioactive and non-radioactive sites, including sites bearing mixed wastes. It will present a dust-free approach to concrete decontamination. The secondary waste will be minimal.

Process optimization and improvement work is needed in the areas of secondary waste concentration and process automation. This work is in progress.

\subsection{PATENT AND LICENSE AGREEMENTS}

Patents exist. The existing structure will prove viable and attractive for commercialization.

\subsection{COMMERCIALIZATION PARTNERS}

The DOE has placed this project in a formal program for commercialization initiative. A showcase of this and other new technologies will take place in October 1996 in Washington, D.C.

\subsection{PLAN FOR TECHNOLOGY TRANSFER TO THE END-USER}

This will be achieved via a strategic alliance partnership or licensing agreement, with ongoing technical support provided by ISOTRON ${ }^{\circledR}$.

\section{REFERENCE}

1. Dickerson, K. S., Wilson-Nichols, M. J., and Morris, M. I., "Contaminated Concrete: Occurrence and Emerging Technologies for DOE Decontamination", a Comprehensive Review Report Prepared for the U:S. DOE by Oak Ridge National Laboratory, August, 199 


\begin{tabular}{c} 
APPENDIX A \\
\hline PROCESS CHEMISTRY AND OPERATING PARAMETERS OF THE \\
ELECTROSORB “ “C” ELECTROKINETIC EXTRACTION TECHNOLOGY
\end{tabular}

E 
September 4, 1996

\section{APPENDIX A}

PROCESS CHEMISTRY AND OPERATING PARAMETERS OF THE ELECTROSORB ${ }^{\circledR}$ "C" ELECTROKINETIC EXTRACTION TECHNOLOGY

\section{ABSTRACT}

The electrokinetic removal of thorium from concrete at Mound Building 21 has revealed some important process parameters which are tied to chemistry of solubilizer solution.

This technical summary examines the process, including the various cleanup scenarios and then provides conclusions directed toward an optimum process regime.

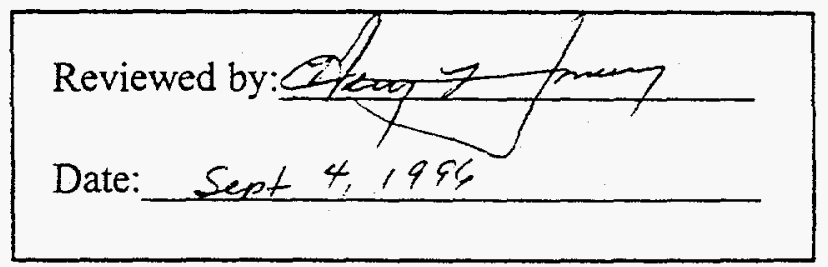


ISOTRON ${ }^{\circledR}$ Corporation/Appendix A

Contract DE-AC21-93MC30162

$09 / 04 / 96$

Process Chemistry and Operating Parameters

ELECTROSORB "C" Technology

\section{DESCRIPTION OF PROCESS}

\section{Process Concept}

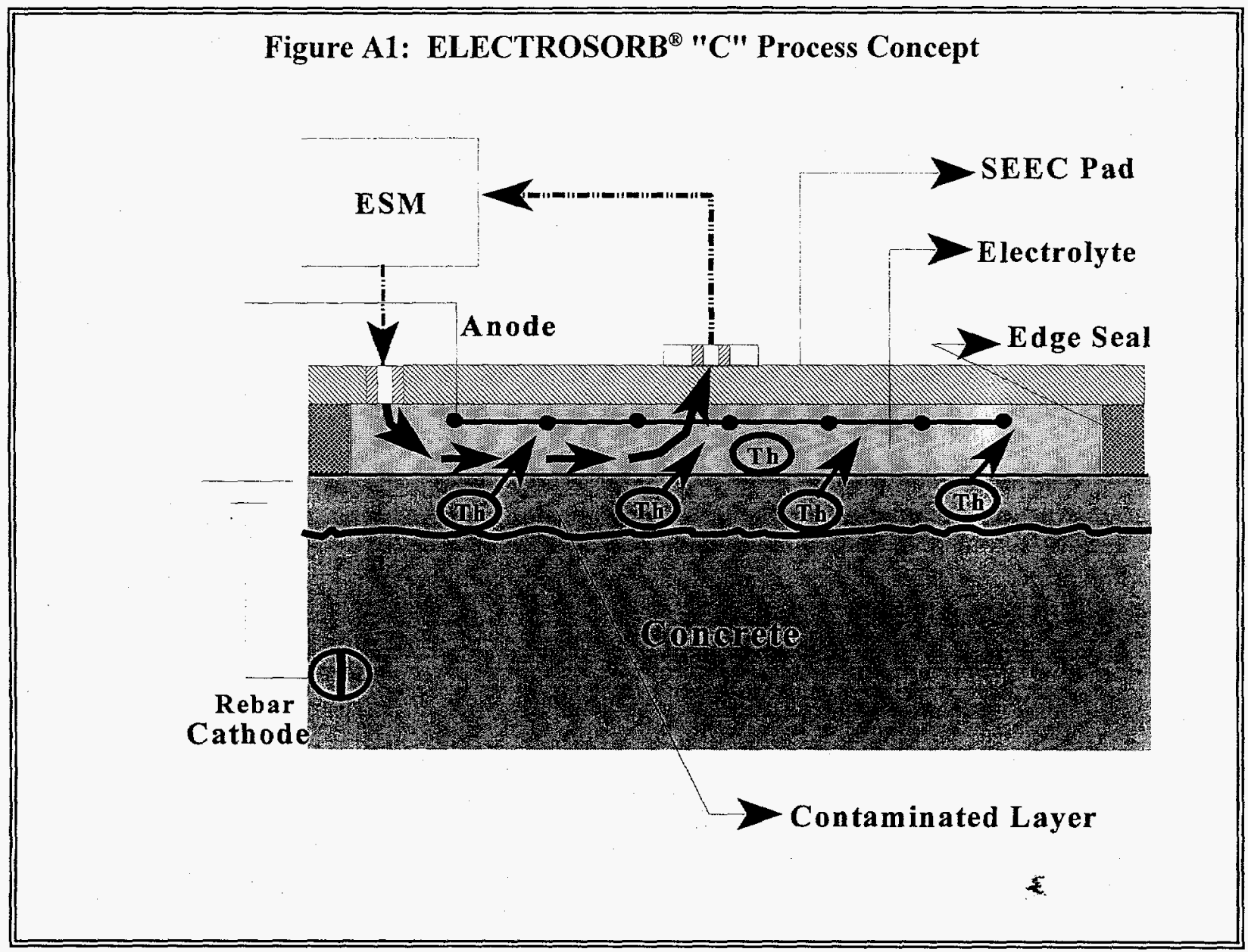

Figure A1 illustrates the concept underlying the ELECTROSORB ${ }^{\otimes}$ " $\mathrm{C}$ " electrokinetic extraction process. A DC electric field is applied between the concrete rebar and a planar electrode enclosed in an extraction pad, called the SEEC pad. This pad is a resilient and compliant material. The planar electrode serves as the anode and the rebar as the cathode. An electrolyte, essentially a contaminant solubilizer solution, is confined by the SEEC pad which incorporates a sealing feature along the perimeter. The electrolyte contacts the concrete surface while being circulated between the SEEC pad and a solution processing module (ESM). The ESM maintains the desired chemical conditions for the electrolyte. The sorbed or the precipitated metal contaminants are made soluble by the solubilizer. The dissolved contaminants are collected in the circulating electrolyte. The contaminant-laden solution is processed in the ESM for the recovery of contaminants. The processed solution is recycled, and the separated contaminants are solidified in a stable wasteform. 
Contract DE-AC21-93MC30162

Process Chemistry and Operating Parameters

ELECTROSORB " ${ }^{\mathbb{C}}$ " Technology

\section{Process Operation and Hardware}

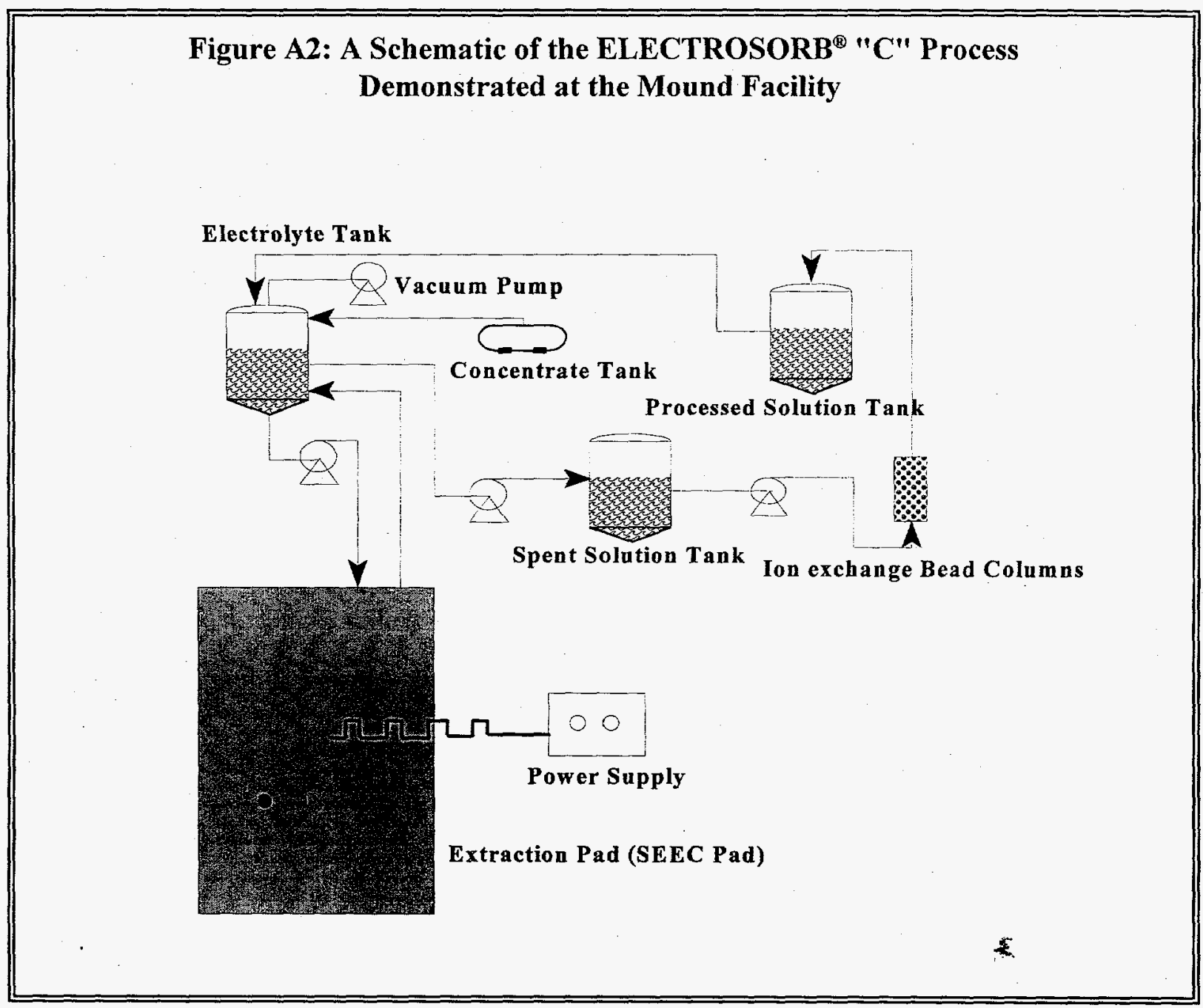

Figure A2 depicts the process demonstrated at the Building 21 site. In this demonstration, a $6 \mathrm{ft}$. long and $4 \mathrm{ft}$. wide SEEC pad was used, which provides an "active" area of 20 sq.ft. The SEEC pad incorporates a DSA wire-mesh electrode (planar electrode). The pad is provided with multiple inlet ports for receiving an electrolyte (solubilizer solution) pumped from a holding tank within the ESM. The electrolyte contacts the wire-mesh electrode and the concrete surface underneath the SEEC pad. The pad is held firmly against the concrete surface by means of reduced pressure (vacuum of approximately 0.1 Atmosphere). This negative pressure prevents leakage of the electrolyte out of the pad area. The ESM maintains continuous circulation of this solution between the SEEC pad and the electrolyte tank. The solution is pumped to the SEEC pad at the rate of approximately $1.2 \mathrm{~L} / \mathrm{min}$. A $20 \mathrm{~L}$ batch of the solution is used in each run. A DC voltage is applied between the planar electrode and the rebar. 
Process Chemistry and Operating Parameters

ELECTROSORB ${ }^{\circledR}$ "C" Technology

The electrolyte $\mathrm{pH}$ is highly critical to the process operation and efficiency. The $\mathrm{pH}$ data is collected by means of an on-line $\mathrm{pH}$ monitoring device, connected to a remote data acquisition system (DAS). The DAS continuously monitors the electrolyte $\mathrm{pH}$ during process operation. The solution is considered exhausted when its $\mathrm{pH}$ attains the maximum permissible operating level of 3.5 . The spent solution is drained into a standby tank for temporary storage pending processing. This tank feeds a set of five ion exchange bead columns (three cation exchange bead columns followed by two anion exchange bead columns) used for solution cleanup. The bead column effluent is collected in a third tank. This "cleaned" processed solution is available for reuse.

The ESM incorporates a solubilizer concentrate tank. The concentrate is fed to the electrolyte tank under manual control. This permits remote control of $\mathrm{pH}$ and solubilizer concentration.

Electrical power is delivered to the SEEC pad by means of a DC power supply rated at $200 \mathrm{~V}$ and $100 \mathrm{~A}$. The electrical power supply, data acquisition system, and the controller for feeding concentrate to the electrolyte tank are housed in a remote trailer unit. This unit is connected to the ESM by an electrical cable.

Photo A1 shows the process hardware operated during the Mound facility demonstration.

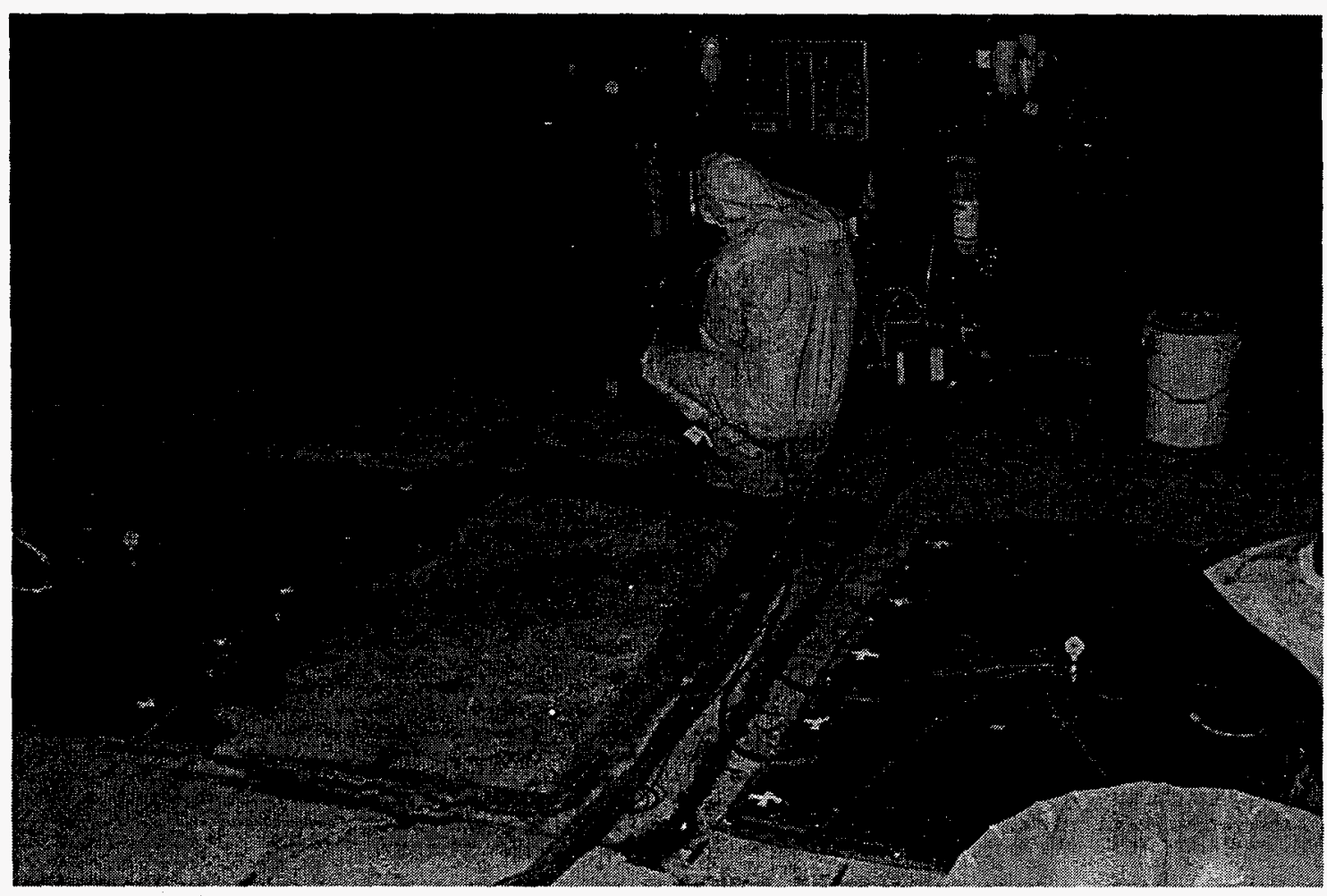

Photo A1 
Process Chemistry and Operating Parameters

ELECTROSORB" "C" Technology

\section{SITE CONDITIONS AND THEIR IMPACT}

\section{Contaminant Speciation}

The thorium species present in concrete floors of Building 21 include thorium dioxide (commonly known as thoria), thorium oxalate, and thorium hydroxide. These species are insoluble in water. Extraction of these species requires the use of thorium solubilizing reagents. In this process demonstration, two different solubilizer systems were evaluated. These reagents comprised of an organic acid, and a mixture of the same organic acid and a mineral acid. Thoria is known as a stable, refractory material whose rapid dissolution calls for the use of mineral acid solubilizers [1,2].

\section{Floor Coating Complication}

Upon arrival at the site, ISOTRON ${ }^{\circledR}$ staff found that the contaminated concrete floor in Building 21 was "capped" with a concrete topping material. The thorium contamination was underneath this coating. It was therefore necessary to "chip off" the topping material to expose the contaminated surface. Photo A2 shows the floor conditions.

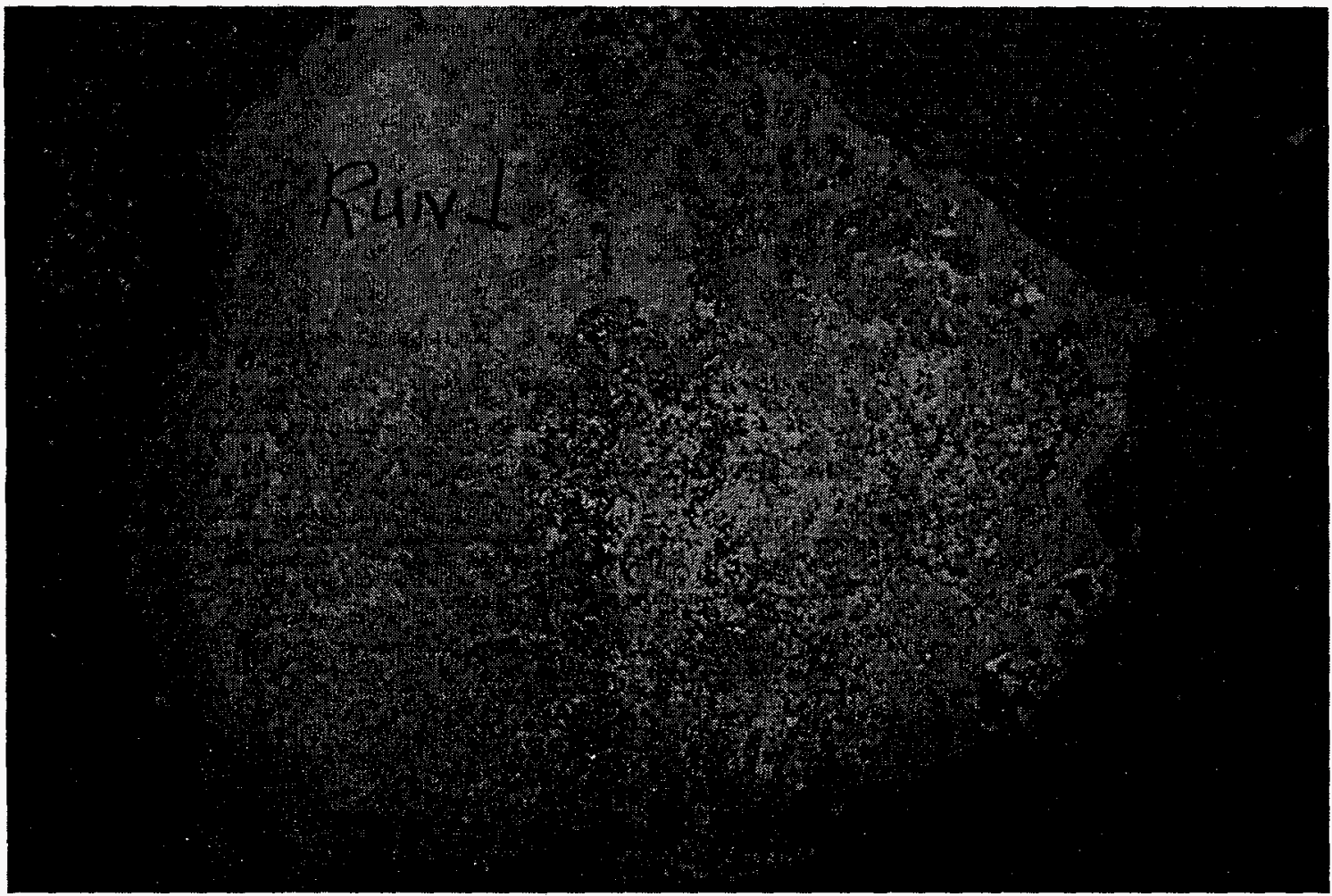

Photo A2 


\section{ACCOUNT OF THE EXPERIMENTS PERFORMED}

\section{Approach}

The test plan followed for this process demonstration was organized to permit six different extraction tests. The operation parameters such as solubilizer chemistry, electrical current, and treatment time were varied through these test scenarios. The parameters which were held constant are extraction pad geometry, electrode spacing, circulation rate of solubilizer solution and its temperature. The ESM parameters including amount of cation and anion exchange beads were identical for all tests.

Two solubilizer systems were evaluated, citric acid alone, and a mixture of citric and nitric acids. The first four tests were planned to evaluate the effects of solubilizer concentration and electrical current on thorium extraction rate and efficiency. However, due to floor coating reason, an additional parameter, electrolyte volume to treated concrete area ratio, was also varied through the tests. These tests allowed selection of the best conditions for extraction, which would then proceed to two additional tests. These two tests were planned to provide a parallel comparison of cleanup level in scenarios where the effect of electrical power could be clearly shown. One of these tests would use electricity for contaminant extraction, while the other would use no electricity.

\section{Experimental Conditions for Tests 1 through 4}

\section{Floor Conditions}

The areas of exposed contaminated concrete surface in the first four tests are shown in Figure A3. Approximately $40 \%$ of the exposed surfaces in Tests 1 and 4 were coated with a hard coating.

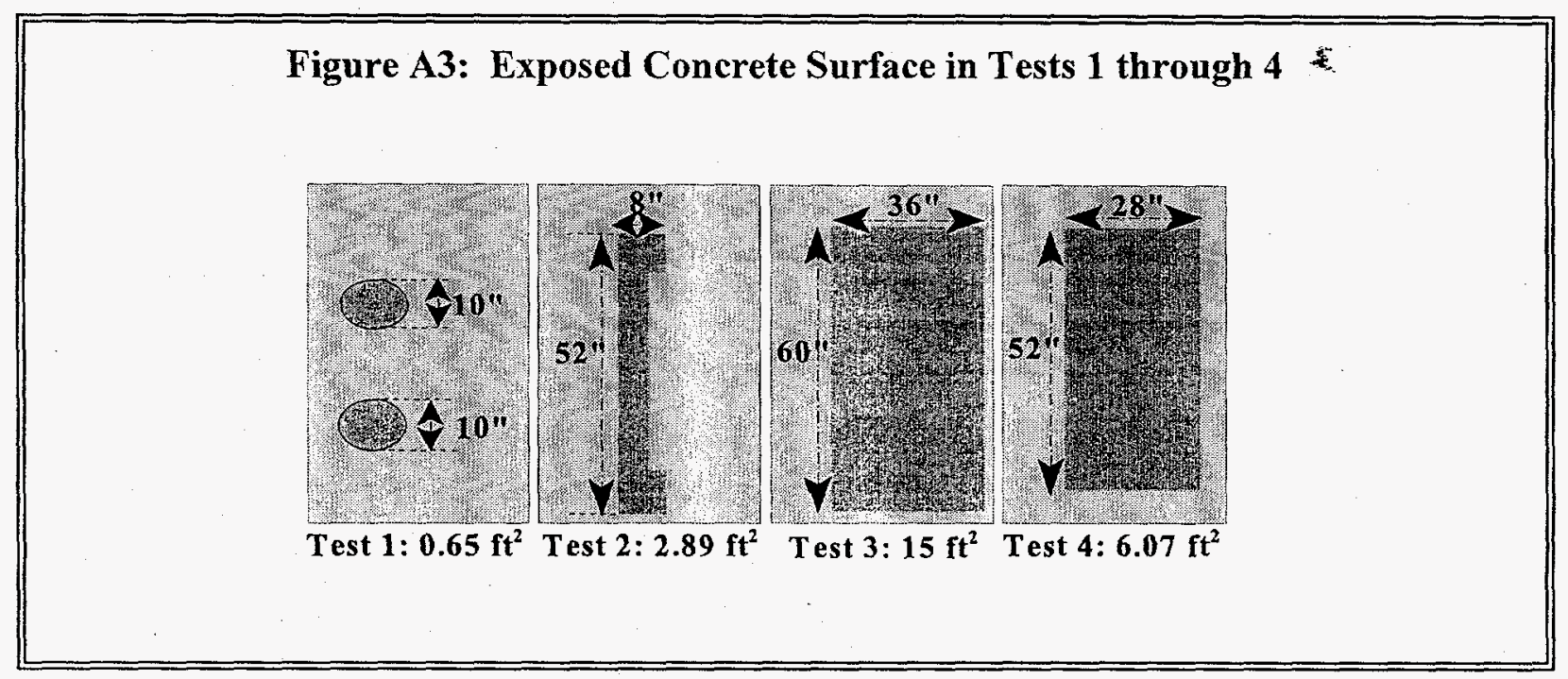


ISOTRON ${ }^{\circledR}$ Corporation/Appendix A

Contract DE-AC21-93MC30162

$09 / 04 / 96$

Process Chemistry and Operating Parameters

ELECTROSORB ${ }^{\otimes} " C$ " Technology

\section{Operating Conditions}

Solubilizer concentration was varied through the first three tests, but electrical current was the same for all three tests. Test 4 was carried out at a higher electrical current, using the same solubilizer as in the previous tests. The operating conditions for these four tests are presented in Table A1.

Table A1: Operating Conditions for Tests 1 through 4

\begin{tabular}{|c|c|c|c|c|}
\hline Test No. & $\begin{array}{l}\text { Electrolyte, } \\
\text { Concentration, } \\
\text { Duration of Use }\end{array}$ & $\begin{array}{c}\text { Current, } \\
\text { Time-Averaged } \\
\text { Voltage }\end{array}$ & Duration, hr. & $\begin{array}{l}\text { Electrical } \\
\text { Energy, } \\
\text { kW-hr }\end{array}$ \\
\hline 1 & $\begin{array}{l}0.05 \text { M Citric Acid } \\
\text { 1st Batch: } 0.63 \mathrm{hr} . \\
\text { 2nd Batch: } 1.17 \mathrm{hr} . \\
\text { 3rd Batch: } 1.92 \mathrm{hr} . \\
\text { 4th Batch: } 6.17 \mathrm{hr} .\end{array}$ & $\begin{array}{r}5.5 \mathrm{~A} \\
91.5 \mathrm{~V}\end{array}$ & 9.9 & 5 \\
\hline 2 & $\begin{array}{l}0.08 \text { M Citric Acid } \\
\text { 1st Batch: } 1.25 \mathrm{hr} . \\
\text { 2nd Batch: } 2.25 \mathrm{hr} \text {. } \\
\text { 3rd Batch: } 6 \mathrm{hr} . \\
\text { 4th Batch: } 6 \mathrm{hr} . \\
\text { 5th Batch: } 4.58 \mathrm{hr} \text {. }\end{array}$ & $\begin{array}{c}5.5 \mathrm{~A} \\
70.8 \mathrm{~V}\end{array}$ & 20.1 & 7.8 \\
\hline 3 & $\begin{array}{l}0.12-0.63 \mathrm{M} \text { Citric Acid } \\
\text { 1st Batch: } 2.17 \mathrm{hr} \text {. } \\
\text { 2nd Batch: } 4 \mathrm{hr} \text {. } \\
\text { 3rd Batch: } 4.12 \mathrm{hr} \text {. } \\
\text { 4th Batch: } 12.46 \mathrm{hr} \text {. } \\
\text { 5th Batch: } 4.5 \mathrm{hr} \text {. } \\
\text { 6th Batch: } 5.6 \mathrm{hr}{ }^{*}\end{array}$ & $\begin{array}{r}5.5 \mathrm{~A} \\
60.4 \mathrm{~V}\end{array}$ & $32.9^{* *}$ & 10.9 \\
\hline 4 & $\begin{array}{l}0.08 \text { - } 0.25 \mathrm{M} \text { Citric Acid } \\
\text { 1st Batch: } 7.33 \mathrm{hr} . \\
\text { 2nd Batch: } 9.08 \mathrm{hr} .\end{array}$ & $\begin{array}{c}8.5 \mathrm{~A} \\
93.6 \mathrm{~V}\end{array}$ & 16.4 & 13 \\
\hline
\end{tabular}

*At 4 hours into the process run with the 6th batch of electrolyte, nitric acid was added to a concentration of $3 \mathrm{wt} . \%$ and the test was continued for an additional 1.6 hours.

**Electrical power was switched off for 0.5 hour during the course of this test. 


\section{Electrolyte Conditions}

The strategy for Tests 1 and 2 called for use of relatively dilute solutions of citric acid as the contaminant solubilizer. As result of contact with concrete, the $\mathrm{pH}$ of the electrolyte increased steadily during the cycle. The process protocol provided that the solution should be replaced when $\mathrm{pH}$ of 3.5 was reached (see Table A1).

In Test 3, only the first three batches of electrolyte were allowed to reach the $\mathrm{pH}$ limit of 3.5 . In the subsequent runs, a different process protocol was imposed. The $\mathrm{pH}$ was allowed to increase (from its initial value of 2.2) until it reached the value of 2.6. It was then maintained at this value by the addition of concentrated citric acid electrolyte. The citric acid concentrate added to the fourth and the fifth batches increased the concentration of electrolyte. The concentration reached approximately $0.6 \mathrm{M}$ and $0.63 \mathrm{M}$, respectively. The sixth batch of electrolyte reached concentration of approximately $0.39 \mathrm{M}$. Toward the end of run, this batch of electrolyte also received nitric acid supplement.

In Test 4 , the $\mathrm{pH}$ of the first batch of electrolyte was allowed to increase to 3 (from an initial value of 2.6). It was then maintained at the value of 3 by adding citric acid concentrate to the electrolyte tank. The amount of concentrated citric acid solution added corresponds to approximately $0.25 \mathrm{M}$. In the case of the second batch, the citric concentration was added only at the beginning of the process run. The concentration of this batch was $0.15 \mathrm{M}$.

\section{Analysis of Results from Tests 1 through 4}

The relationship between thorium extraction and treatment time for Tests 1 through 4 is depicted in Figures A4 through A7. The slope of the curve at any point in time provides the corresponding extraction rate. Table $\mathbf{A 2}$ presents the time-averaged thorium and calcium extraction rates normalized by the area of exposed concrete surface in the four tests. A conparison of the normalized thorium and calcium extraction rates in the four tests are presented in Figure A8. The quantity of calcium extracted is significant in that it strongly influences the amount of secondary waste generated. It follows that the ratio of thorium to calcium extraction is an indicator of extraction efficiency. A higher value of this ratio represents the preferred operational regime.

These test results reveal the effects of the process variables on thorium extraction rate and efficiency, and thus point toward those parameters that will improve the process. The notable features are as follows:

- A reduction in thorium extraction rate is observed as the electrolyte becomes exhausted. Periodic replacement of exhausted electrolyte ensures continued extraction of thorium at an efficient rate. (See Figures A5 through A7 which corresponds to Tests 2 through 4.) 
- Solubilizer concentrate addition extends the active-life of the electrolyte. This provides continuity in the extraction rate (as evident from Figures A6 and A7, see concentrate addition regime).

- An increase in solubilizer concentration results in an increased thorium extraction rate (as evident from Figures A6 and A7, see concentrate addition regime).

- The ratio of electrolyte volume to treated surface area has an effect on thorium extraction and secondary waste generation (as can be seen from the data presented in Table A2 for Tests 1 through 3 carried out under the same electrical current). The extraction of thorium is enhanced. Unfortunately, the volume of secondary waste is also increased.

- The use of a higher electrical current improves the contaminant extraction efficiency. The ratio of thorium to calcium extraction increases as the electrical current is raised (as indicated by the data presented in Table A2).

- The use of nitric acid in the electrolyte facilitates thorium extraction (as can be seen from Figure A6).

The last four features warrant further discussion.

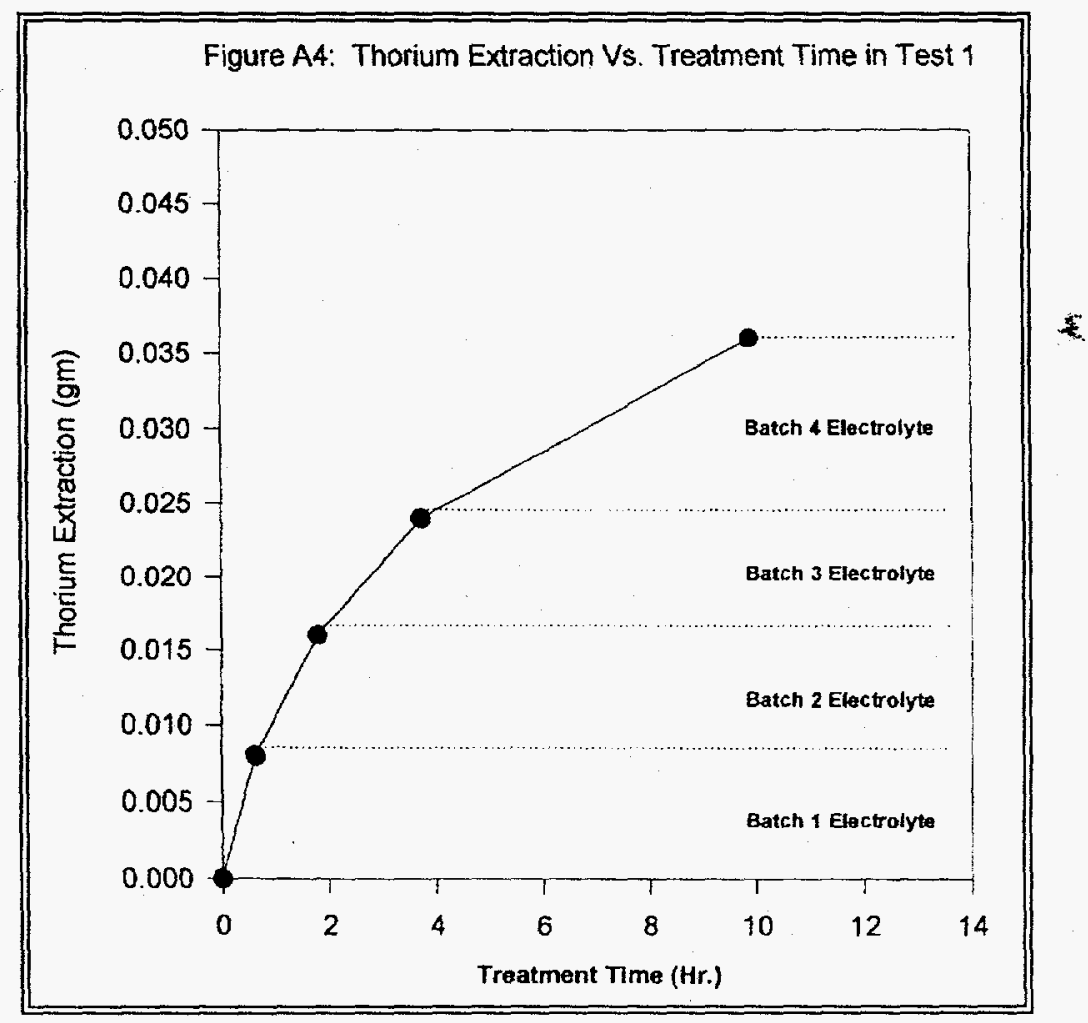


ISOTRON ${ }^{\circledR}$ Corporation/Appendix A

Contract DE-AC21-93MC30162

$09 / 04 / 96$

Process Chemistry and Operating Parameters

ELECTROSORB ${ }^{\circledR ~ " C " ~ T e c h n o l o g y ~}$
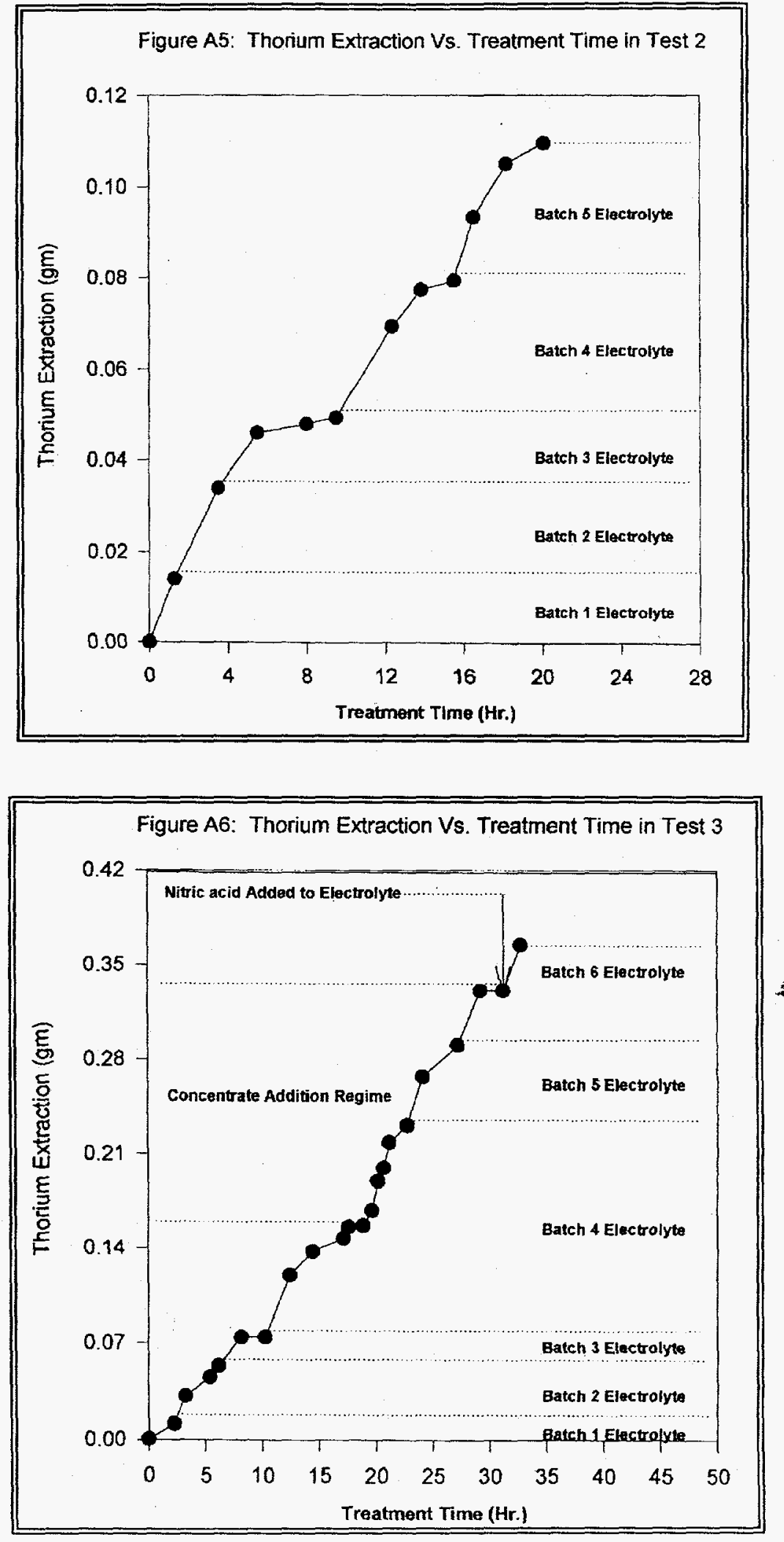
ISOTRON ${ }^{\otimes}$ Corporation/Appendix A

Process Chemistry and Operating Parameters

ELECTROSORB " C" Technology
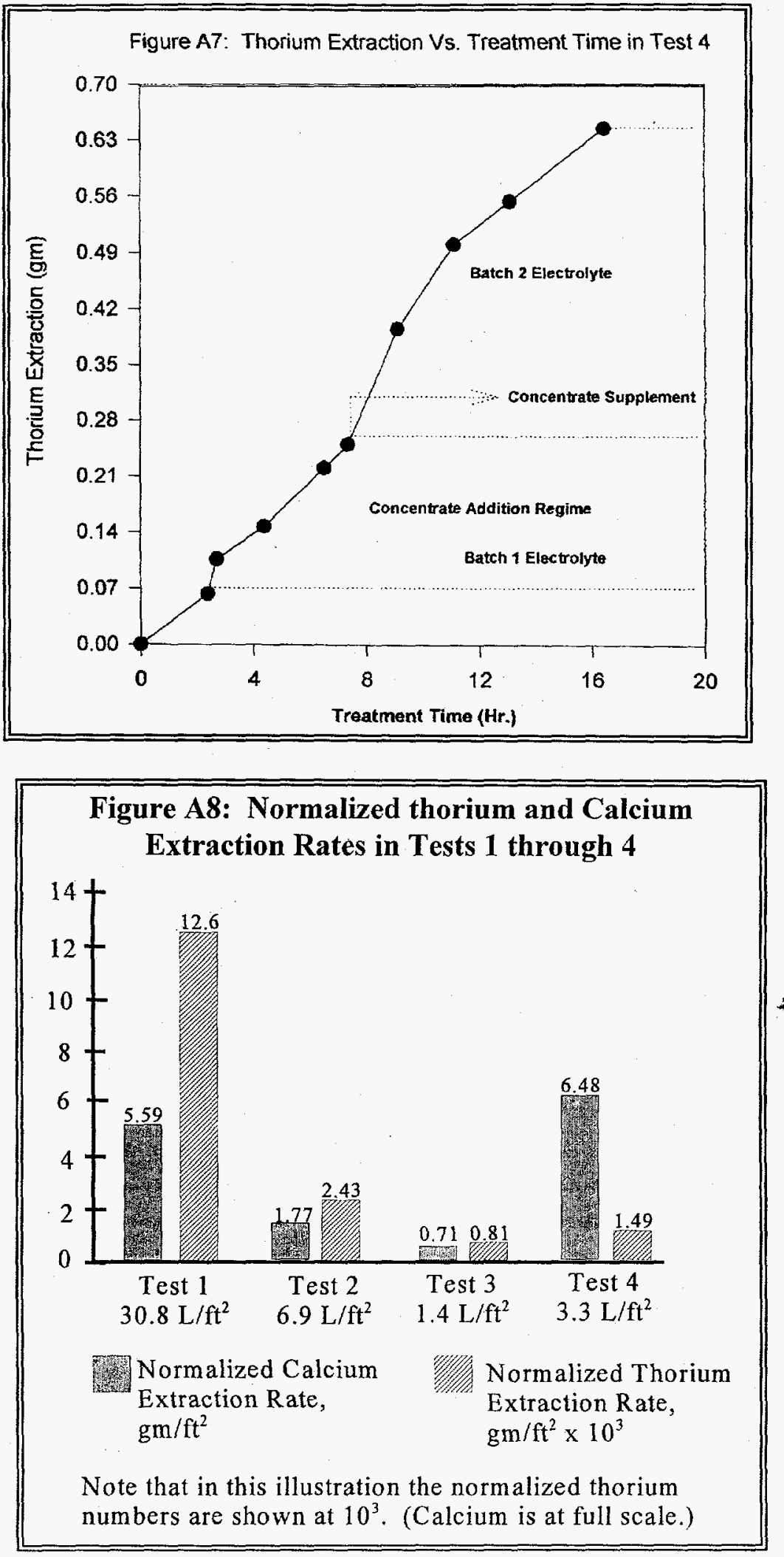
ISOTRON ${ }^{\circledR}$ Corporation/Appendix A

Contract DE-AC21-93MC30162

Process Chemistry and Operating Parameters

ELECTROSORB " "C" Technology

Table A2: Thorium and Calcium Extraction in Tests 1 through 4

\begin{tabular}{|c|c|c|c|c|c|c|c|}
\hline $\begin{array}{l}\text { Test } \\
\text { No. }\end{array}$ & $\begin{array}{c}\text { Exposed } \\
\text { Concrete } \\
\text { Area, } \\
\text { ft }^{2}\end{array}$ & $\begin{array}{c}\text { Time- } \\
\text { Averaged } \\
\text { Citric Acid } \\
\text { Concn., } \\
\text { M }\end{array}$ & $\begin{array}{c}\text { Electrolyte } \\
\text { Volume : } \\
\text { Concrete } \\
\text { Area, } \\
\text { L/ft' }\end{array}$ & Current, & \multicolumn{2}{|c|}{$\begin{array}{c}\text { Normalized } \\
\text { Th \& Ca Extraction } \\
\text { Rates, } \\
\text { gm } / \mathbf{h r} / \mathrm{ft}^{2} \\
\end{array}$} & $\begin{array}{c}\text { Th : Ca } \\
\text { Extraction } \\
\text { Ratio }\end{array}$ \\
\hline 1 & 0.65 & 0.05 & 30.8 & 5.5 & $\begin{array}{l}559 \times 10^{-5} \\
12.6\end{array}$ & $\begin{array}{l}\text { (Th) } \\
\text { (Ca) }\end{array}$ & $45 \times 10^{-5}$ \\
\hline 2 & $2.89^{\circ}$ & 0.08 & 6.9 & 5.5 & $\begin{array}{l}177 \times 10^{-5} \\
2.43\end{array}$ & $\begin{array}{l}\text { (Th) } \\
\text { (Ca) }\end{array}$ & $73 \times 10^{-5}$ \\
\hline 3 & 15 & 0.42 & 1.4 & 5.5 & $\begin{array}{l}74 \times 10^{-5} \\
71 \times 10^{-5} \\
1.02 \\
0.81\end{array}$ & $\begin{array}{l}\text { (Th) } \\
(\mathbf{T h})^{*} \\
(\mathrm{Ca}) \\
(\mathrm{Ca})\end{array}$ & $\begin{array}{l}73 \times 10^{-5} \\
88 \times 10^{-5} *\end{array}$ \\
\hline 4 & 6.07 & 0.19 & 3.3 & 8.5 & $\begin{array}{l}648 \times 10^{-5} \\
1.49\end{array}$ & $\begin{array}{l}\text { (Th) } \\
\text { (Ca) }\end{array}$ & $435 \times 10^{-5}$ \\
\hline
\end{tabular}

*The nitric acid regime is eliminated. 


\section{Effects of Solubilizer Concentration and Electrolyte Volume to Concrete Area Ratio}

The following explains the dependence of contaminant solubilization rate as a function of solubilizer concentration and electrolyte volume to concrete area ratio.

\section{Chemical Reaction Rate}

Solubilization of metal contaminants by metal complexing ligands is a reversible chemical reaction which may be described as:

$$
M+L \rightleftharpoons M L
$$

The forward reaction leads to the formation of the metal complex, while the reverse reaction results in the breakdown of the complex into its constituents. At any point in time, both reactions proceed simultaneously, but at different individual rates. For the sake of simplicity, these rates are expressed as follows (although the actual rate expressions may be more complex than the ones given below): The rate of formation of the metal complex, ML, is

$$
r_{M L, \text { forward. }}=k_{1} C_{M} C_{L}
$$

where $C_{M}$ is the concentration of the metal species, $C_{L}$ the concentration of the ligand, and $k_{1}$ is a constant called the rate constant. Similarly, the rate of disappearance of ML by the reverse reaction is

$$
-r_{M L, \text { reverse }}=k_{2} C_{M} C_{L}
$$

where $\mathrm{C}_{\mathrm{ML}}$ is the concentration of the metal complex, and $\mathrm{k}_{2}$ the rate constant for the reverse reaction. Equation [2] indicates that an increase in solubilizer or ligand concentration will increase the rate of formation of the metal complex; on the other hand, a depletion of the metal species would have an opposite effect. Equation [3] shows that the rate of the reverse reaction is increased by an increase in the concentration of the metal complex (as it is formed). At equilibrium, these rates become equal, and there is no net formation of the metal complex. This implies that the rate of the reverse reaction will be reduced if the reaction product, the metal complex, is removed from the reaction medium or diluted. The result will be continued formation of the metal complex until the metal or the ligand source is depleted. 
Contract DE-AC21-93MC30162

$09 / 04 / 96$

Process Chemistry and Operating Parameters

ELECTROSORB ${ }^{\circledR ~ " C " ~ T e c h n o l o g y ~}$

\section{Diffusion}

Solids dissolution represents a heterogeneous (two-phase) chemical reaction where materials are transported across a phase boundary by diffusion. Two different mechanisms may be postulated for such chemical reactions. These are illustrated in Figure A9.

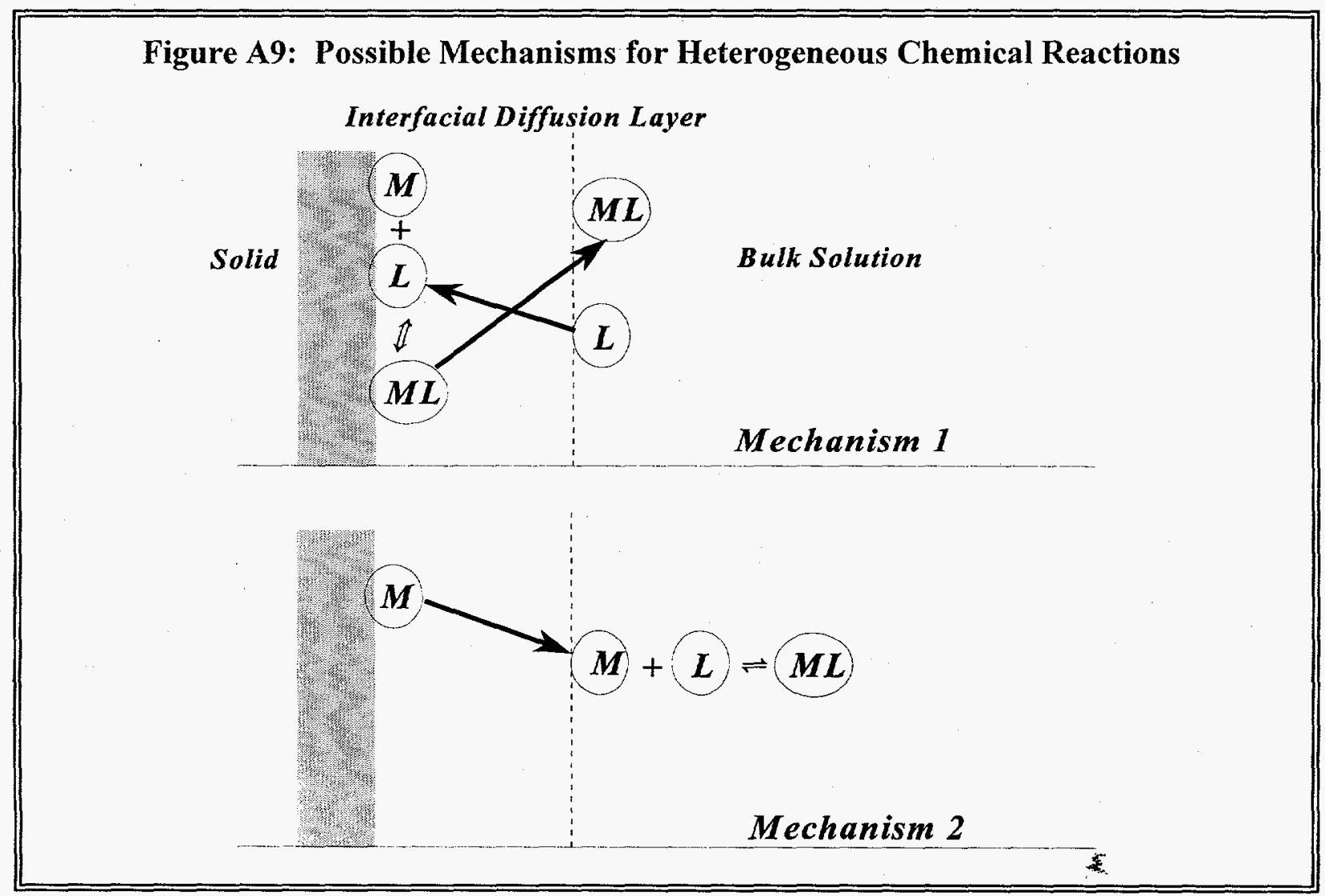

The first mechanism involves diffusion of the ligand, $\mathrm{L}$, across the solid-solution interface to the site at which the contaminant is sorbed on the solid surface (the solid in this case is concrete matrix). The metal complexation reaction takes place on the surface, and the complexed metal species diffuses back through the interfacial layer to the bulk solution phase.

The second mechanism involves diffusion of the metal species from the solid phase to the bulk solution phase. The ligand available in the solution then complexes with the metal cation, forming the metal complex.

The concentration gradient of species across the interfacial layer provides the driving force for their diffusion from one phase to the other. The higher the concentration gradient, the greater will be the rate of diffusion. This implies that an increased solubilizer concentration would result in a greater 
rate of its diffusion across the solution-solid interface. Similarly, a lower concentration of the metal complex in solution would provide a greater driving force for the metal complex to diffuse into the bulk solution phase if it is formed via surface complexation mechanism.

The overall rate of dissolution of metal contaminants by complexing ligands will depend on a complex interplay between the rates of interphase mass transfer and chemical reaction. The rate of the slowest step involved will dictate this overall rate. In any event, the observation that thorium extraction was enhanced by an increase in solubilizer concentration can be explained based on some of the aforementioned phenomena. A higher ratio of electrolyte volume to treated surface area will provide a means for lowering the concentration of the dissolution reaction product, i.e., the solubilized thorium, in the solubilizer solution. A reduced concentration of solubilized thorium in the solution phase could only favor its further dissolution. It is therefore reasonable to observe an enhancement in thorium extraction with an increase in electrolyte volume to treated surface area ratio. The data presented in Table A2 shows that the thorium extraction rate is more sensitive to an increase in electrolyte volume as compared to a stronger solubilizer concentration.

\section{Effect of Electrical Current}

The solubilizer concentration was lower in Test 4 as compared to Test 3. In spite of a lower solubilizer concentration, the thorium extraction rate was greater in Test 4 than in Test 3 . The ratio of electrolyte volume to concrete area was higher in Test 4 which would tend to explain part of the trend. However, this alone does not account for the magnitude of the increased thorium extraction rate. One cannot ignore the possibility that the enhanced thorium extraction rate might be a result of the presence of any "hot spots" (thorium-enriched spots) in the Test 4 area. If this possibility is ignored, one can conclude that the use of a higher electrical current caused the higher thorium extraction rate.

The following explanation supports the higher thorium to calcium extraction ratio in Test 4 as an effect of higher electrical current. This is also related to the complexation chemistry of thorium and calcium with citrate ligand. This chemistry is discussed first. Citrate anion forms anionic complexes with thorium and calcium cations. The stability constant (ratio of the rates of the forward and the reverse reaction discussed above, and which may be viewed as a measure of metal complex stability) of thorium citrate complex is $11.61\left(\mathrm{~K}_{1}\right)$, while the same for calcium citrate complex is 3.364 [3]. The higher stability constant of thorium citrate complex indicates that the complex has less tendency to dissociate into its constituent ions. As a result, upon solubilization in citric acid solution, thorium will remain predominantly in the form of an anionic complex. This is not the case with calcium. Calcium hydroxide and calcium carbonate dominate the concrete matrix. Upon contact by a citric acid solution, these alkaline species will react with the hydrogen ions present in this acidic solution, resulting in dissolution of calcium in the solution. Once dissolved in citric acid solution, unlike thorium, calcium will exist primarily as a cation and not as an anionic calcium citrate complex. Calcium citrate being an unstable species will readily dissociate to release the calcium cation. The significance of this can be viewed as follows: Calcium dissolved in citric acid solution will spend 
more of its lifetime as a cation. Thorium will spend much less. This phenomenon is supported by the observation that calcium can be removed from spent citrate solubilizer solution by means of a cation exchange column.

The next step in the analysis is to explain the behavior of the solubilized thorium and calcium species under an electric field. The anode being (enclosed in the SEEC pad) placed on the concrete surface, the cations electromigrate into the concrete matrix. The anions move out. A higher electrical current resulting from a higher applied electric field (electric potential gradient) implies an increased electromigration flux. The significance of this is that under a higher electrical field, the solubilized calcium cations would be electrically driven away from the anode site (or from the electrolyte surrounding the anode) into the concrete matrix at an increased rate. Under the same electrical condition, the anionic thorium species would be concentrated at the anode at a higher rate (as evident from the test results). Unlike calcium, these anionic thorium species would not electromigrate back into the concrete matrix. The result should be an enrichment of the electrolyte with thorium species relative to calcium species. This phenomenon is pictorially described in Figure A10.

Figure A10: Relative Thorium and Calcium Extraction Under Varying Current

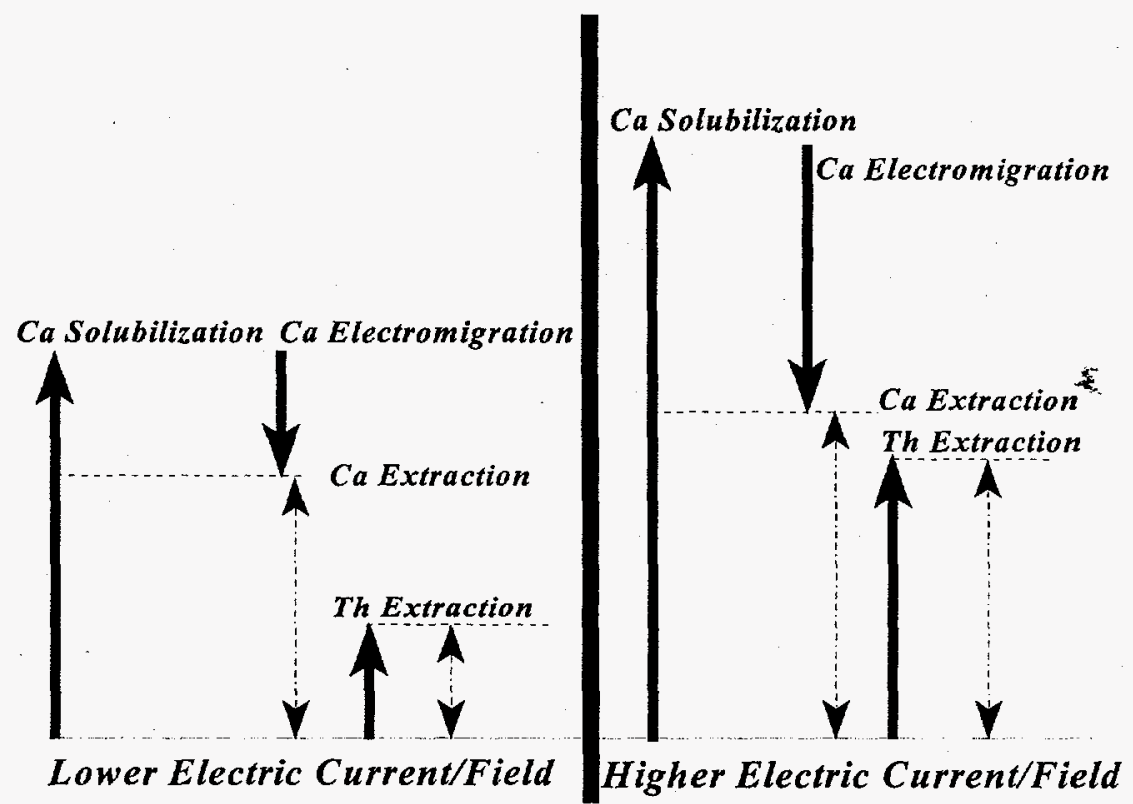

The above explains why an improved thorium extraction efficiency is observed as the electrical current flux increases. This finding is particularly significant because it suggests that by using 
electrical current, one is able to enhance thorium extraction without having to pay much penalty in terms of calcium extraction. It should be further noted that a non-electrical extraction scenario would not provide for the described "stripping" effect on calcium inventory in the solubilizer solution.

\section{Effect of Nitric Acid as a Solubilizer Component}

Figure A6 shows two intervals during which there was hardly any thorium extraction. In the first, the electrolyte $\mathrm{pH}$ was approaching the maximum permissible operating limit of 3.5. In the second interval, the electrolyte $\mathrm{pH}$ was maintained at $2.6 \pm 0.05$ by means of concentrated citric acid addition. This might have indicated that the thorium source was depleted. Thorium extraction resumed upon addition of nitric acid to the electrolyte. The extraction process continued for an additional 1.6 hours. During this period, $0.033 \mathrm{gm}$ of thorium was extracted. This corresponds to extraction of nearly $10 \%$ of the total thorium removed. Equally important, this significant extraction occurred within only $5 \%$ of the test duration. This phase of thorium extraction is clearly related to the $3 \mathrm{wt} \%$ of nitric acid added to the sixth batch of electrolyte.

The explanation for this phenomenon is as follows. Any thorium dioxide, a stable, refractory material, present in the Test 3 area would dissolve only slightly (i.e., at an unacceptably slow rate) in an electrolyte containing only citric acid. On the other hand, it would be solubilized at an increased rate when a mineral acid such as nitric acid is added to the same electrolyte.

\section{Experimental Conditions for Tests 5 and 6}

\section{Floor Conditions}

The areas of exposed contaminated concrete surface in Tests 5 and 6 are shown in Figure A11.

\section{Operating Conditions}

These two tests were carried out under identical conditions except that an electric field was not applied during Test 6. The operating conditions for these tests are presented in Table A3. As indicated in Table A2, a mixture of nitric acid and citric acid was used as the electrolyte. The rationale behind the use of nitric acid as a solubilizer component is that thoria (thorium dioxide) is soluble only in mineral acids. Thoria is one of the thorium species present in the Building 21 concrete floor. Also, Test 3 demonstrated that the use of dilute nitric acid as a solubilizer would enhance thorium extraction. In Tests 5 and 6 , the $\mathrm{pH}$ of the electrolyte was considerably lower than the prior tests. The maximum $\mathrm{pH}$ of 2.5 was well below the limiting value. In spite of the $\mathrm{pH}$ being well below the established limit, two batches of work solution were used in each of these tests. This precaution was intended to facilitate the contaminant dissolution process. Replacement of contaminant-laden electrolyte would shift the chemical equilibrium to favor dissolution of the contaminant. A higher electrical current was used in Test 5 as compared to Tests 1 through 3 . 
ISOTRON ${ }^{\circledR}$ Corporation/Appendix A

Contract DE-AC21-93MC30162

Process Chemistry and Operating Parameters

ELECTROSORB ${ }^{\circledR} " C$ " Technology

Figure A11: Exposed Concrete Surface in Tests 5 and 6
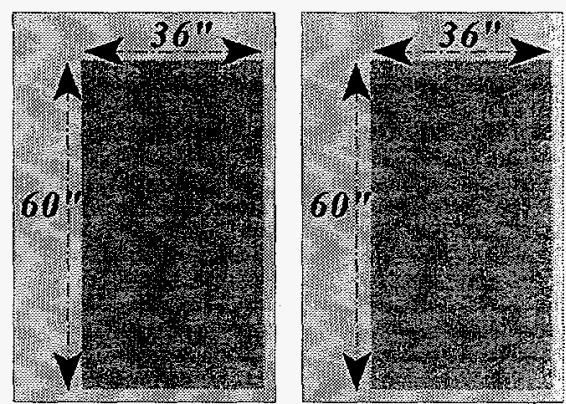

Test 5: $15 \mathrm{ft}^{2}$

Test 6: $15 \mathrm{ft}^{2}$

Table A3: Operating Conditions for Tests 5 and 6

\begin{tabular}{|c|l|c|c|c|}
\hline Test No. & \multicolumn{1}{|c|}{$\begin{array}{c}\text { Electrolyte, } \\
\text { Concentration, } \\
\text { Duration of Use }\end{array}$} & $\begin{array}{c}\text { Current, } \\
\text { Time-Averaged } \\
\text { Voltage }\end{array}$ & Duration, hr. & $\begin{array}{c}\text { Electrical } \\
\text { Energy, } \\
\text { kW-hr }\end{array}$ \\
\hline \hline 5 & $\begin{array}{l}5 \%(\sim 0.8 \mathrm{M}) \text { Nitric Acid }+ \\
0.2 \text { M Citric Acid }\end{array}$ & $\begin{array}{l}7.5 \mathrm{~A} \\
96 \mathrm{~V}\end{array}$ & 11.9 & 8.57 \\
& $\begin{array}{l}\text { 1st Batch: } 5.3 \mathrm{hr} . \\
\text { 2nd Batch: } 6.6 \mathrm{hr} .\end{array}$ & & & \\
\hline 6 & $\begin{array}{l}5 \%(\sim 0.8 \mathrm{M}) \text { Nitric Acid }+ \\
0.2 \text { M Citric Acid }\end{array}$ & $0 \mathrm{~V}$ & 11.9 & 0 \\
& $\begin{array}{l}\text { 1st Batch: } 4.4 \mathrm{hr} . \\
\text { 2nd Batch: } 7.5 \mathrm{hr} .\end{array}$ & & & \\
\hline
\end{tabular}


ISOTRON ${ }^{\circledR}$ Corporation/Appendix A

Contract DE-AC21-93MC30162

Process Chemistry and Operating Parameters

ELECTROSORB ${ }^{\circledR} " C "$ "Technology

\section{Analysis of Results from Tests 5 and 6}

Figure A12 shows a comparison of the extent of thorium extraction in the two tests. Table A4 presents the time-averaged thorium and calcium extraction rates normalized by the area of an exposed concrete surface in the two tests. The thorium to calcium extraction ratio is also tabulated therein.

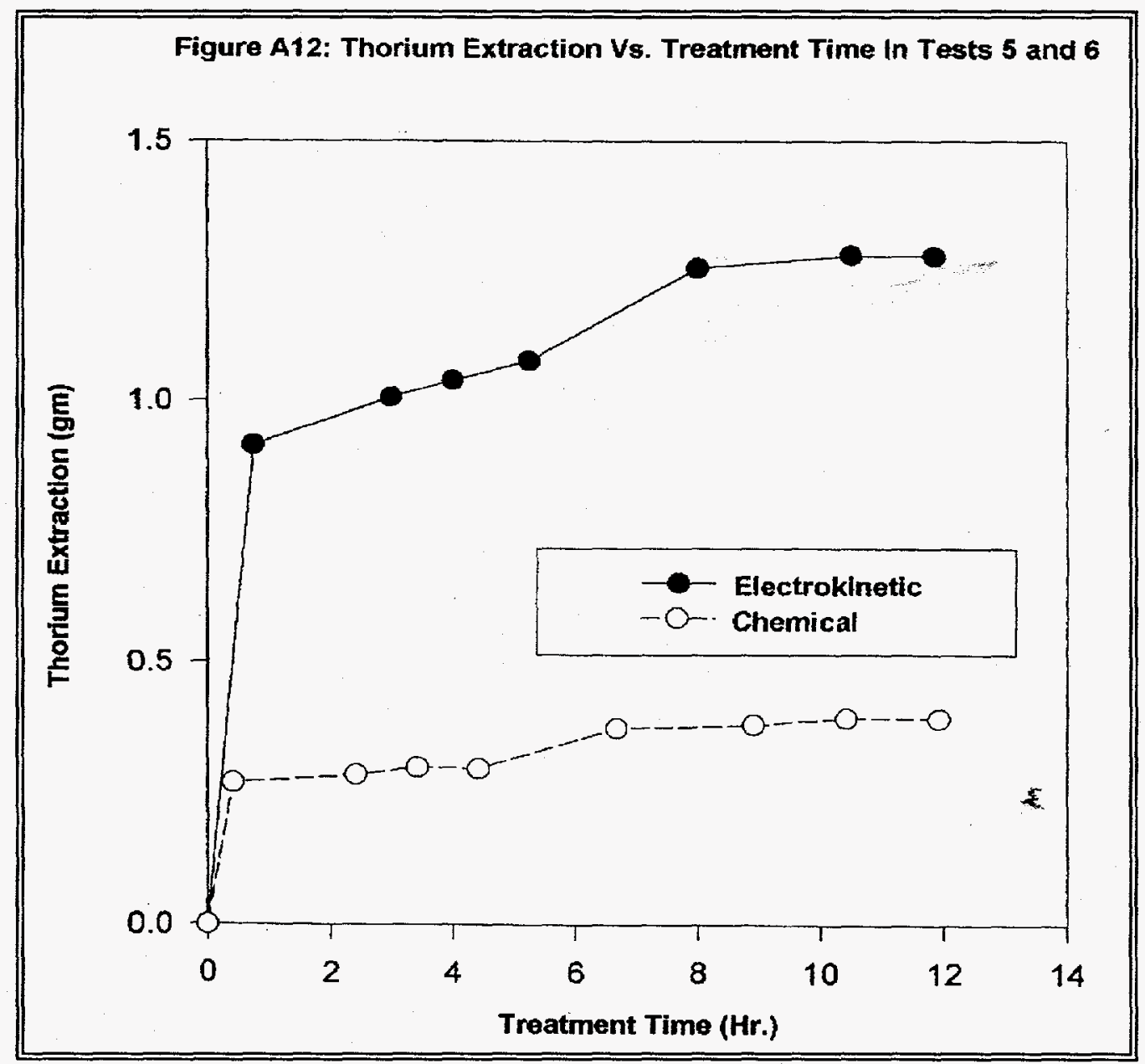


Table A4: Thorium and Calcium Extraction in Tests 5 and 6

\begin{tabular}{|c|c|c|c|c|c|c|c|}
\hline $\begin{array}{l}\text { Test } \\
\text { No. }\end{array}$ & $\begin{array}{c}\text { Exposed } \\
\text { Concrete } \\
\text { Area, } \\
\mathbf{f t}^{\mathbf{2}} \\
\end{array}$ & $\begin{array}{l}\text { Solubilizer Concn., } \\
\mathbf{M} \\
\end{array}$ & $\begin{array}{c}\text { Electrolyte } \\
\text { Volume : } \\
\text { Concrete Area, } \\
\mathrm{L} / \mathrm{ft}^{2} \\
\end{array}$ & $\begin{array}{c}\text { Current, } \\
\text { A } \\
\end{array}$ & $\begin{array}{r}\text { Normali } \\
\text { Th \& Ca Ex } \\
\text { Rates } \\
\text { gm/hr } \\
\end{array}$ & ction & $\begin{array}{c}\text { Th : Ca } \\
\text { Extraction } \\
\text { Ratio }\end{array}$ \\
\hline 5 & 15 & $\begin{array}{l}5 \% \text { Nitric Acid } \\
+0.2 \mathrm{M} \text { Citric Acid }\end{array}$ & 1.4 & 7.5 & $\begin{array}{l}720 \times 10^{-5} \\
4.44\end{array}$ & $\begin{array}{l}\text { (Th) } \\
\text { (Ca) }\end{array}$ & $162 \times 10^{-5}$ \\
\hline 6 & 15 & $\begin{array}{l}5 \% \text { Nitric Acid } \\
+0.2 \mathrm{M} \text { Citric Acid }\end{array}$ & 1.4 & 7.5 & $\begin{array}{l}220 \times 10^{-5} \\
3.69\end{array}$ & $\begin{array}{l}\text { (Th) } \\
\text { (Ca) }\end{array}$ & $60 \times 10^{-5}$ \\
\hline
\end{tabular}

A significant amount of thorium was extracted in a relatively short time during Test 5 . As expected, the amount of thorium extracted in Test 6 fell short of the same in Test 5. These two tests were carried out under identical process conditions except that an electric field was not applied during Test 6 . The thorium to calcium extraction ratio was much higher in Test 5 than in Test 6 (see Table A4). The above findings are in agreement with the key inference drawn from the Test 4 results. These results showed that the use of a higher electrical current augments the contaminant extraction rate and efficiency.

The presence of hydrogen ions (protons) in solution has a contributory role in the solubilization of contaminants from concrete matrix using metal complexants. Typically $\mathrm{pH}$ is greater than 13 in concrete pores [4]. At this high $\mathrm{pH}$, a majority of metal contaminants are likely to be present as precipitates. They may be also incorporated into the calcium and silica-bearing mineral phases of the matrix by several mechanisms. Contaminants may exist as inclusions or be subjected to chemisorption, chemical incorporation, or other binding mechanisms such as ion exchange reactions [4]. By lowering the pore solution $\mathrm{pH}$, protons will provide the condition under which metal precipitates can be solubilized by complexing ligands. In addition, protons themselves will serve as solubilizing ligands for the dissolution of mineral phases into which contaminants are incorporated. This will release the contaminant ions from the solid phase of the concrete. These ions can then form complexes with an anionic ligand (e.g., citrate). Protons may also release metal contaminant cations bound to the ion exchange sites in concrete matrix. 
Application of an electric field facilitates material transport which is otherwise limited to diffusion and convection. Considering all of the above, a number of possible causes can be speculated for the observed enhancement in contaminant extraction in the case of electrokinetic extraction over chemical extraction. These are narrated under the following heading.

\section{Contributory Features of Electrokinetics}

- In an electrokinetic extraction process, protons are generated at the anode due to the electrolysis of water. The anode therefore serves as a proton source. Due to this continuous supply of protons by the anode, their facilitating effect on contaminant dissolution would be greater in the case of electrokinetic extraction.

- It was indicated earlier that solubilization of contaminants from concrete matrix by a solubilizer solution represents a two-phase chemical reaction. The concentration gradient of species between the two phases often governs the rates of these chemical reactions. The higher the concentration gradient, the greater is the dissolution rate. Electrokinetics would be instrumental in maintaining an elevated concentration gradient of dissolving species between the concrete-solid phase and the solution phase. Electrokinetic transport of dissolved species would result in their removal from the vicinity of a dissolution site. This in turn would create a local concentration gradient of these species (near a dissolution site) greater than what would be achieved in the absence of such transport. The result would be an enhancement in contaminant dissolution.

- It is also expected that electrokinetics would allow treatment of concrete strata deep within the matrix. The contaminants dissolved in concrete pore solution deep in the matrix can be electrokinetically driven up to the concrete surface and recovered in a timely fashion. This may not be achievable in non-electrical extraction processes.

Further observations from Test 5 are as follows. The thorium extraction rate was greater in Test 5 than in Test 3. The electrolyte volume to concrete area ratio was the same for the two tests, although the electrical current was $7.5 \mathrm{~A}$ in Test 5 as compared to $5.5 \mathrm{~A}$ in Test 3 . Enhancement of thorium extraction in Test 5 appears dramatic in the backdrop of a comparison between this test and Test 4 . The electrical current, as well as the electrolyte volume to concrete area ratio, was higher in Test 4 than in Test 5 , yet the thorium extraction rate was greater in the latter test. The increased thorium extraction rate in Test 5 is therefore attributed to the solubilizer chemistry used in this test, namely to the incorporation of nitric acid as a solubilizer component. 


\section{Decontamination Effectiveness}

Indications are such that the concrete surface affected by Test 5 was rendered clean. This conclusion is based on the following.

- The mean radiation count from the Test 5 area was reduced to nearly the background level. This is indicated by the results of independent post-treatment measurement of radiation count carried out by ISOTRON ${ }^{\circledR}$ staff and site personnel.

- Mass balance of thorium. The amount of thorium extracted during Test 5 is nearly $83 \%$ of the entire inventory of thorium that is expected to be present in the treated area (based on site survey results).

- The thorium extraction vs. treatment time curve was found to level off even though the process conditions were maintained highly conducive to thorium extraction. The conclusion that is most compelling is that the thorium "source" has been depleted considerably.

Details on these observations are presented below.

\section{Radiation Level}

The concrete surface affected by Tests 5 and 6 was grid-marked. The radiation count from each of the grid units was recorded (using BICRON Surveyor 50 radiation counter) before and after treatment. These radiation counts are presented in Figures A13 and A14. The data indicate that the radiation count was reduced to the background level $(200-250 \mathrm{cpm})$ at a majority of the sampled locations in the Test 5 area. This corresponds to approximately $84 \%$ reduction in radiation count.

A survey of the Building 21 floor for radiation level was also carried out by site personnel, both before and after treatment. Grids showing thorium concentration at various sampled locations were prepared based on the survey results. Copies of these pre and post-treatment survey results are enclosed. In Figure 15, the locations of Tests 5 and 6 areas are superimposed on the grid for thorium concentration. The concentration data for locations near Spot \#2,3,5, and 6 (shown in the survey report) apply to the Test 5 area. Assuming that these data well represent the average thorium concentration in the Test 5 area, nearly $82 \%$ reduction (from $14.98 \mathrm{pCi} / \mathrm{g}$ to $2.77 \mathrm{pCi} / \mathrm{g}$ ) in radiation level is estimated. This is in good agreement with the results presented in Figure A10. 
ISOTRON ${ }^{\circledR}$ Corporation/Appendix A

Contract DE-AC21-93MC30162

Process Chemistry and Operating Parameters

ELECTROSORB ${ }^{\circledR}$ "C" Technology

Figure A13-1: Radiation Count in the Test 5 Area before Treatment

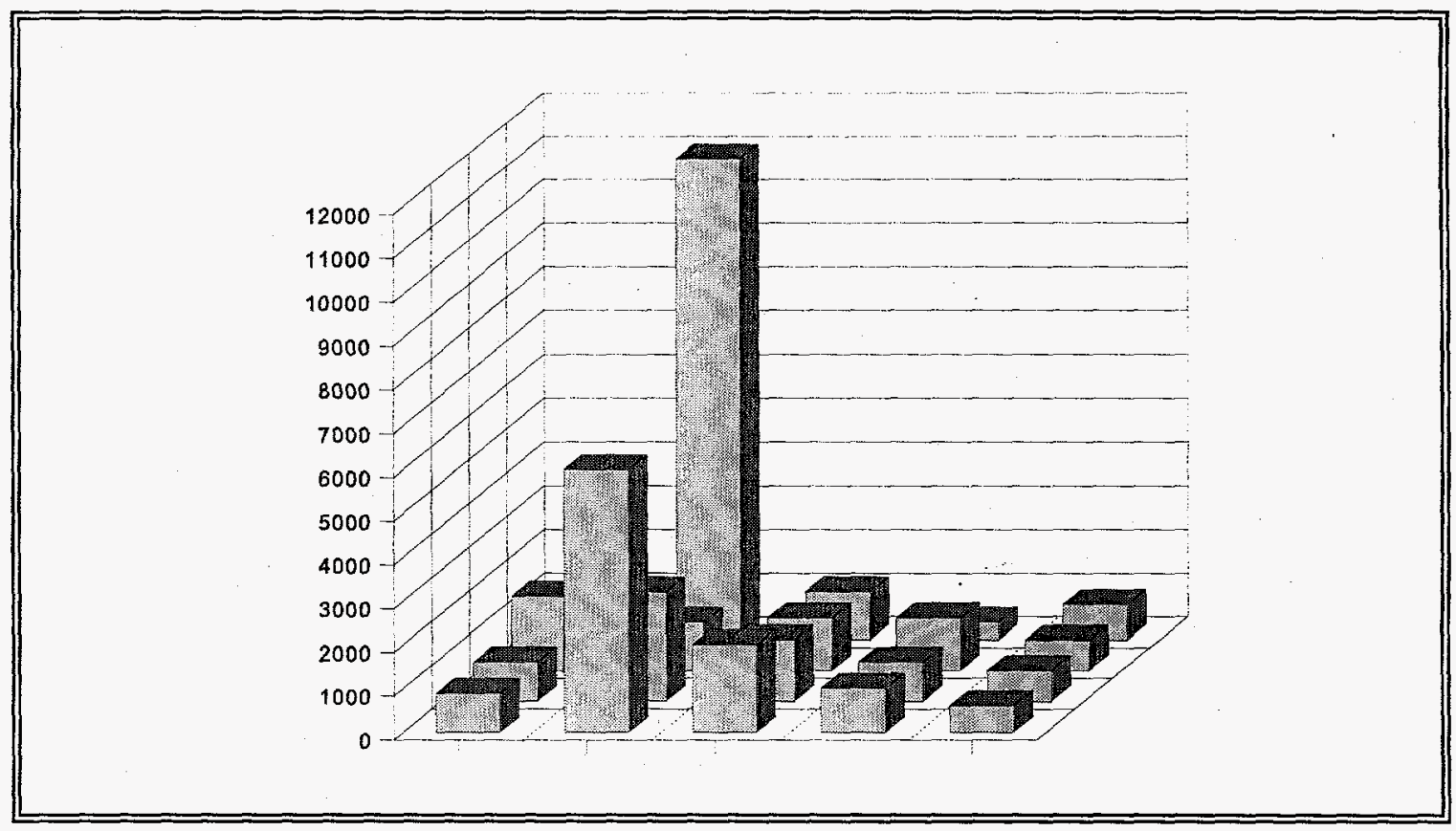

Figure A13-2: Radiation Count in the Test 5 Area after Treatment

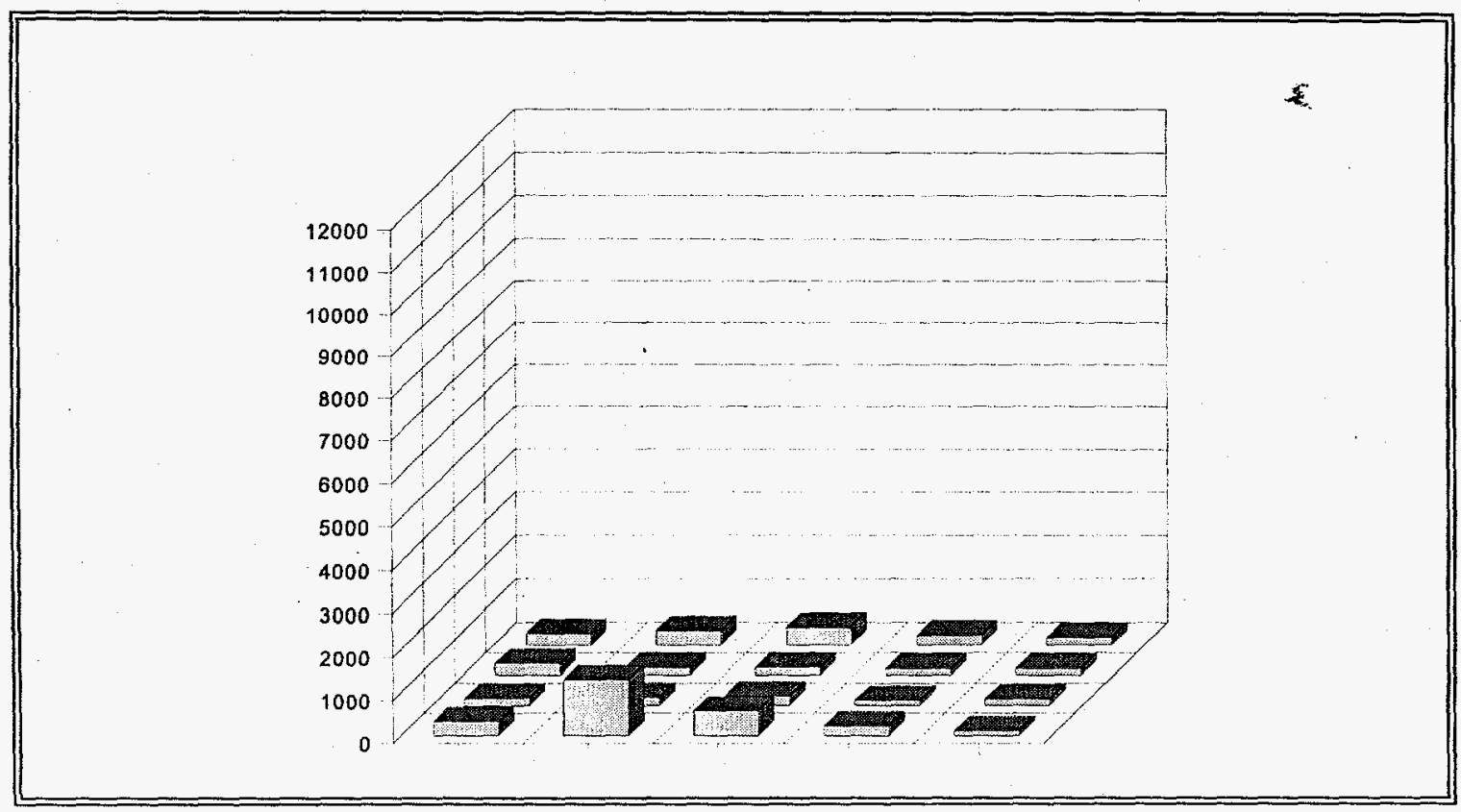


ISOTRON ${ }^{\otimes}$ Corporation/Appendix A

Contract DE-AC21-93MC30162

Process Chemistry and Operating Parameters

ELECTROSORB ${ }^{\circledR}$ "C C" Technology

Figure A14-1: Radiation Count in the Test 6 Area before Treatment

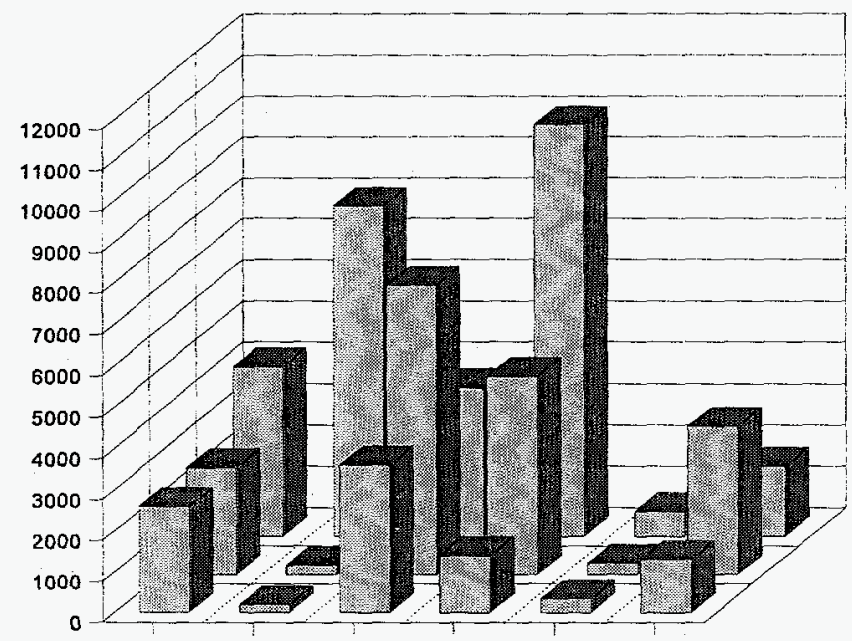

Figure A14-2: Radiation Count in the Test 6 Area after Treatment

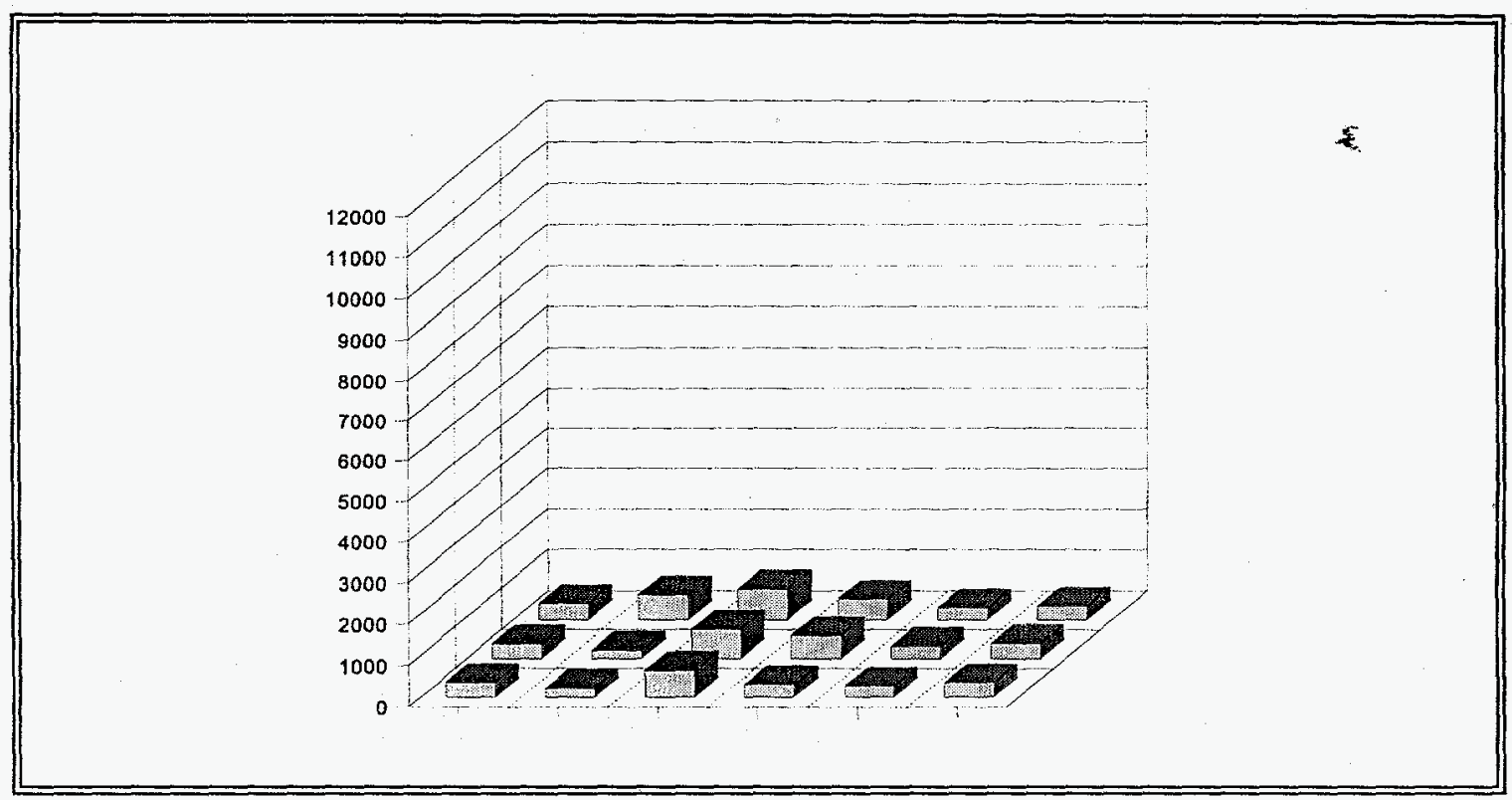


ISOTRON ${ }^{\circledR}$ Corporation/Appendix A

Contract DE-AC21-93MC30162

$09 / 04 / 96$

Process Chemistry and Operating Parameters

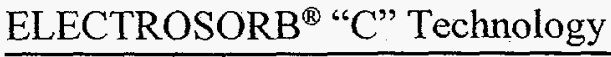

Figure A15: Locations of Tests 5 and 6 Areas on the Radiation Level Grid

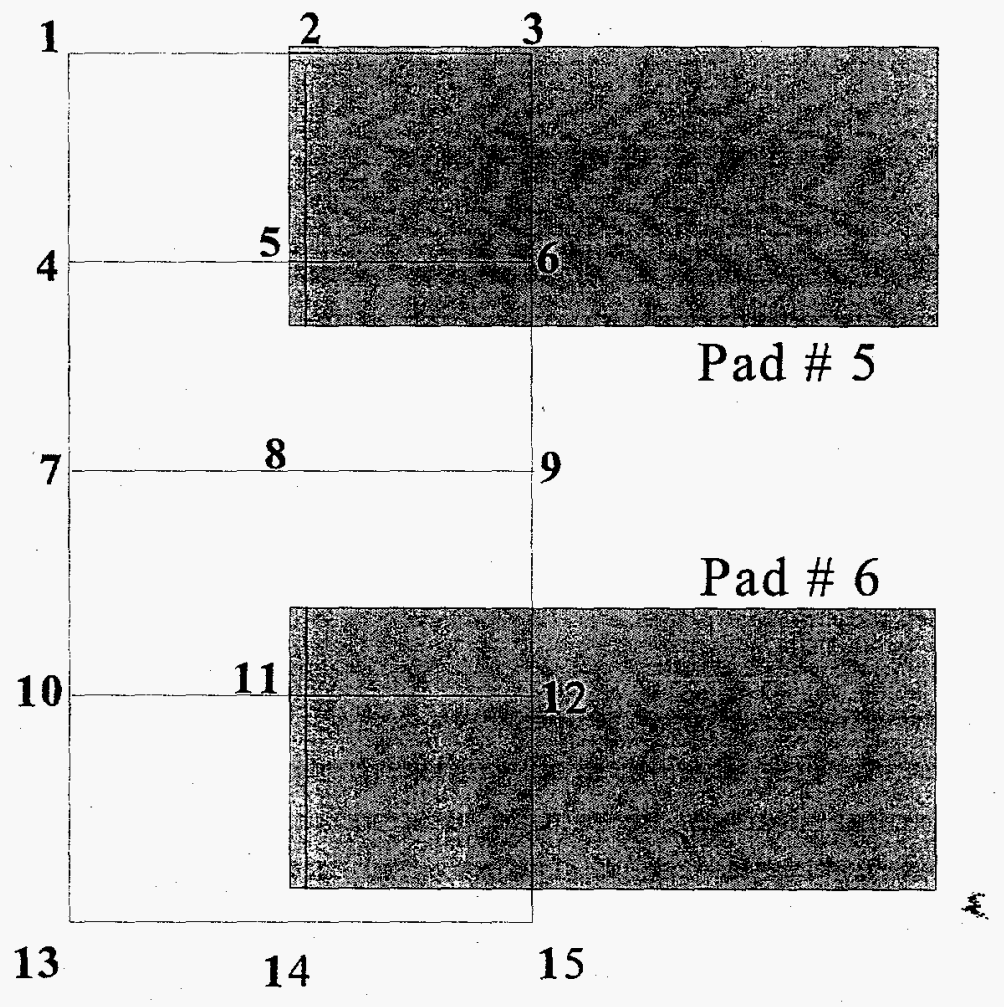




\section{Estimating the Amount of Thorium Initially Present in Concrete}

Based on the thorium concentration data presented in the survey report, the average thorium concentration at the surface of the untreated floor is $14.98 \mathrm{pCi} / \mathrm{g}$ or $106 \mathrm{ppm}$. Thorium contamination is not expected to penetrate the concrete to any great depth. It is reported in the literature [4] that in the case of thorium contamination, radiation dose decreases from $32,900 \mathrm{mrem} /$ year to $0.205 \mathrm{mrem} /$ year in moving from 0.125 inches $(0.3175 \mathrm{~cm})$ below the concrete surface to 0.25 inches $(0.635 \mathrm{~cm})$ below the same. Considering this, it is assumed that in the Building $21 \mathrm{floor}$, thorium concentration diminishes exponentially over a depth of $1 \mathrm{~cm}$ from the concrete surface. In that case, the thorium concentration distribution function is given by:

$$
[T h], p p m=167.69 e^{-X}-61.69
$$

where $X$ denotes the depth (in $\mathrm{cm}$ ) from the concrete surface. The total inventory of thorium (in $\mathrm{mg}$ ) in the Test 5 area $\left(15 \mathrm{ft}^{2}\right.$ of area) is estimated by integrating the above function between the limits of $X=0 \mathrm{~cm}$ to $X=1 \mathrm{~cm}$ and then multiplying the result by a constant equal to 34.84 . This constant represents the mass of concrete (in $\mathrm{kg}$ ) in a $1 \mathrm{~cm}$ deep slab of $15 \mathrm{ft}^{2}$ area, at a density of $2.5 \mathrm{gm} / \mathrm{cc}$. The thorium inventory is estimated to be $1540 \mathrm{mg}$ or $1.54 \mathrm{gm}$.

\section{Mass Balance}

During Test 5, $1.28 \mathrm{gm}$ of thorium was extracted (see Figure A12). This corresponds to approximately $83 \%$ extraction of the thorium that was initially present. This percent extraction figure is found to be consistent with estimates based on reduction in radiation level, as well as with the preliminary report provided by EG\&G Mound based on post treatment characterization data.

\section{Thorium Extraction vs. Treatment Time Data}

Figure A12 shows that thorium extraction rate was not significantly improved when the Batch 1 electrolyte was replaced. Replacement of used electrolyte resulted in an increase in extraction rate in most of the prior tests. Thorium extraction was also found to completely level off during the Batch 2 electrolyte regime. This batch of electrolyte contained nitric acid. Its $\mathrm{pH}$ reached a maximum value of 2.5 which was well below the limiting value. An appreciable electrical current was in use. These process conditions are quite favorable for thorium extraction, yet the extraction rate was rather slow during the second process run. It therefore appears that this retarded extraction rate is possibly due to the depletion of thorium from the concrete matrix.

All of the above data supports the conclusion that the ELECTROSORB ${ }^{\circledR}$ Process is effective in extracting thorium contamination present in the Building 21 floor. 


\section{Secondary Waste Generation}

The first batch of electrolyte from both Tests 5 and 6 was processed by contact with ion-exchange bead columns. Approximately $98 \%$ of thorium and calcium could be removed in the ion exchange bead columns. Unfortunately, the columns were spent after the first batch of electrolyte was processed. Additional ion exchange beads were required for processing the second batch of electrolyte. The result was an unacceptable volume of secondary waste.

\section{SUMMARY OF OBSERVATIONS}

Effective solubilization of contaminants is the key to extracting them from concrete. The rate and efficiency of the extraction process will depend on how conducive the process conditions are for rapid and selective contaminant dissolution. Citric acid is an effective solubilizer for most thorium species. However, the presence of a hard-to-dissolve species such as thorium dioxide will call for a more aggressive solubilizer.

The use of acidic solubilizers will permit rapid but not selective solubilization of contaminants from an alkaline matrix such as concrete. The alkaline components of the matrix will co-dissolve with the target contaminant to an extent. The elements such as calcium and magnesium associated with these elements will be extracted alongside.

The test results lead to the optimum process conditions (such as $\mathrm{pH}$, solubilizer concentration, electrolyte volume to concrete area ratio, and electrical current) that must be maintained in order to achieve rapid and more efficient thorium extraction. Although co-extraction of calcium is inevitable, the test results point to a means of minimizing it - the use of electricity. It was found that the use of electricity not only achieves a greater extraction of thorium, but also suppresses unwanted calcium extraction. This is one of the most significant findings from this process demonstration.

Confirming that solubilization of species such as thorium dioxide would require a mineral acid solubilizer is significant for future applications of this technology at thorium-contaminated sites. Equally important is the demonstration that the ELECTROSORB ${ }^{\circledR}$ Process is an effective method for concrete decontamination at full-scale. 


\section{OVERALL CONCLUSIONS AND SCOPE OF PROCESS OPTIMIZATION}

- At full-scale, the process is effective in extracting contaminants from concrete.

- The process hardware is operationally stable and reliable.

- The use of electricity increases contaminant extraction efficiency and reduces chemical demand.

- Electrokinetic extraction is shown to be more effective than chemical extraction.

- Rapid extraction of hard-to-dissolve contaminant species requires the use of aggressive solubilizers.

- The secondary waste disposal scheme must be optimized to achieve reduction in waste volume and hence in disposal cost.

ISOTRON $^{\oplus}$ is presently working on an advancement of secondary waste processing technique. This advanced scheme is depicted in Figure A16. A closed-loop cold vaporization unit is used for separating the dissolved solids (including the contaminants) from the spent work solution. The distillate is recycled for making solubilizer solution. The evaporator sludge is solidified either in a ceramic or in a cement matrix. The matrix offers a relatively high waste loading capacity. The final waste-form is a low-volume solid whose disposal complies with 10CFR PART 61 burial criteria. 
Process Chemistry and Operating Parameters

ELECTROSORB ${ }^{\circledR ~ “ C ” ~ T e c h n o l o g y ~}$

Figure A16: Process Scheme for Secondary Waste Minimization

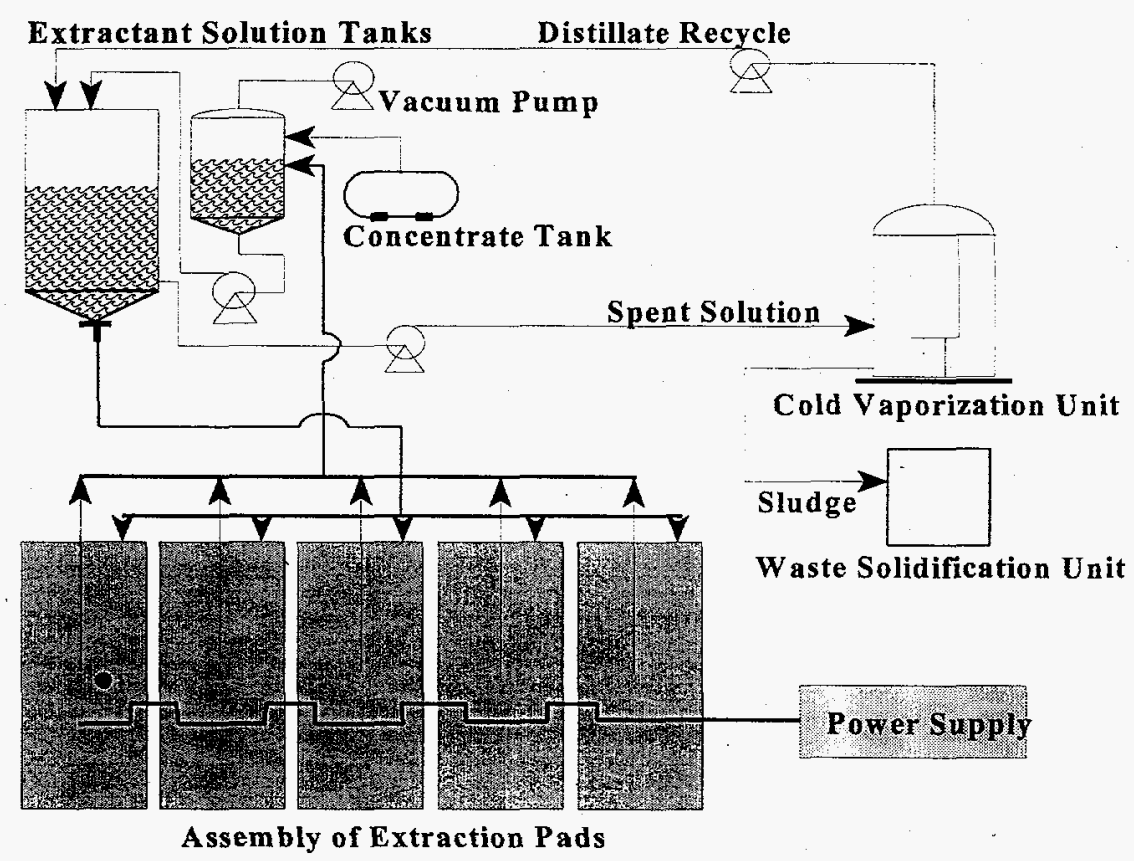

\section{REFERENCES}

1. Cotton, F. A. and Wilkinson, G., "Advanced Inorganic Chemistry", John Wiley \& Sons, 1972.

2. Cuthbert, F. L., "Thorium Production Technology", Addison-Wesley Publishing Company, 1958.

3. IUPAC Stability Constant Database, 1993.

4. Dickerson, K. S., Wilson-Nichols, M. J., and Morris, M. I., "Contaminated Concrete: Occurrence and Emerging Technologies for DOE Decontamination", Report Prepared by Oak Ridge National Laboratory for the U. S. Department of Energy, August 1995. 
ISOTRON $^{\circledR}$ Technical Report dated June 15, 1994

\begin{tabular}{|c|}
\hline REPORT № 061594 \\
\hline ELECTROKINETIC EXTRACTION OF \\
RADIONUCLIDES FROM CONCRETE \\
(Complexants - Carbonate, Citrate, Chloride) \\
\hline
\end{tabular}


Page 1 of 16

REPORT NO. 061594

ELECTROKINETIC EXTRACTION OF

RADIONUCIIDES FROM CONCRETE

(Complexants - Carbonate, Citrate, Chloride)

\section{SECTION NO. 1}

\section{OBJECTIVE:}

Identify a solubilizer to enhance the electrokinetic transport of uranium through concrete. Evaluate same with both the "1-D Transport" and "SEEC-Pad" test cells.

\section{OBSERVATIONS:}

- Carbonate and citrate anions do not transit through concrete, probably due to the presence of calcium.

- Remarkably, the direction of electroosmotic transport of water through concrete is not as expected. The osmotic transport is cathode to anode in the case of deionized water. On the other hand, when sodium carbonate was used, the osmotic transport is anode to cathode, which is the expected direction.

\&.

- It was found that two complexants ( $\mathrm{Cl}^{-}$and sodium salt of cyclohexylsulfamic acid) demonstrated good complexation properties for uranium and at the same time, can move through concrete.

Prepared by:

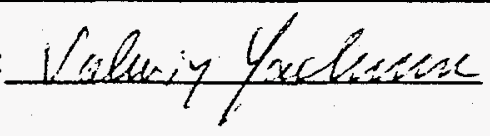

Date:

$$
6-15-94
$$

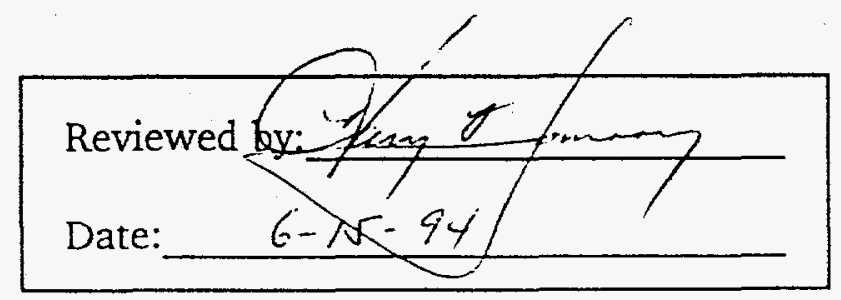


Report No. 061594

Electrokinetic Extraction of

Radionuclides from Concrete

DESCRIPTION OF THE EXPERIMENTS:

Test Series No. 1 - Using "1-D Transport Cell":

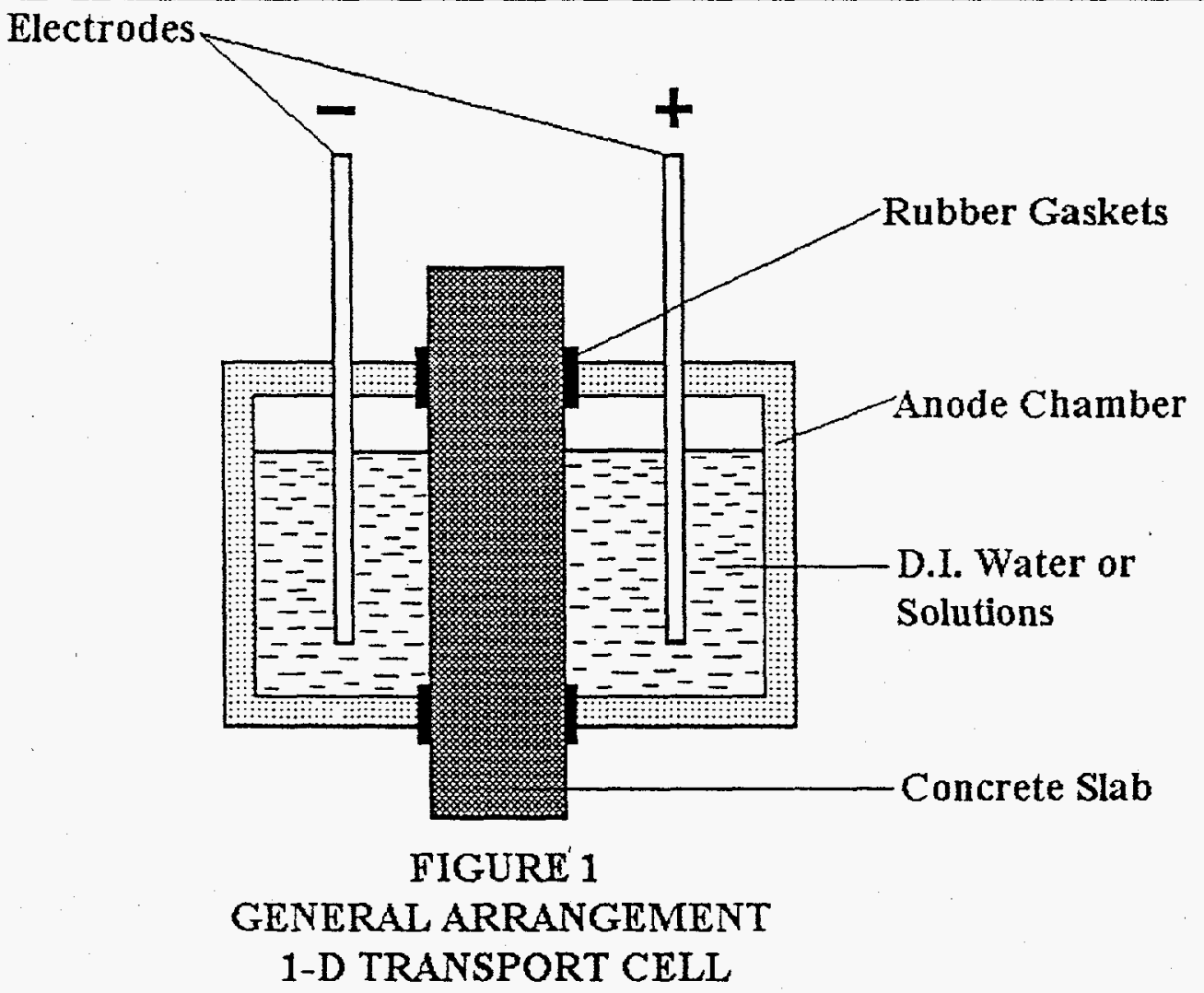

Experiment Cells 1 \& 2:

E

Two identical test cells were prepared (Figure 1). DI water was filled in both anodic and cathodic chambers. One hour of contact provided for preliminary wetting of both concrete slabs with DI water. Samples of water from anodic chambers were analyzed for carbon concentration to establish initial amount of carbonate in water. After the preliminary internal wetting, the current in both cells was switched on. After two hours of delivery of current through both concrete slabs (approximately 0.080 amps and 40 volts D.C.), a second set of samples was taken for analysis for carbonate. At this time, a mixture of 0.5 $\mathrm{M} \mathrm{Na}_{2} \mathrm{CO}_{3}$ and $0.5 \mathrm{M}$ sodium citrate solution was added to the cathodic chambers of both cells. After two additional hours of power delivery (with the same current in both cells), a third set of samples was taken for analysis for carbonate and citrate in anodic chambers. 
Report No. 061594

Page 3 of 16

Electrokinetic Extraction of

Radionuclides from Concrete

\section{Results and Conclusions:}

This experiment failed because the measurement of carbon by ICP was found to be unreliable and not reproducible. A phone call to Perkin Elmer revealed the following:

Mike Duffy said that the ICP Plasma 400 can not measure carbon with sufficient reliability because of interfering background $\left(\mathrm{CO}_{2}\right.$ in water, argon, air).

As an alternative, the following detection method was called upon:

$\mathrm{BaCl}_{2}$ creates a white precipitation with $\mathrm{CO}_{3}^{-}\left(\mathrm{Na}_{2} \mathrm{CO}_{3}+\mathrm{BaCl}_{2} \rightarrow \mathrm{NaCl}+\mathrm{BaCO}_{3}\right)$. On the other hand, citrate ion creates a green complex with iron.

Experiments were repeated with the result that:

a) Carbonate ions do not go through concrete. (Also, surfactants do not help.)

b) Citrate anions can go through concrete only in trace amount. (Surfactants do not help.)

c) It was observed that in the situation where both cathodic and anodic chambers are filled with DI water, and after $1 \frac{1 / 2}{2}$ to 2 hours of power delivery, a significant electroosmotic flow is observed. However, it is not in the expected direction to the anodic chamber. 
Report No. 061594

Electrokinetic Extraction of

Page 4 of 16

Radionuclides from Concrete

Test Series No. 2 - Study of "Reversed" Electroosmosis:

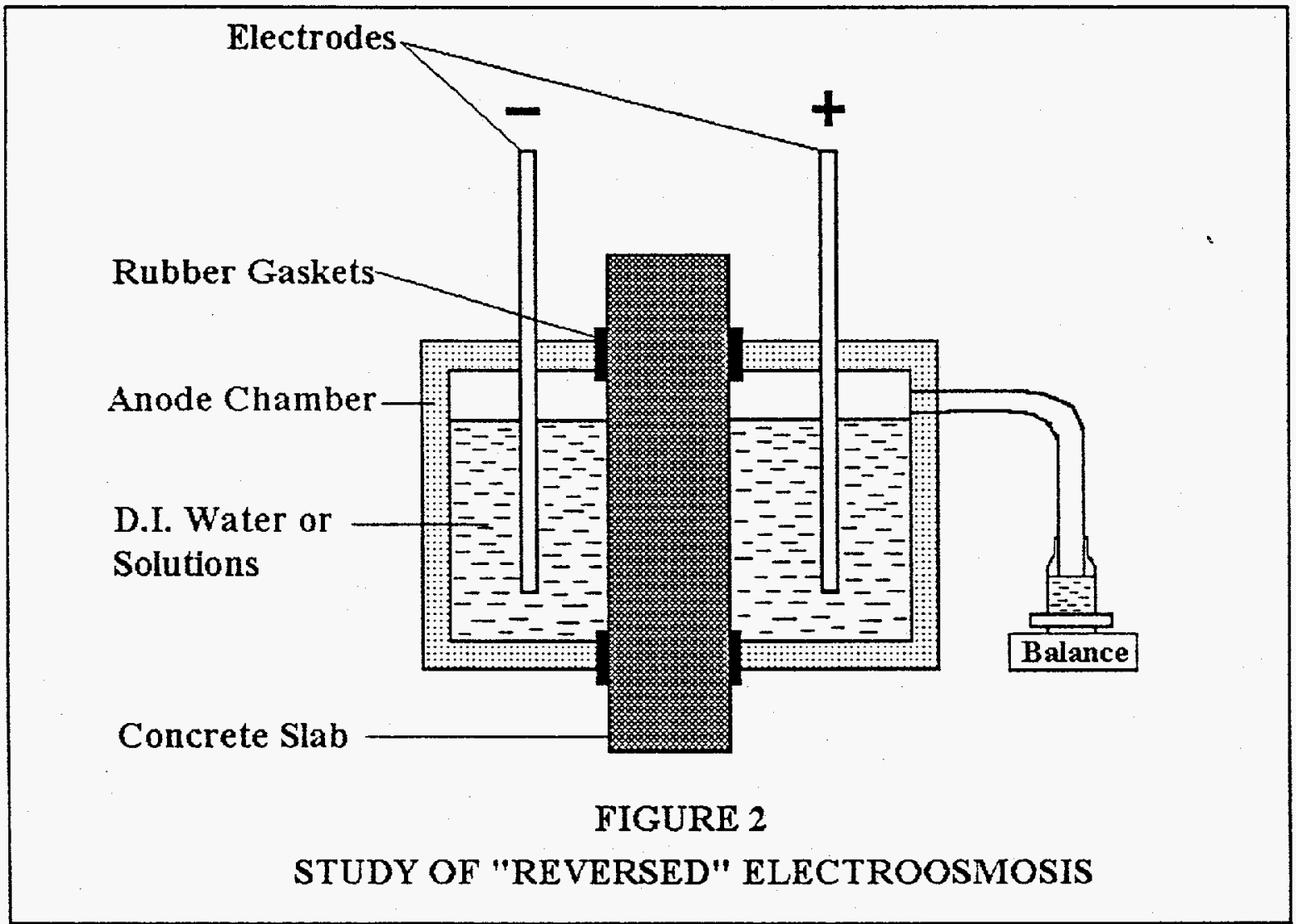

Experiment Cells 3 \& 4:

Results and Conclusions:

The experimental cells used in the previous experiment were modified to permit an accurate measurement of effluent from anodic chambers. During these experiments, specific additions were studied:

- emulsion of TBP with uranium

- solution of EDTA with uranium

were introduced into cathodic chambers of cell \#3 and cell \#4 correspondingly. 
Report No. 061594

3 Electrokinetic Extraction of

Page 5 of 16

Radionuclides from Concrete

TABLE 1

\begin{tabular}{|c|c|c|c|c|c|c|c|c|c|}
\hline \multirow[t]{2}{*}{ TIME } & \multicolumn{4}{|c|}{$\begin{array}{l}\text { 1-D TRANSPORT } \\
\text { CELL \#3 }\end{array}$} & \multicolumn{4}{|c|}{$\begin{array}{l}\text { 1-D TRANSPORT } \\
\text { CELL \#4 }\end{array}$} & \multirow[t]{2}{*}{ NOTES } \\
\hline & $\begin{array}{c}\zeta \\
\text { amps }\end{array}$ & $\begin{array}{c}\mathrm{V} \\
\text { volts }\end{array}$ & $\underset{\text { gram }}{\mathrm{M}}$ & $\begin{array}{c}\text { Pore } \\
\text { Volumes } \\
\text { per hour }\end{array}$ & $\begin{array}{c}\zeta \\
\text { amps }\end{array}$ & $\begin{array}{c}\mathrm{V} \\
\text { volts }\end{array}$ & $\begin{array}{c}\text { M } \\
\text { gram }\end{array}$ & $\begin{array}{c}\text { Pore } \\
\text { Volumes } \\
\text { per hour }\end{array}$ & \\
\hline $\begin{array}{l}10: 45 \\
\text { A.M. }\end{array}$ & 0.240 & 104 & 0.0 & 0.0 & 0.191 & 104 & 0.0 & 0.0 & \\
\hline $11: 30$ & 0.188 & 76 & 13.2 & 2.4 & 0.168 & 76 & 8.7 & 1.6 & \\
\hline $12: 00$ & 0.174 & 92 & 23.5 & 2.8 & 0.201 & 92 & 16.8 & 2.2 & \\
\hline \multicolumn{9}{|c|}{ at at this $\rightarrow$} & $\begin{array}{l}\text { add } \\
\text { emulsion } \\
\text { with U } \\
\text { to \#4 }\end{array}$ \\
\hline $\begin{array}{c}12: 30 \\
\text { P.M. }\end{array}$ & 0.171 & 104 & 36.2 & 3.4 & 0.164 & 104 & 21.0 & 1.1 & \\
\hline $1: 00$ & 0.190 & 104 & 47.8 & 3.1 & 0.200 & 104 & 22.6 & 0.4 & \\
\hline $1: 40$ & 0.203 & 91 & 64.1 & 3.3 & 0.195 & 91 & 23.4 & 0.2 & \\
\hline $2: 05$ & 0.193 & 104 & 80.8 & 4.5 & 0.178 & 104 & 23.4 & 0.0 & \\
\hline $2: 30$ & 0.200 & 104 & 93.5 & 3.8 & 0.110 & 104 & 23.4 & 0.0 & \\
\hline & & & & & & at & this & time $\rightarrow$ & $\begin{array}{l}\text { add } \\
\text { EDTA } \\
\text { with U } \\
\text { to \#3 }\end{array}$ \\
\hline $3: 00$ & 0.202 & 104 & 93.8 & 0.1 & 0.092 & 104 & 23.4 & 0.0 & \\
\hline $4: 00$ & 0.181 & 104 & 94.2 & 0.1 & 0.102 & 104 & 23.4 & 0.0 & \\
\hline $5: 00$ & 0.085 & 104 & 95.3 & 0.1 & 0.131 & 104 & 23.4 & 0.0 & \\
\hline
\end{tabular}


Report No. 061594

Page 6 of 16

Electrokinetic Extraction of

Radionuclides from Concrete

\section{DISCUSSION:}

This experimental study of the "Reversed" electroosmosis demonstrated the following:

- The amount of water transported by "reversed" electroosmosis is larger than that suggested by conventional electroosmosis (approximately 10 times greater in the case of cell \#3 and 5 times for cell \#4).

- $\quad$ "Reversed" electroosmosis is very sensitive to the additives, to solution and can be suppressed (for example, addition of EDTA to cell \#3). It can be reversed to restore the normal electroosmosis flow (for example, after addition of the emulsion to cell \#4).

Note: Some insignificant amount of uranium was transported through concrete by emulsion of TBP. (Concentration of uranium in anodic chamber was $0.6 \mathrm{ppm}$.) Note that uranium was introduced into the cathodic chamber together with emulsion of TBP. 
Report No. 061594

Electrokinetic Extraction of

Radionuclides from Concrete

Test Series No. 3 - Study of Uranium Migration Through Concrete:

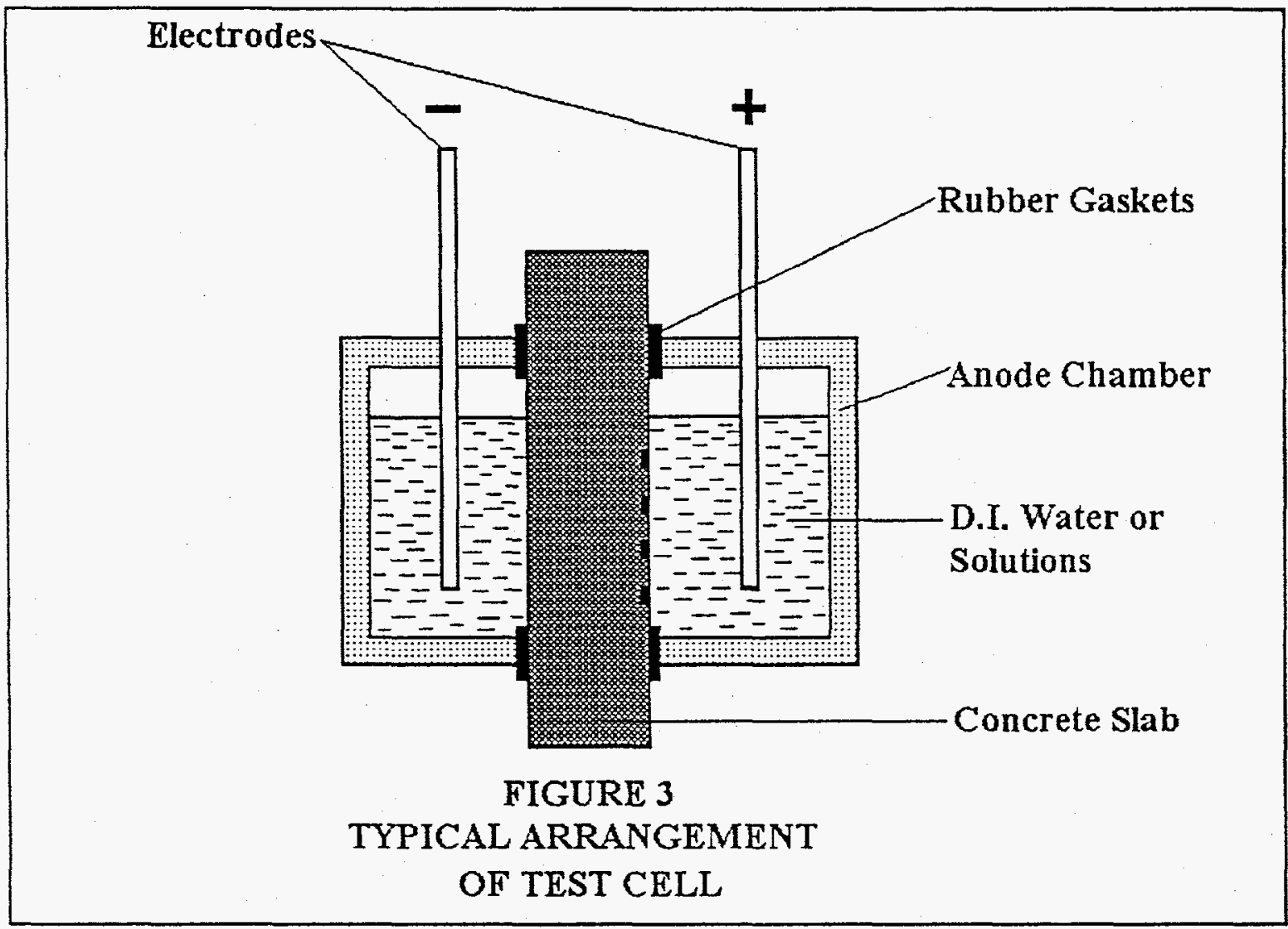

\section{Experiment Cells 5 \& 6:}

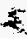

Two concrete slabs were contaminated by soluble uranium (AAS Standard) applied drop wise to one side of concrete surface. Two identical test cells were set up with the uranium contaminated side contacting the anodic chamber (Figure 3). One hour was allowed for preliminary wetting of the electrolytes. Current was then switched on. After $2 \frac{1 / 2}{2}$ hours of current delivery, an emulsion solution was added. Solutions comprised TBP and sodium carbonate solution $(0.4 \mathrm{M})$. Solution was introduced into the cathodic chamber. (This procedure was applied to both cell \#5 and cell \#6.

The concentration at uranium in anodic chambers was measured by ICP (Perkin Elmer Plasma 400).

Note: Cell \#5 received the TBP emulsion. Cell \#6 received the sodium carbonate. 
Report No. 061594

Electrokinetic Extraction of

Radionuclides from Concrete

The results of these measurements are presented below:

TABLE 2

\begin{tabular}{|c|c|c|c|c|c|c|c|c|c|}
\hline \multirow[t]{2}{*}{ TIME } & \multicolumn{4}{|c|}{$\begin{array}{l}\text { 1-D TRANSPORT } \\
\text { CELL \#5 }\end{array}$} & \multicolumn{4}{|c|}{$\begin{array}{l}\text { 1-D TRANSPORT } \\
\text { CELL \#6 }\end{array}$} & \multirow[t]{2}{*}{ NOTES } \\
\hline & $\begin{array}{c}\zeta \\
\text { amps }\end{array}$ & $\begin{array}{l}\text { V } \\
\text { volts }\end{array}$ & $\underset{\mathrm{ppm}}{\mathrm{U}}$ & $\begin{array}{c}\% \\
\text { removal }\end{array}$ & $\begin{array}{c}\zeta \\
\text { amps }\end{array}$ & $\begin{array}{c}\mathrm{V} \\
\text { volts }\end{array}$ & $\underset{\mathrm{ppm}}{\mathrm{U}}$ & $\begin{array}{c}\% \\
\text { removal }\end{array}$ & \\
\hline $\begin{array}{l}12: 30 \\
\text { P.M. }\end{array}$ & 0.029 & 44 & 0.0 & 0.0 & 0.029 & 44 & 0.0 & 0.0 & \\
\hline $1: 30$ & 0.130 & 88 & $\ldots$ & $\ldots$ & 0.147 & 88 & $\ldots$ & $\ldots$ & \\
\hline $2: 00$ & 0.122 & 88 & $\ldots$ & $\ldots$ & 0.142 & 88 & .. & $\ldots$ & \\
\hline $2: 30$ & 0.111 & 88 & $\ldots$ & $\ldots$ & 0.120 & 88 & $\ldots$ & $\ldots$ & \\
\hline $3: 00$ & 0.080 & 88 & 2.1 & 10.5 & 0.104 & 88 & 1.6 & 8.0 & \\
\hline & & & & & & at & this & time $\rightarrow$ & $\begin{array}{l}\text { addition } \\
\text { of } \\
\text { emulsion } \\
\text { of TBP to } \\
\text { cell \#5 } \\
\text { and } \\
\text { sodium } \\
\text { carbonate } \\
\text { to cell \#6 } \\
\text { (into } \\
\text { cathode } \\
\text { chambers) }\end{array}$ \\
\hline $4: 00$ & 0.039 & 88 & - & $\cdots$ & 0.167 & 88 & - & $\ldots$ & \\
\hline $4: 30$ & 0.081 & 88 & 2.7 & 13.5 & 0.258 & 88 & 2.1 & 10.5 & \\
\hline $5: 30$ & 0.170 & 88 & 3.1 & 15.5 & 0.105 & 88 & 1.8 & 9.0 & \\
\hline
\end{tabular}

Results of experiment revealed that an insignificant amount of complexant is driven through concrete (note an especially pour mobilization in the case of sodium carbonate.)

A review of prior experimental data revealed that potassium iodide complex of mercury was reported to migrate rapidly through concrete. 
Report No. 061594

Electrokinetic Extraction of

Page 9 of 16

Radionuclides from Concrete

\section{Experiment Cells 7 \& 8:}

The question which remained was to determine if a potassium iodide complexant could mobilize uranium within the concrete matrix. See Table 3 for the results of this study. (Note: The experimental set up is the same (see Figure 3.)

TABLE 3

\begin{tabular}{|c|c|c|c|c|c|c|c|c|c|}
\hline \multirow[t]{2}{*}{ TIME } & \multicolumn{4}{|c|}{$\begin{array}{l}\text { 1-D TRANSPORT } \\
\text { CELL } \# 7\end{array}$} & \multicolumn{4}{|c|}{$\begin{array}{l}\text { 1-D TRANSPORT } \\
\text { CELL \#8 }\end{array}$} & \multirow[t]{2}{*}{ NOTES } \\
\hline & $\begin{array}{c}\zeta \\
\text { amps }\end{array}$ & $\begin{array}{c}\mathrm{V} \\
\text { volts }\end{array}$ & $\begin{array}{c}\mathrm{U} \\
\mathrm{ppm}\end{array}$ & $\begin{array}{c}\% \\
\text { removal }\end{array}$ & $\begin{array}{c}\zeta \\
\text { amps }\end{array}$ & $\begin{array}{c}\mathrm{V} \\
\text { volts }\end{array}$ & $\begin{array}{c}\mathrm{U} \\
\mathrm{ppm}\end{array}$ & $\begin{array}{c}\% \\
\text { removal }\end{array}$ & \\
\hline $\begin{array}{l}\text { 1:30 } \\
\text { P.M. }\end{array}$ & 0.020 & 88 & 0.0 & 0.0 & 0.021 & 88 & 0.0 & 0.0 & \\
\hline 2:00 & 0.111 & 88 & $\ldots$ & $\cdots$ & 0.091 & 88 & - & $\cdots$ & \\
\hline $2: 30$ & 0.157 & 88 & 44 & 22.0 & 0.117 & 88 & 3.2 & 16.0 & \\
\hline & & & & & & at & this & time $\rightarrow$ & $\begin{array}{l}\text { addition } \\
\text { of } \mathrm{KI}_{3} \text { to } \\
\text { cell \#8 } \\
\text { and } \mathrm{I}_{2} \text { to } \\
\text { cell \#7 }\end{array}$ \\
\hline $3: 30$ & 0.161 & 88 & 5.5 & 27.5 & 0.138 & 88 & 4.2 & 21.0 & \\
\hline
\end{tabular}

Iodide moves very easy and in large amounts from cathode chambers through concrete slabs to anode chamber. The transit time through the concrete slab is approximately $30-45$ minutes. Unfortunately, iodine does not form a complex with uranium, and in spite of its rapid transit time, no significant amount of uranium is extracted from concrete. Prior experience with chlorine has shown that a useful complex can be formed with uranium. Follow on experiments were performed to prove the effectiveness of chlorine in removing uranium from concrete. Experimental set up was the same (see Figure 3). 
Report No. 061594

Electrokinetic Extraction of

Page 10 of 16

Radionuclides from Concrete

Experiment Cells 9 \& 10:

After a one hour preliminary wetting of concrete slabs, a concentrated solution of ammonium citrate and $\mathrm{NaCl}$ was introduced into the cathode chambers, cell \#9 and \#10, correspondingly.

TABLE 4

\begin{tabular}{|c|c|c|c|c|c|c|c|c|c|}
\hline \multirow[t]{2}{*}{ TIME } & \multicolumn{4}{|c|}{$\begin{array}{l}\text { 1-D TRANSPORT } \\
\text { CELL } \# 9\end{array}$} & \multicolumn{4}{|c|}{$\begin{array}{l}\text { 1-D TRANSPORT } \\
\text { CELL \#10 }\end{array}$} & \multirow[t]{2}{*}{ NOTES } \\
\hline & $\begin{array}{c}\zeta \\
\text { amps }\end{array}$ & $\begin{array}{c}\mathrm{V} \\
\text { volts }\end{array}$ & $\begin{array}{c}U \\
\mathrm{ppm}\end{array}$ & $\begin{array}{c}\% \\
\text { removal }\end{array}$ & $\begin{array}{c}\zeta \\
\text { amps }\end{array}$ & $\begin{array}{c}\mathrm{V} \\
\text { volts }\end{array}$ & $\begin{array}{c}\mathrm{U} \\
\mathrm{ppm}\end{array}$ & $\begin{array}{c}\% \\
\text { removal }\end{array}$ & \\
\hline $\begin{array}{l}\text { 12:00 } \\
\text { P.M. }\end{array}$ & 0.251 & 65 & 0.0 & 0.0 & 0.308 & 65 & 0.0 & 0.0 & \\
\hline 1:00 & 0.200 & 54 & $\cdots$ & $\cdots$ & 0.306 & 54 & $\cdots$ & - & \\
\hline 2:00 & 0.115 & 54 & 3.7 & 18.5 & 0.314 & 54 & 16.3 & 81.5 & \\
\hline 3:00 & 0.200 & 37 & 3.9 & 19.5 & 0.200 & 37 & 16.3 & 81.5 & \\
\hline $5: 00$ & 0.200 & 37 & 3.9 & 19.5 & 0.200 & 37 & 16.3 & 81.5 & \\
\hline
\end{tabular}

This experiment showed effective removal of uranium from concrete with $\mathrm{NaCl}$. (Note: It was not yet clear if the chlorine anion will remove uranium from the uranium contaminated dust.)

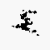

\section{Experiment Cells 11 \& 12:}

Two additional experiments were performed with uranium contaminated dust cast with portland cement into concrete slabs. In these experiments, two different test array were used. (See Figure 4 and Figure 5.) 
Report No. 061594

Page 11 of 16

Electrokinetic Extraction of

Radionuclides from Concrete
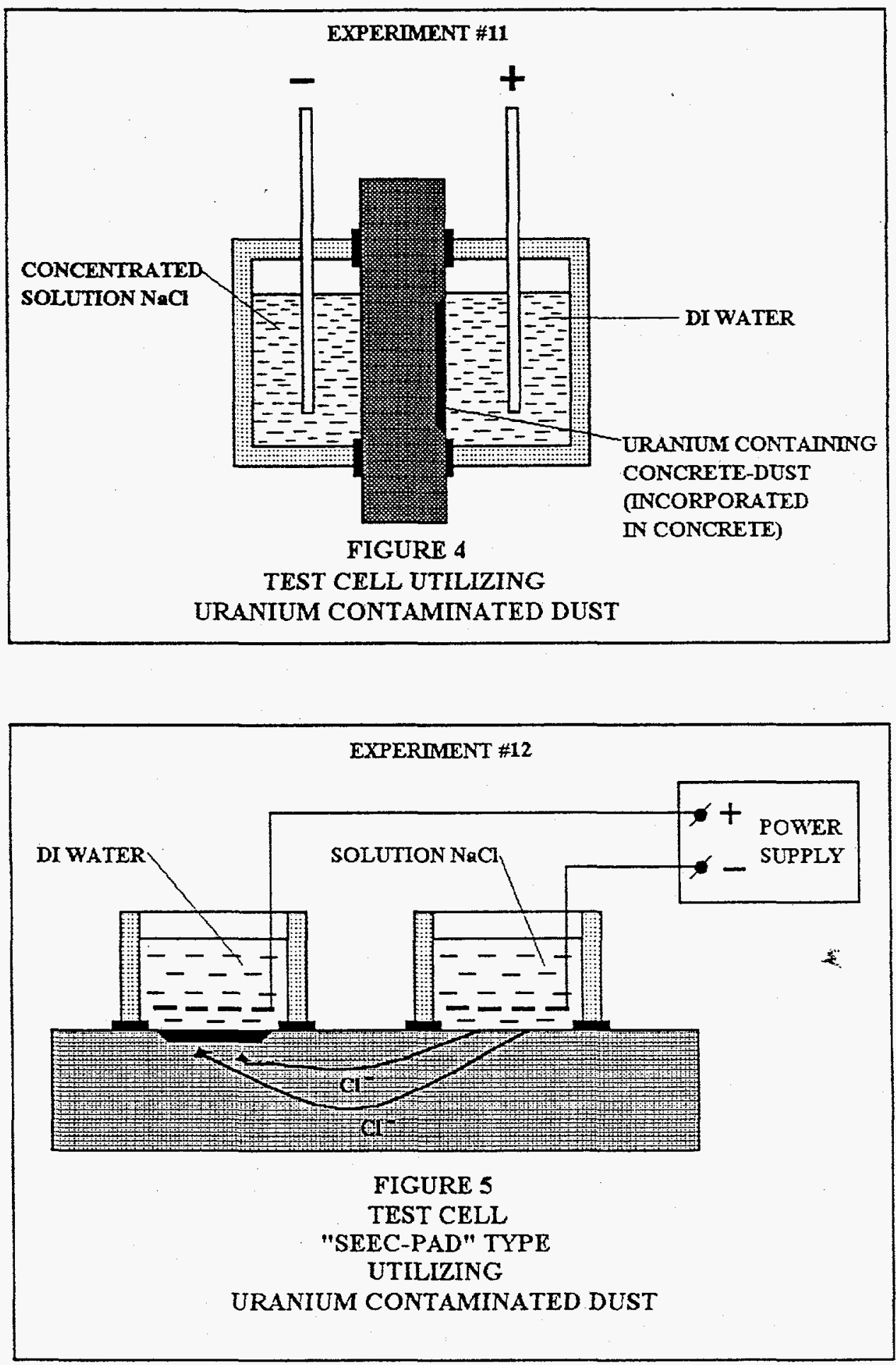
Report No. 061594

Electrokinetic Extraction of

Page 12 of 16

Radionuclides from Concrete

TABLE 5

\begin{tabular}{|c|c|c|c|c|c|c|c|c|c|}
\hline \multirow[t]{2}{*}{ TIME } & \multicolumn{4}{|c|}{$\begin{array}{l}\text { 1-D TRANSPORT } \\
\text { CELL \#11 }\end{array}$} & \multicolumn{4}{|c|}{$\begin{array}{l}\text { 1-D TRANSPORT } \\
\text { CELL \#12 }\end{array}$} & \multirow[t]{2}{*}{ NOTES } \\
\hline & $\underset{\mathrm{amps}}{\zeta}$ & $\begin{array}{c}\mathrm{V} \\
\text { volts }\end{array}$ & $\begin{array}{l}\mathrm{U} \\
\mathrm{ppm}\end{array}$ & $\begin{array}{c}\% \\
\text { removal }\end{array}$ & $\begin{array}{c}\zeta \\
\text { amps }\end{array}$ & $\begin{array}{c}\mathrm{V} \\
\text { volts }\end{array}$ & $\begin{array}{l}\mathrm{U} \\
\mathrm{ppm}\end{array}$ & $\begin{array}{c}\% \\
\text { removal }\end{array}$ & \\
\hline $\begin{array}{l}\text { 12:30 } \\
\text { P.M. }\end{array}$ & 0.265 & 44 & 6.8 & 0.6 & 0.320 & 74 & 43.7 & 2.2 & \\
\hline 2:00 & 0.300 & 16 & 138.6 & 11.4 & 0.300 & 68 & 70.6 & 3.6 & \\
\hline $3: 00$ & 0.313 & 11 & 184.0 & 14.8 & 0.500 & 57 & 86.2 & 4.4 & \\
\hline $4: 30$ & 0.330 & 12 & 282.3 & 23.15 & 0.500 & 47 & 92.0 & 4.7 & \\
\hline
\end{tabular}

Note: The percent of uranium removal is conservative. Calculations are based on the initial amount of uranium incorporated in concrete. This had been depleted in two prior test experiments. (An unknown amount of uranium was removed.)

Results and Conclusions:

The chlorine anion has demonstrated an effectiveness in removing uranium from concrete. This approach holds a potential for success and must be studied further.

\section{Problems To Be Addressed in Follow-On Experiments:}

- What is really working the $\mathrm{Cl}^{-}$anion, or $\mathrm{Cl}_{2}{ }^{-}$? Note: it is planned that flexrock polymer should be positioned directly above the uranium spot on the concrete. Tests must determine if uranium will move through the polymer and will appear in the region above same.

- During this preliminary experiment, a significant amount of $\mathrm{Cl}_{2}$ was released into the air. It is possible that this can be suppressed by adding $\mathrm{FeSO}_{4}$ into the anode chamber.

- It is ultimately necessary to remove the uranium from solution during the decontamination process. Alternatives, include ion exchange beads or precipitation.

- Complexant additives should be considered for addition to the anode chamber to improve process performance (presuming their compatibility with $\mathrm{Cl}$ ?).

- Develop some technical design for a more efficient process. Also to shorten the distance that the $\mathrm{Cl}^{-}$anion must travel prior to reaching the uranium spot. 
Report No. 061594

Electrokinetic Extraction of

Page 13 of 16

Radionuclides from Concrete

\section{SECTION NO. 2}

\section{OBJECTIVE:}

A) Evaluate the use of a "calcium compatible" solubilizer to enhance the electrokinetic transport of uranium through concrete.

B) Investigate the chloride ion $\left(\mathrm{Cl}^{-}\right)$enhanced transport of uranium through the "flexrock" polymer.

\section{DISCUSSION:}

This experiment contemplates the identification of an advanced solubilizer for uranium in concrete. On the basis of previous work, it has been concluded that any solubilizer candidate for electrokinetic extraction of uranium must have two essential properties:

1. It must be a reasonably strong complexant for uranium.

2. It must form a soluble (in water) Ca salt; under high $\mathrm{pH}$ conditions.

To verify this promise, the following experiment was performed with experimental cells \#13 and \#14. (See Figure 4.)

In anodic compartment, both cells had $0.5 \mathrm{M}$ ammonium carbonate. In the cathode compartment, cell \#13 had $0.5 \mathrm{M}$ sodium salt of cyclohexylsulfamic acid and cell \#14 had $1 \mathrm{M}$ sodium chloride.

It should be noted that cyclohexylsulfamic acid was selected because it is relatively good complexant for uranium. The calcium complex with is formed is soluble in water under high $\mathrm{pH}$ condition. 
Report No. 061594

Page 14 of 16

Electrokinetic Extraction of

Radionuclides from Concrete

TABLE 6

\begin{tabular}{|c|c|c|c|c|c|c|c|}
\hline \multirow[t]{2}{*}{ TIME } & \multicolumn{3}{|c|}{$\begin{array}{l}\text { 1-D TRANSPORT } \\
\text { CELL \#13 }\end{array}$} & \multicolumn{3}{|c|}{$\begin{array}{l}\text { 1-D TRANSPORT } \\
\text { CELL \#14 }\end{array}$} & \multirow[t]{2}{*}{ NOTES } \\
\hline & $\begin{array}{c}\zeta \\
\text { amps }\end{array}$ & $\begin{array}{c}\mathrm{V} \\
\text { volts }\end{array}$ & $\begin{array}{l}U \\
\text { ppm }\end{array}$ & $\begin{array}{c}\zeta \\
\text { amps }\end{array}$ & $\begin{array}{c}\mathrm{V} \\
\text { volts }\end{array}$ & $\begin{array}{c}\mathrm{U} \\
\mathrm{ppm}\end{array}$ & \\
\hline $\begin{array}{l}\text { 1:00 } \\
\text { P.M. }\end{array}$ & $\cdots$ & $\cdots$ & $\cdots$ & $\cdots$ & -- & $\cdots$ & start wetting \\
\hline $2: 00$ & 0.25 & 40 & 0.0 & 0.25 & 23 & 0.0 & current switched on \\
\hline $3: 00$ & 0.25 & 32 & 39.6 & 0.25 & 23 & 47.2 & \\
\hline $4: 00$ & 0.25 & 27 & 64.1 & 0.25 & 23 & 75.8 & \\
\hline $5: 00$ & 0.25 & 25 & 69.6 & 0.25 & 18 & 83.0 & \\
\hline
\end{tabular}

\section{OBSERVATIONS:}

The sodium salt of cyclohexylsulfamic acid has demonstrated comparable performance to chlorine. (The minor difference in performance can be explained as variation in the amount of uranium initially incorporated in the concrete slabs.) It is important to note that in cell \#13 a large "reverse" electroosmotic flow is observed; i.e., to anode, this flow suggests that the water is moving in the same direction as cyclohexylsulfamic anion. Note that the ionic concentration is comparatively high $(-0.5 \mathrm{M})$. It was also observed that the precious metal coating on the titanium anode (the Yitrium coating) was quickly "destroyed" (or otherwise rendered non-conductive). It was necessary to replace this anode electrode three times during the experiment (cell \#13). 
Report No. 061594

Page 15 of 16

Electrokinetic Extraction of

Radionuclides from Concrete

\begin{tabular}{|c|} 
SECTION NO. 3 \\
THE TRANSPORT OF URANIUM \\
THROUGH \\
FLEXROCK POLYMER \\
\hline
\end{tabular}

This test (cell \#15) involved a slightly modified version of the cells used in prior tests (see Figure 6 below):

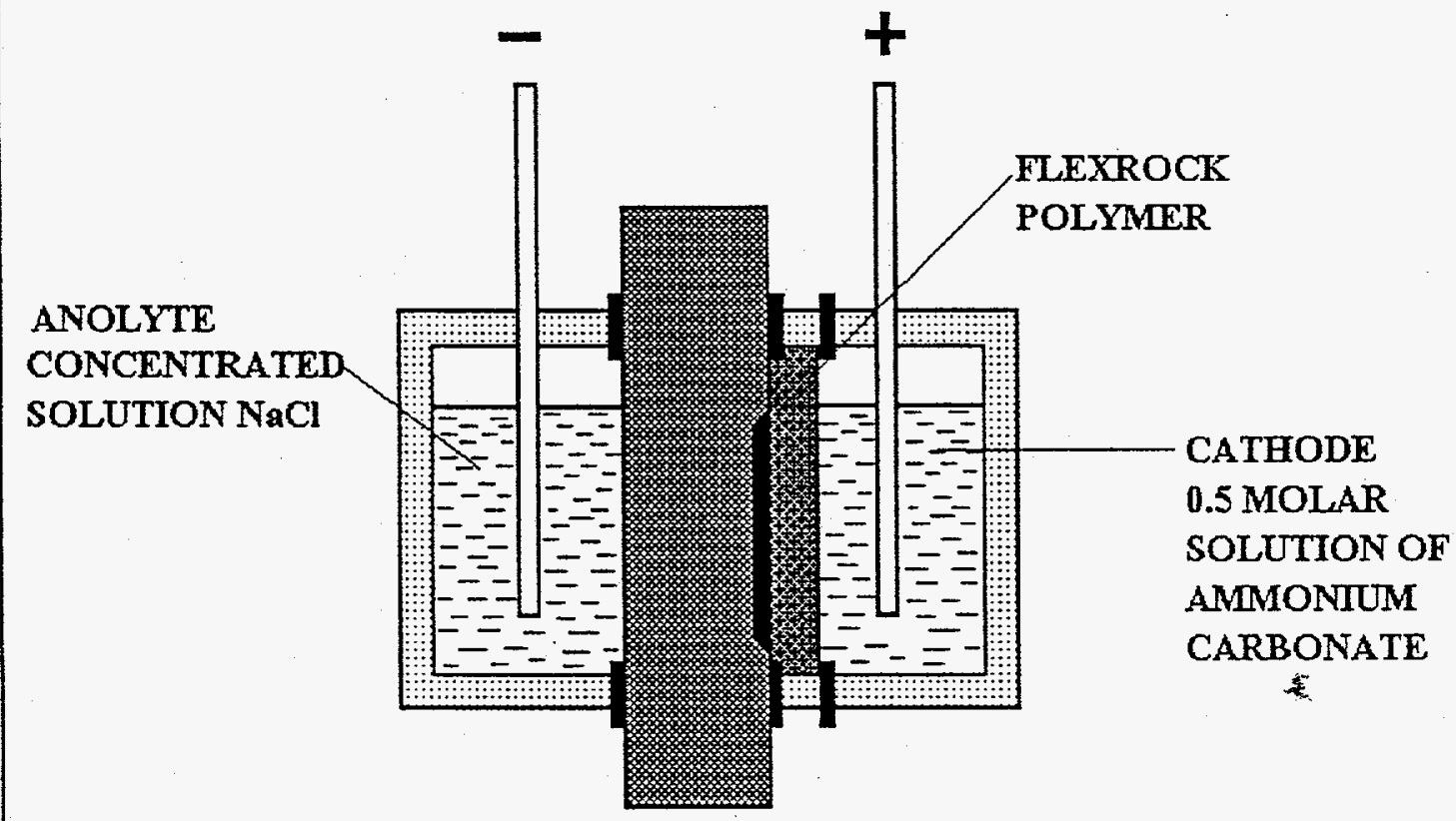

FIGURE 6

Flexrock polymer was cast into a polyvinylchloride ring. It was positioned above the uranium contaminated spot. For results of experiment, see Table 7. 
Report No. 061594

Electrokinetic Extraction of

Page 16 of 16

Radionuclides from Concrete

TABLE 7

\begin{tabular}{|l|c|c|c|l||}
\hline \multirow{2}{*}{ TIME } & \multicolumn{3}{|c|}{\begin{tabular}{c} 
1-D TRANSPORT \\
\multirow{2}{*}{ CELL \#15 }
\end{tabular}} & \multirow{2}{*}{ NOTES } \\
\cline { 2 - 4 } & $\begin{array}{c}\zeta \\
\text { amps }\end{array}$ & $\begin{array}{c}\mathrm{V} \\
\text { volts }\end{array}$ & $\begin{array}{c}\mathrm{U} \\
\mathrm{ppm}\end{array}$ & \\
\hline $\begin{array}{l}10: 30 \\
\text { A.M. }\end{array}$ & - & - & - & start wetting \\
\hline 11:30 & 0.25 & 26 & 0.0 & current switched on \\
\hline $\begin{array}{l}\text { 12:30 } \\
\text { P.M. }\end{array}$ & 0.25 & 20 & 0.7 & \\
\hline $1: 30$ & 0.25 & 19 & 7.5 & \\
\hline $2: 30$ & 0.25 & 20 & 13.8 & \\
\hline \hline
\end{tabular}

CONCLUSIONS:

This experiment showed that flexrock polymer is an acceptable medium for transport of the chlorine/uranium complex. Unfortunately, it was quickly destroyed by $\mathrm{Cl}^{-}$. This experiment was cancelled at 2:40 P.M. due to polymer shrinkage and separation from concrete surface. 
ISOTRON $^{\circledR}$ Technical Report dated June 15, 1995 (Revision 02)

\begin{tabular}{|c|}
\hline CONTRACT № DE-AC-21-93MC30162 \\
\hline INTERIM STATUS REPORT \\
ELECTROKINETIC DECONTAMINATION OF CONCRETE \\
\hline Results of Third In-Situ Test \\
at K-25 Site (Oak Ridge, TN) \\
April 24-28, 1995
\end{tabular}


June 15, 1995

Rev. 02

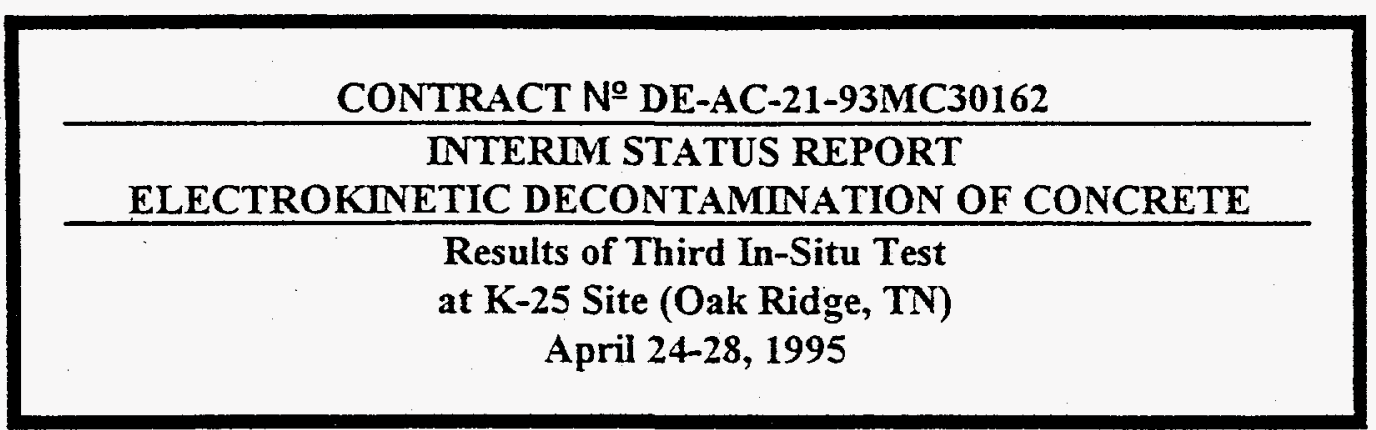

\section{OBJECTNE:}

a) Study the extraction kinetics of uranium extraction associated with different types of SEEC pads.

b) Study of energy consumption versus extraction of uranium from concrete.

c) Quantify the relationship between chemical and electrokinetic extraction.

d) Test performance of equipment in an extended extraction cycle.

\section{CONCLUSION:}

a) Working solution W.10 showed consistent and reliable performance in this service.

b) All SEEC pads demonstrated stable and generally satisfactory performance.

c) Altogether, more than 2.0 grams of uranium was removed from less than four square feet of floor.

d) A preliminary analysis of these results indicate approximately $40 \%$ of all collected uranium was removed by chemical extraction and approximately $60 \%$ by electrokinetic extraction.

Prepared by: Valeviy Yacluceu

Date: $6 /(6-95$

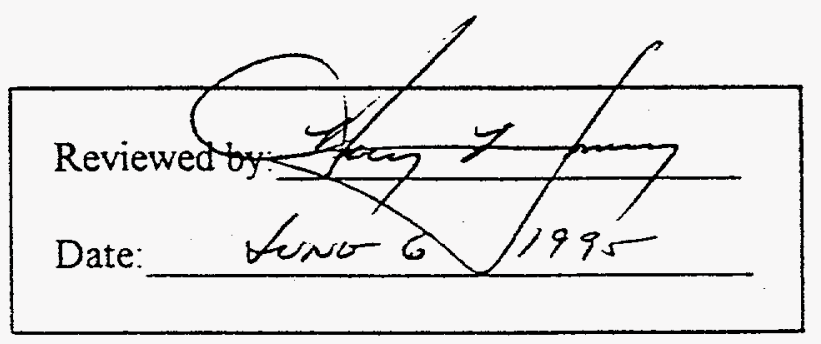


Contract № De-AC-21-93MC30162

Page 2 of 11

Interim Status Report

June 15,1995

Results of Third In-Situ Test

Rev. 02

at $\mathrm{K}-25$ Site (Oak Ridge, TN)

April 24-28, 1995

\section{DESCRIPTION OF THE EXPERIMENTS:}

Five SEEC pad design variations were placed above selected "hot" spots on concrete floor in lithium storage vaults at K-25 site in Oak Ridge (see Figures 1, 2, 3 and 4).

Solubilization of uranium in concrete was achieved using modernized versions of solutions W. 2 and W.10. Also, recently developed W.11 and W.12 solutions were also evaluated.

Experiments F-1, F-2 and S-1 used ground rod for counter electrode and experiments FM-1, R-1 and R-2 used an adjacent cathode SEEC pad for counter electrode. Experiments F-1, F-2 and FM-1 provided for circulation of work solutions between the SEEC pad and the surface of the concrete.

Ion exchange columns were provided for removal of dissolved uranium from the work solution, in order to insure against reintroduction of uranium contaminants to the floor

This experimental work was carried out in a manner that would differentiate (to extent practical) the chemical extraction versus electrokinetic extraction of uranium contaminants from the concrete.

This work was carried out with a sampling frequency that was designed to permit the determination of the onset of complete cleanup of the concrete (as evidenced by an exponential decay of uranium extracted from the concrete floor). 
Contract № De-AC-21-93MC30162

Page 3 of 11

Interim Status Report

June 15, 1995

Results of Third In-Situ Test

Rev. 02

at K-25 Site (Oak Ridge, TN)

April 24-28, 1995

Figure 1. Experiments F-1 and F-2

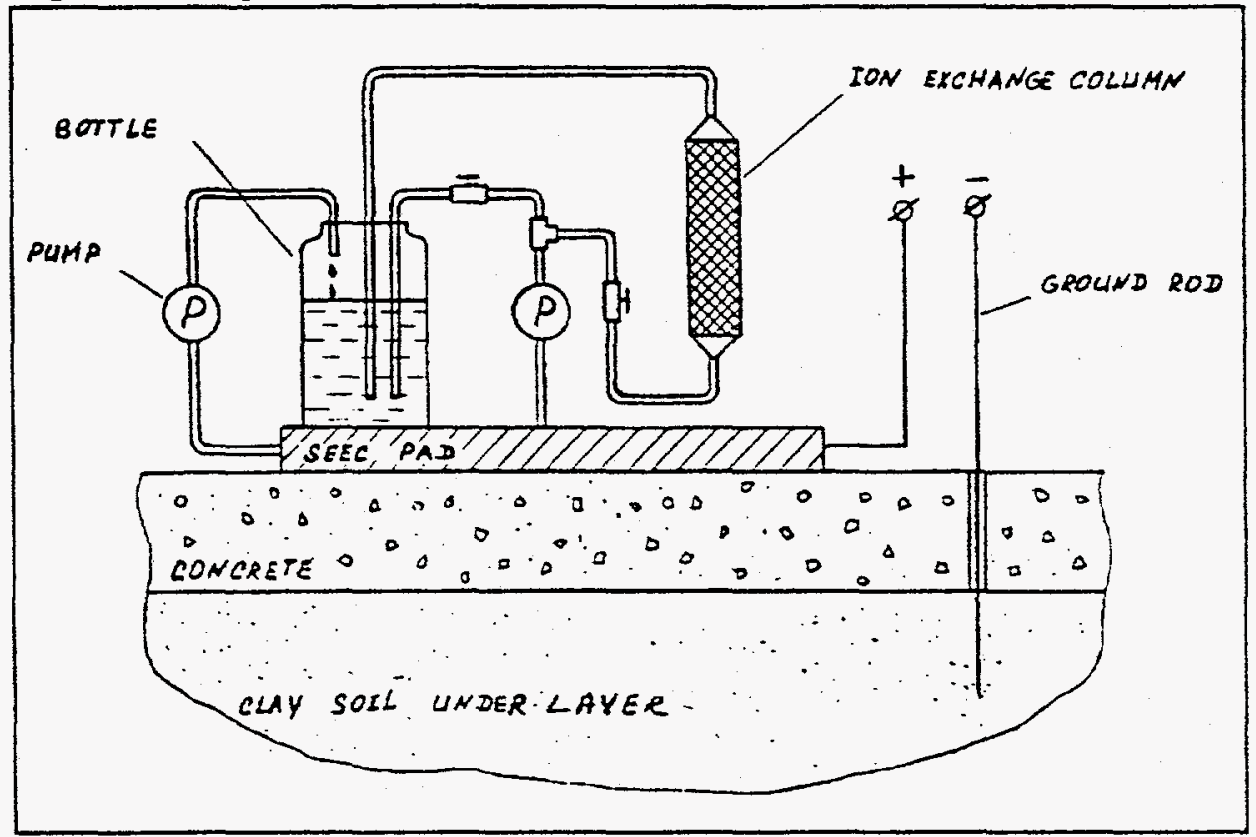

Figure 2. Experiment FM-1

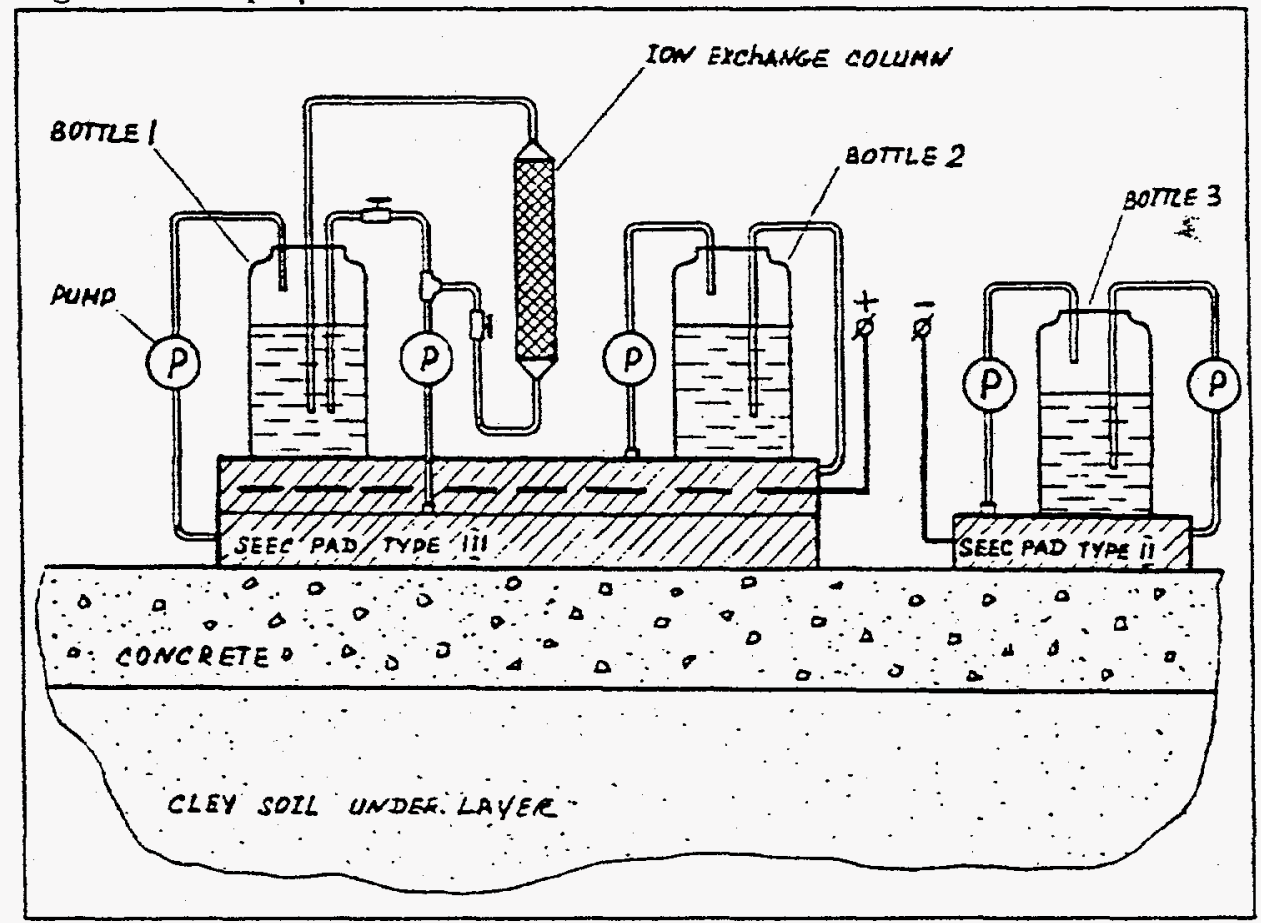



at K-25 Site (Oak Ridge, TN)

April 24-28, 1995

Figure 3. Experiments R-1 and R-2

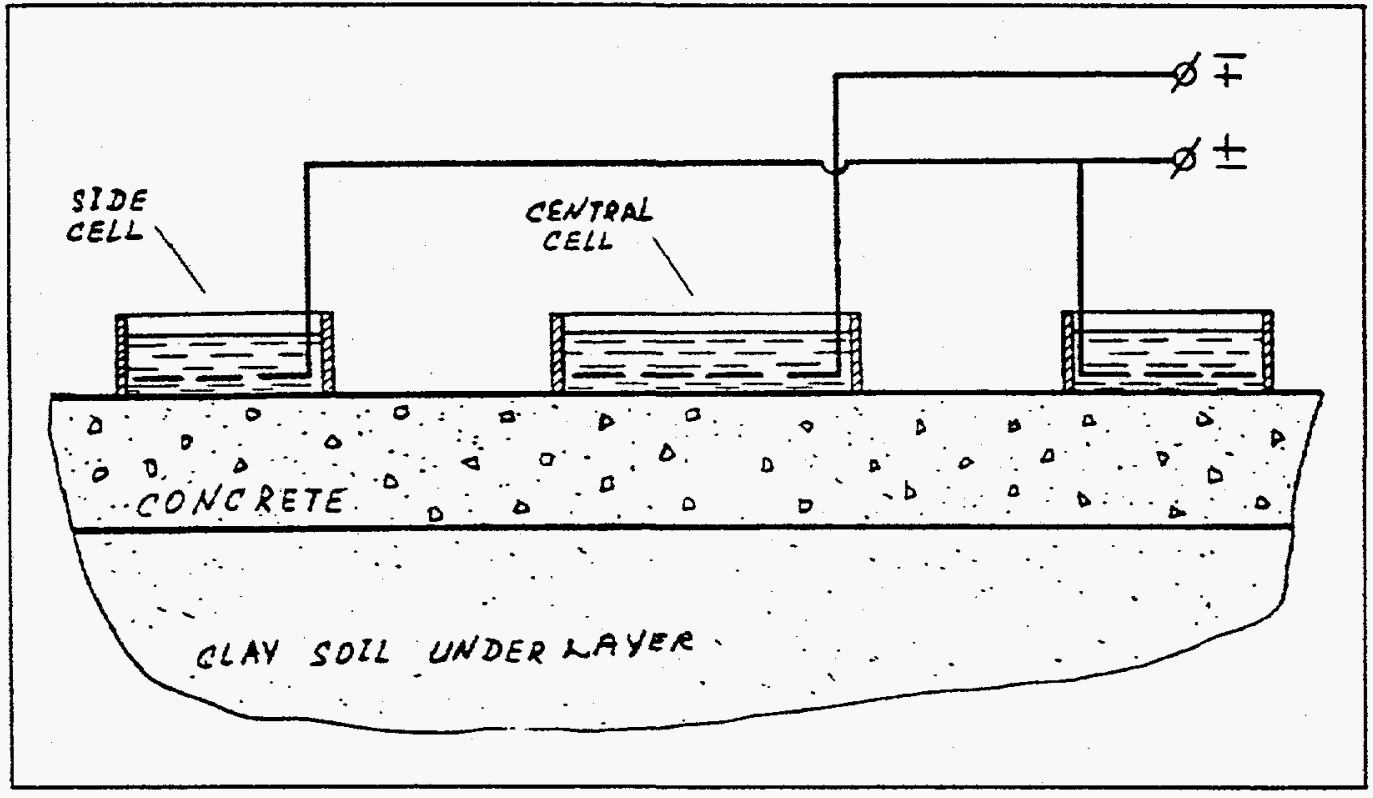

Figure 4. Experiment S-1

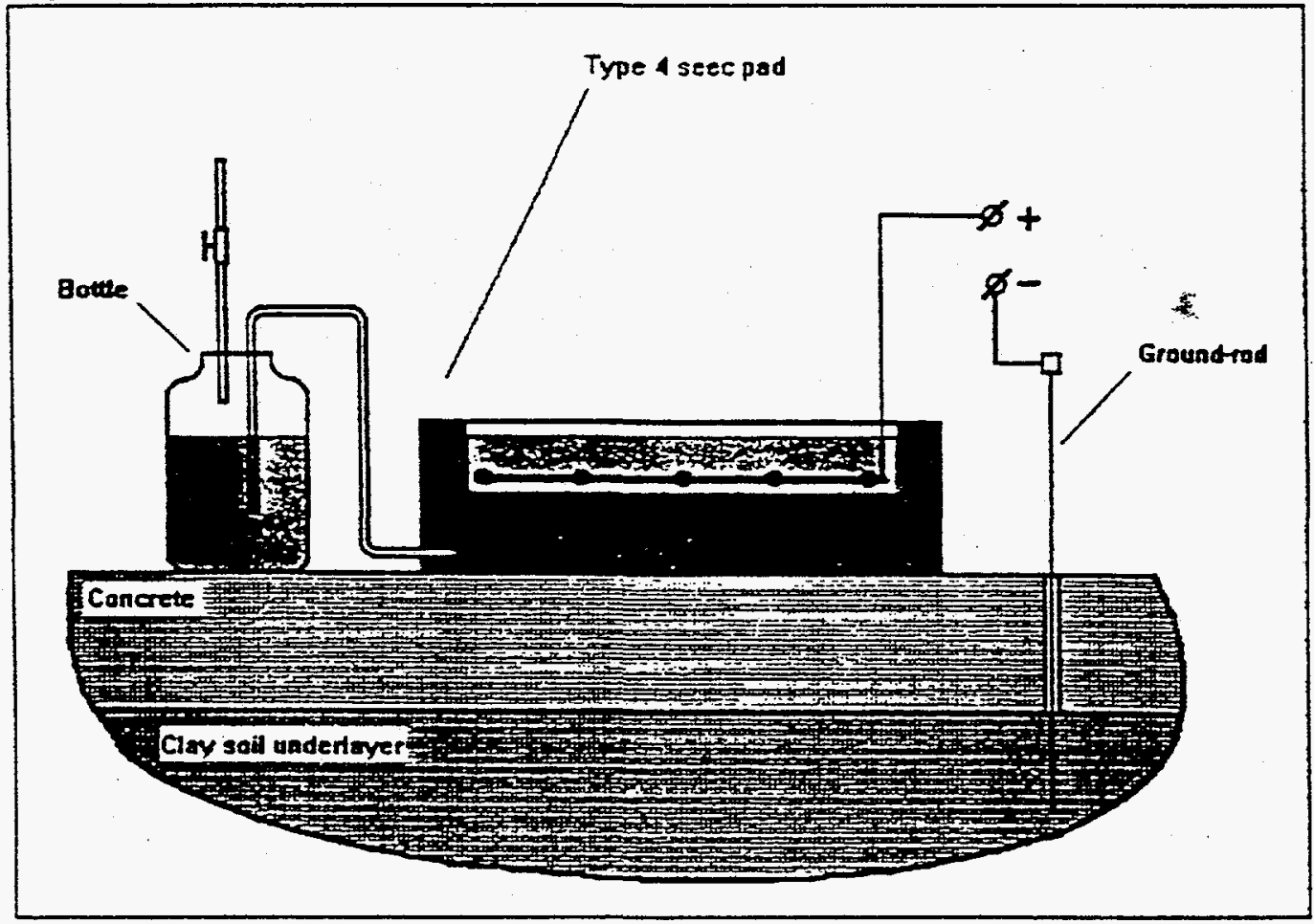


Contract № De-AC-21-93MC30162

Page 5 of 11

Interim Status Report

June 15,1995

Results of Third In-Situ Test

Rev. 02

at K-25 Site (Oak Ridge, TN)

April 24-28, 1995

\section{RESULTS OF EXPERIMENTS:}

Preliminary results of test are shown in Table 1 and Figures 5, 6 and 7.

Table 1. Preliminary Results of Tests at K-25 Site

\begin{tabular}{|c|c|c|c|c|c|c|c|c||}
\hline Experiment & Solution & $\begin{array}{c}\text { Volume } \\
\text { of Work } \\
\text { Solution } \\
\text { (liters) }\end{array}$ & $\begin{array}{c}\text { Cleaned } \\
\text { Surface } \\
\mathrm{ft}^{2}\end{array}$ & KWH & $\begin{array}{c}\text { Total } \\
\text { Collected } \\
\text { Uranium } \\
\text { (mg) }\end{array}$ & $\begin{array}{c}\text { Power } \\
\text { Consumption } \\
\text { for } \\
\text { Removing } \\
\text { lgof } \\
\text { Uranium } \\
\text { (KWH) }\end{array}$ & $\begin{array}{c}\text { Uranium } \\
\text { Collected } \\
\text { via } \\
\text { Chemical } \\
\text { Extraction } \\
\%\end{array}$ & $\begin{array}{c}\text { Uranium } \\
\text { Collected } \\
\text { via } \\
\text { Electrokinetic } \\
\text { Extraction } \\
\%\end{array}$ \\
\hline F-1 & W.10 & 1.5 & 1.0 & 0.366 & 663 & 0.6 & 37 & 63 \\
\hline F-2 & W.2 & 1.5 & 1.0 & 0.459 & 610 & 0.8 & 63 & 37 \\
\hline FM-1 & $\begin{array}{l}\text { W.11 } \\
\text { W.12 }\end{array}$ & 1.5 & 1.0 & -- & 751 &.- & 100 & - \\
\hline R-1 & W.11 & 0.15 & 0.11 & 0.025 & 8.4 & 3.0 & 18 & 82 \\
\hline R-2 & W.12 & 0.15 & 0.11 & 0.039 & 28.8 & 1.4 &.- & 100 \\
\hline S-1 & W.2 & 0.25 & 0.33 & 0.046 & 1.5 & 30.7 & - & 100 \\
\hline
\end{tabular}


Contract № De-AC-21-93MC30162

Page 6 of 11

Interim Status Report

June 15, 1995

Results of Third In-Situ Test

Rev. 02

at K-25 Site (Oak Ridge, TN)

April 24-28, 1995

Figure 5

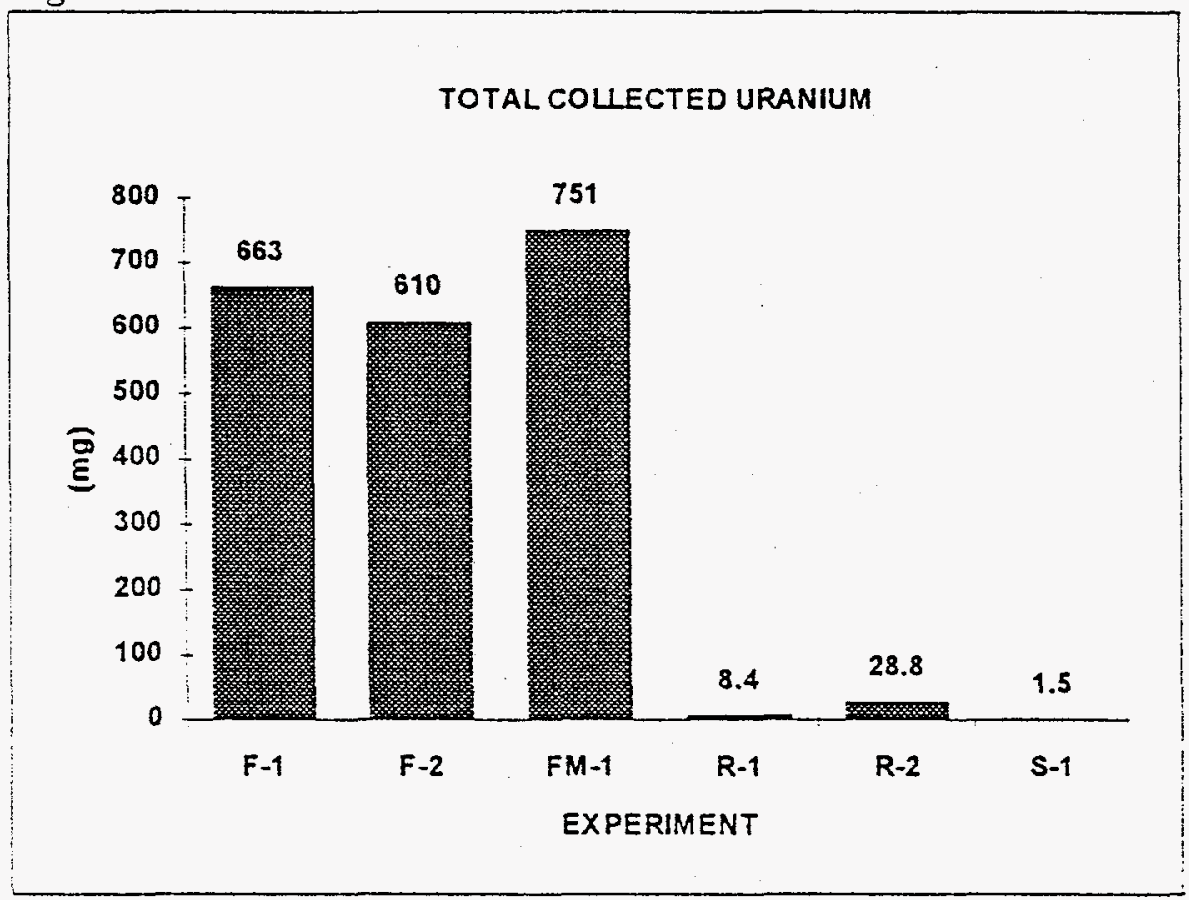

Figure 6

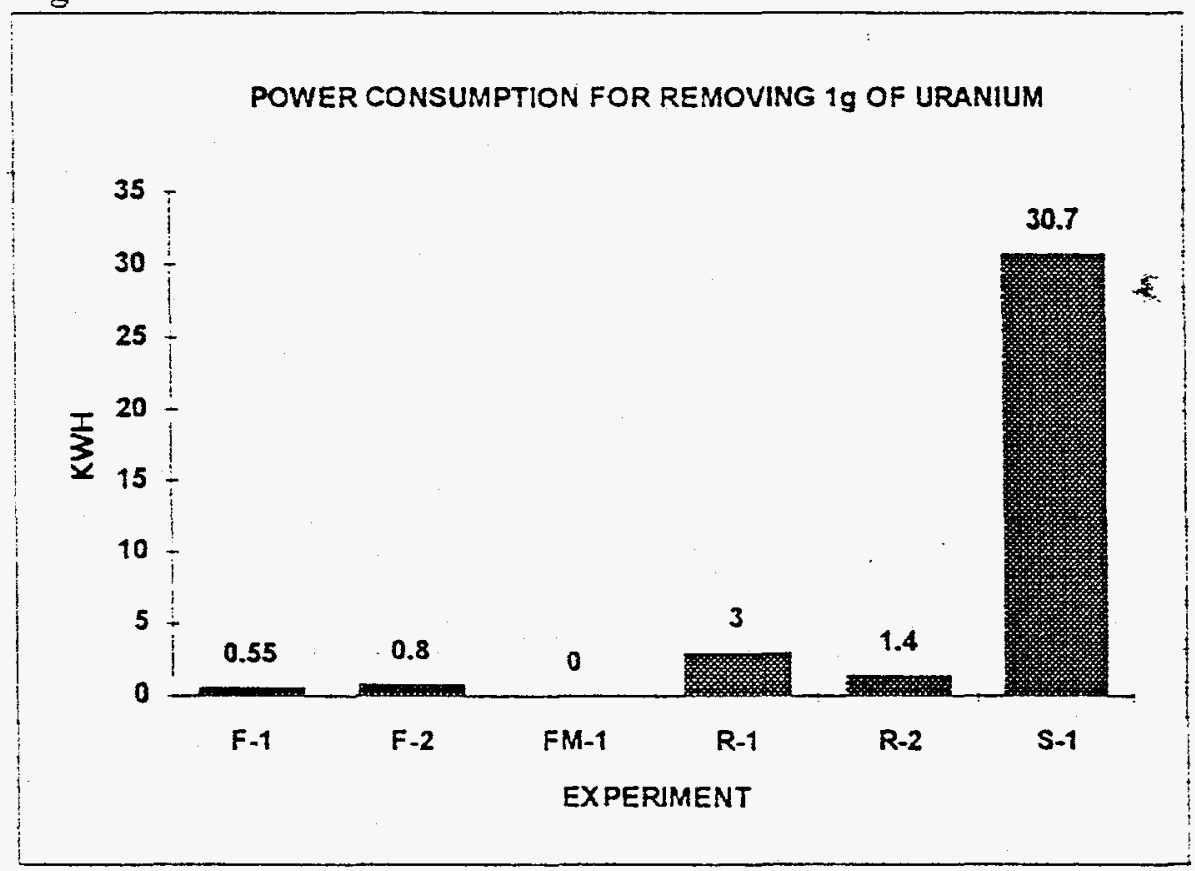


Contract NNo De-AC-21-93MC30162

Page 7 of 11

Interim Status Report

June 15,1995

Results of Third In-Situ Test

Rev. 02

at K-25 Site (Oak Ridge, TN)

April 24-28, 1995

Figure 7

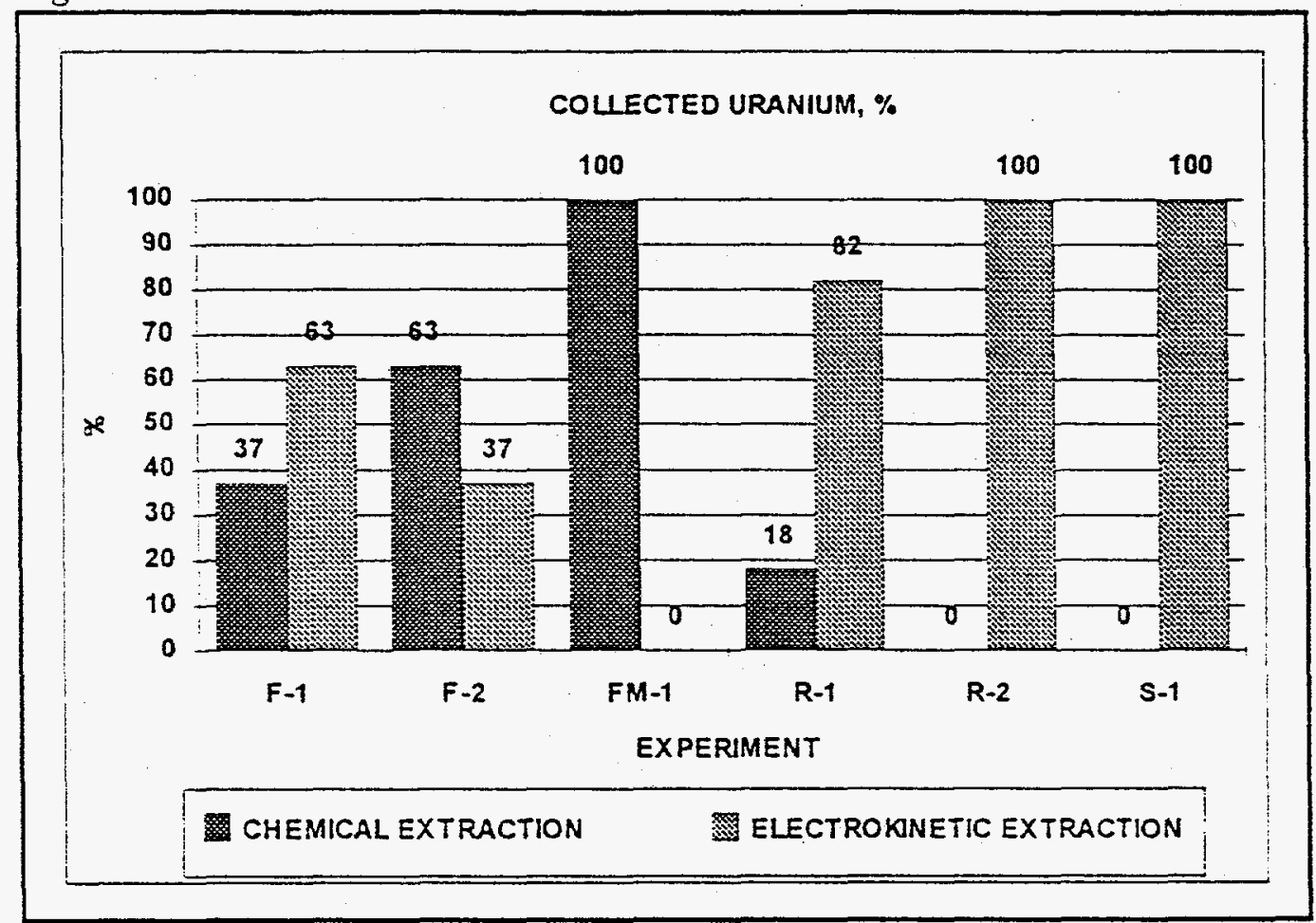




\section{Figure 8}

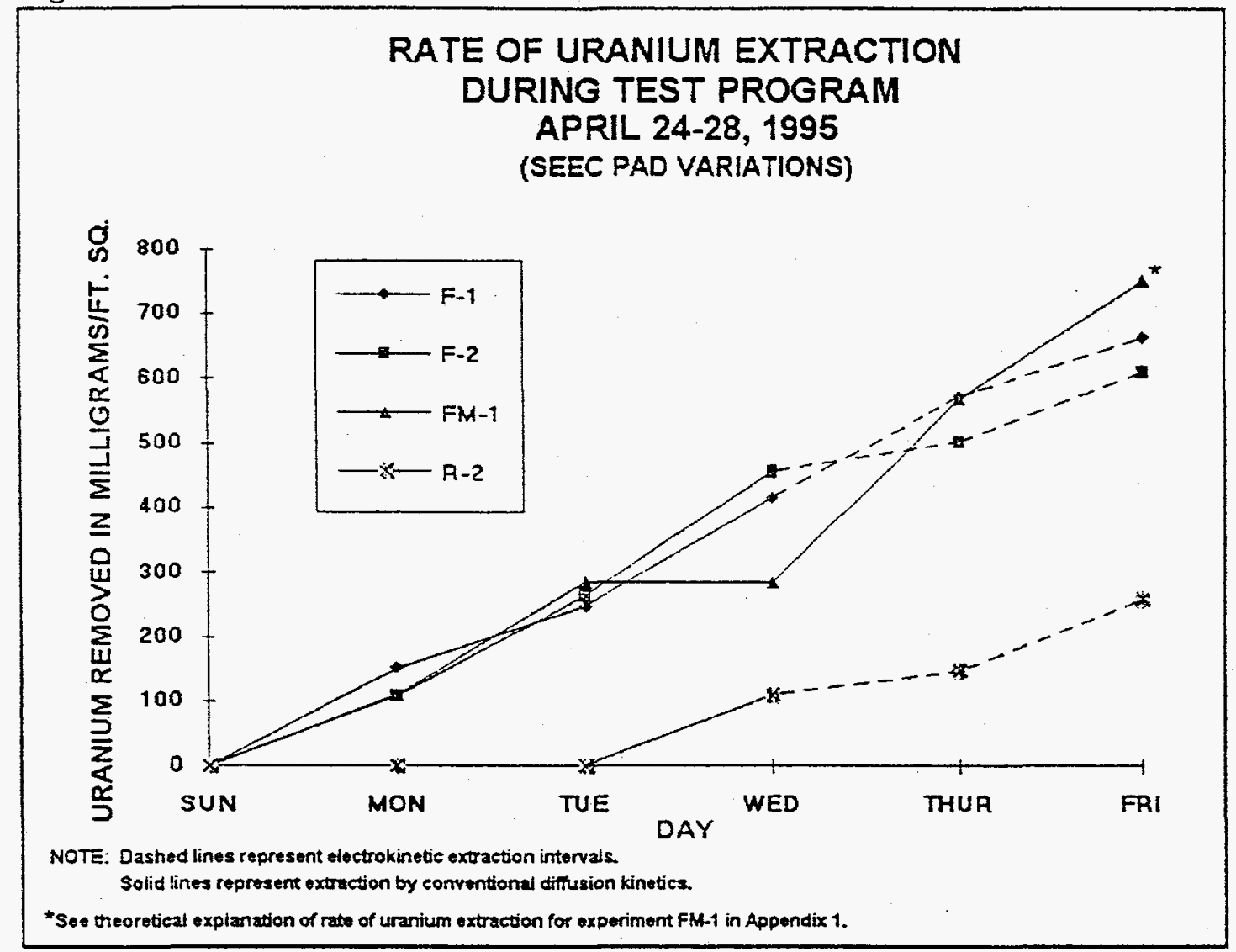

In the above figure, the electrokinetic process can be seen to extend the cleaning effectiveness of these solubilizer solutions. In the first phase of this concrete cleaning cycle, the concfete is contacted by a chemical solubilizing solution. (No electrical power is used.) These solutions were "rejuvenated" periodically to enhance their effectiveness in solubilizing the contaminants. This dissolution and diffusion phase efficiently removed a substantial amount of contaminant. In the second phase, the electrical power was applied to mobilize the deeper uranium in pores of concrete. The lower quantity of extracted uranium observed in test R-2 is explained by the less efficient dissolution by solubilizer solution which was used.

In test FM-1, no electrical power was used and yet the amount of uranium removed exceeded all other tests. That result is explained by higher initial concentration of uranium in "hot" spot under FM-1 SEEC pad. All SEEC pads were placed above localized "hot" spots with different initial concentrations of uranium. The application of electrical power to the FM-1 would undoubtedly have caused a substantial increase in the amount of uranium removed from this surface, but the constraints in number of electrical power leads did not permit this to be demonstrated. (In the next demo, sideby-side scenarios will permit this demonstration.) 


\section{OBSERVATIONS:}

1. The 37 hour duration of this divided extraction scenario, which was designed to permit the study of chemical electrokinetic extraction, was not long enough to achieve complete decontamination of concrete floor.

2. The ion exchange columns used in these experiments showed only marginal capability to effectively remove uranium from the working solution. It is necessary to significantly improve the ability to remove the contaminants quickly and efficiently from the working solution.

3. It is necessary to control the pH of the working solution between $\mathrm{pH} 8.6$ and 9.6 , as the solution circulates through the electrokinetic cleanup circuit.

4. An evaluation was made of the total mass of uranium in the working solution. One analysis was based on radioactive assay of the samples. A second analysis was based on the concentration of uranium (measured by ICP spectrophotometer "Plasma 400"). The evaluation clearly shows that the ISOTRONIC SEEC pads have collected a significant amount of other radioactive species. (An additional radionucide analysis is pending.)

5. It is necessary to maintain the oxidizer solution in the $\mathrm{W} .10$ working solution within the range of $2-4$ percent.

6. It does not appear to be necessary to keep the working solution at the 0.5 molar concentration used in these experiments. A more dilute level of 0.4 molar is proposed for test № 4 . 
Contract № De-AC-21-93MC30162

Page 10 of 11

Interim Status Report

June 15,1995

Results of Third In-Situ Test

Rev. 02

at K-25 Site (Oak Ridge, TN)

April 24-28, 1995

\section{APPENDLX 1}

Figure 9

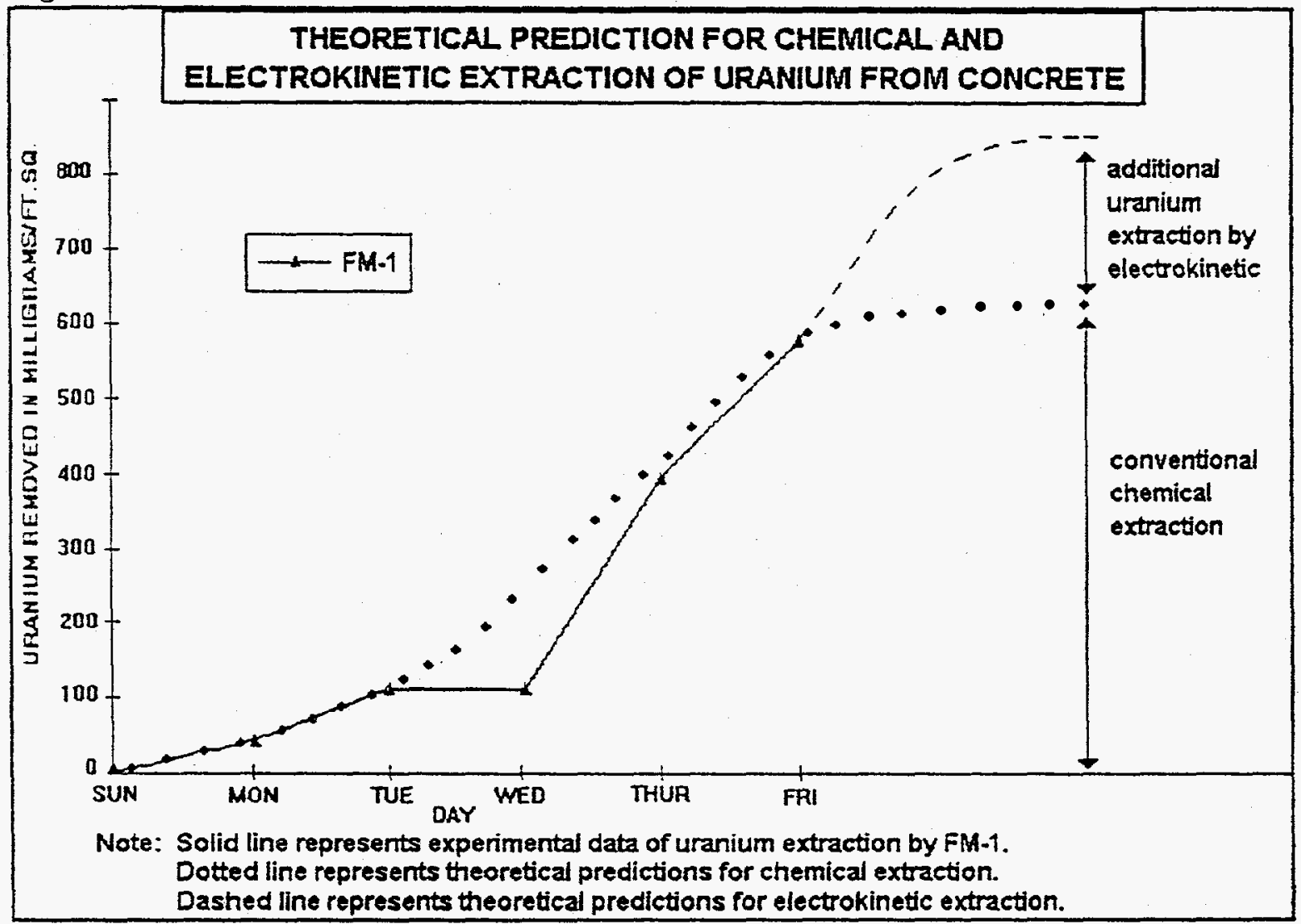


Contract № De-AC-21-93MC30162

Page 11 of 11

Interim Status Report

June 15,1995

Results of Third In-Situ Test

Rev. 02

at K-25 Site (Oak Ridge, TN)

April 24-28, 1995

\section{Appendix 1 (Continued)}

\section{Chemical Extraction of Uranium}

1. In the process of chemical extraction of uranium, complexant and uranium complexes are distributed in relatively narrow reaction zone. The thickness of this zone depends on complexant diffusion coefficient and rate constant of complexation reaction.

2. When the electrical field is applied to concrete, the complexant is delivered by electromigration mechanism into the depth of concrete. The thickness of reaction zone increases. This permits to extract uranium from all the contaminated regions. Since uranium complexes are charged, their removal by electromigration intensifies transport processes, thus making the decontamination procedure more effective in comparison to the chemical extraction.

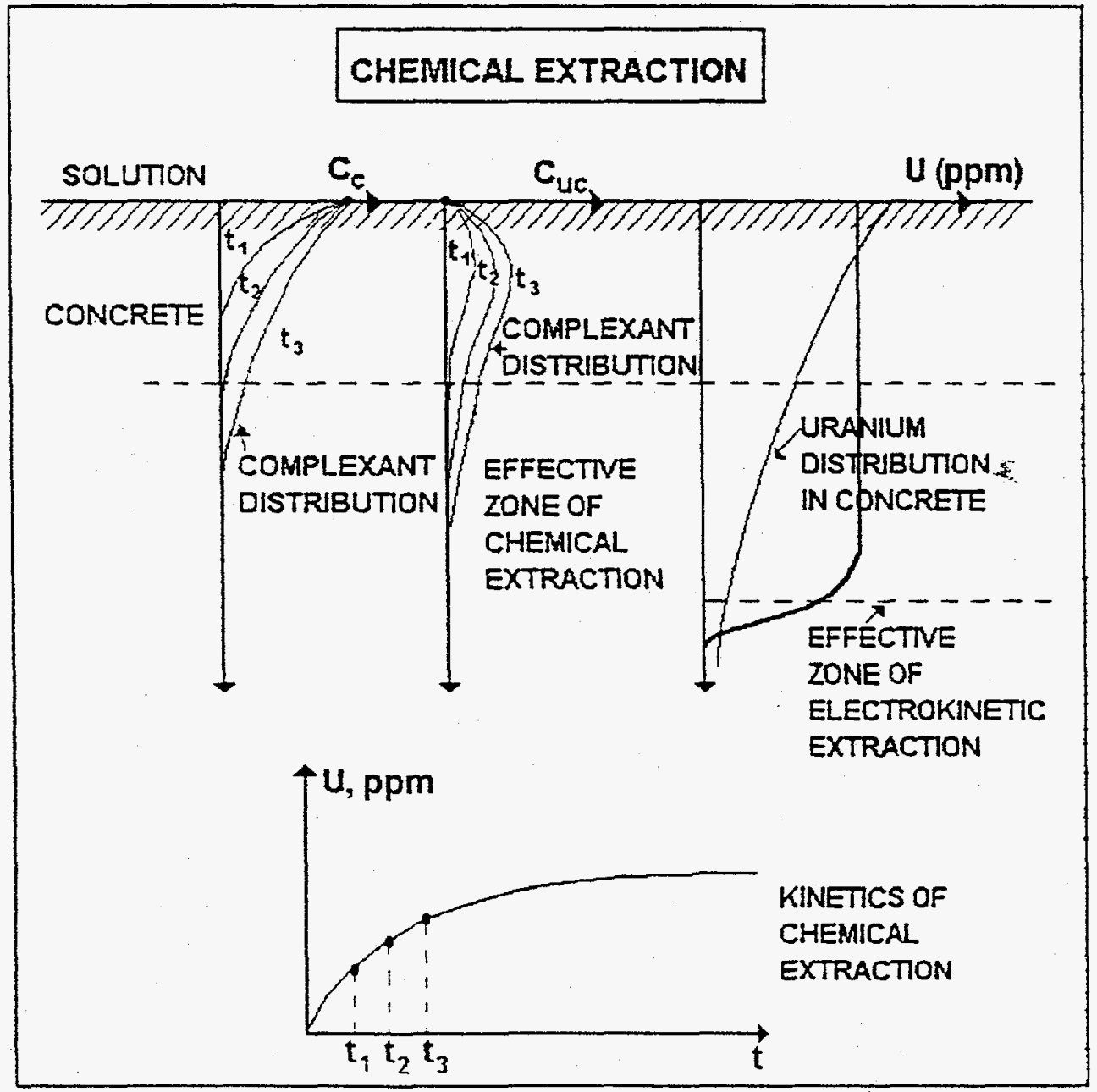


ISOTRON $^{\circledR}$ Technical Paper

for

Environmental Technology Development Through Industry Partnership Meeting

October 1995

"ELECTROKINETIC DECONTAMINATION OF CONCRETE" 
Environmental Technology Development

Through Industry Parnership Meeting

\section{AUTHOR DATA SHEET}

\section{Please type or print}

Paper's Exact Titie:

Electrokinetic Decontamination of Concrete

Alstion(s)/Affiliation(s):

ISOTRON ${ }^{3}$ Corporation

13152 Chef Menteur Hwy.

New Orleans, LA 70129

Presenting Author.

Presenting Author's Phone No.:

Henty I Lriasney

$504254-1624$

FAX/Telex: $\quad 504254-5172$

Presenting Author's E-mail Address:

CIAMASNEYOATTMAIL.COM

Altemate Presenter/Affliation (in the event the designated Presenter becomes unavailabie):

Name

Afiliation

Phone No.

Brief Biographical Statement on the Presenter (use the reverse side if additional space is required):

Mr. Lomasney graduated with a B.S. in Mechanical Engineering from Tulane University. He is a member of the American Society of Mechanical Engineers, American Society Testing Materials, National Association of Corrosion Engineers, and Steel Structure Painting Council. Mr. Lomasney has 30 years of experience in the field of polymers, coatings, radionuclide decontamination, cathodic protection, and electrochemical phenomena. He is a former Chairman of ASTM-33. ft on Decontaminability, U,S. delegate to ISO-T-C-85 on "Ease of Decontamination", and is consultant to

Signature:

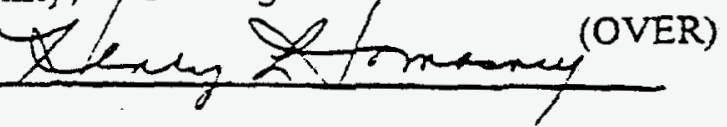

Date: $9 / 28 / 95$

Note: Please sign and retum this form with your manuscript Retain a copy of this Data Sheet for your files. This form will be distributed to your Session Chairperson:

\section{ENCLOSE THE COMPLEIED FORM WITH YOUR MANUSCRIPT} THIS FOAM MUST BE RECEIVED BY AUGUST 11, 1995

Conference Services Morgantown Energy Technology Center

P.O. Box 880, MIS K07

Morgantown, WN 25507-0880

onulusingsi24

Phone No:: (304) 285-4108; FAX: (304) $285-4469$ 


\title{
Electrokinetic Decontamination of Concrete
}

\author{
H. Lomasney (clamasnev@attmail com: 504-254-4624) \\ ISOTRON Corporation \\ 13152 Chet Menteur Hwy \\ New Orieans, LA 70129
}

\section{Introduction:}

The U.S. Department of Energy has assigned a priority to the advancement of technology for decontaminating concrete surfaces which have become contaminated with radionuclides, heavy metals, and toxic organics. This agency is responsible for decontamination and decommissioning of thousands of buildings.

Electrokinetic extraction is one of the several innovative technologies which emerged in response to this initiative.

This technique utilizes an electropotential gradient and the subsequent electrical transport mechanism to cause the controlled movement of ionics species, whereby the contaminants exit the recesses deep within the concrete.

\section{Objectives:}

The primary mission of this PRDA was to demonstrate the feasibility of this approach as a means to achieve "release levels" which could be consistent with unrestricted use of a deconraminated building.

The secondary objectives were:

Research sponsored by the U.S. Deparment of Energy's Morgantown Energy Technology Center, under contract DE-AC21-93MC30162 with ISOTRON Corporation. 13152 Chet Menteur Hwy. New Orleans, LA 70129. telefax: $504-254-5172$.
- To establish process parameters;

- To quantify the economics;

- To ascertain the ALARA considerations;

- To evaluate wasteform and waste volume

Observations to Date: The work carried out to this point has achieved promising resuits to the extent that ISOTRON ${ }^{*}$ has been authorized to expand the planned activity to inciude the fabrication of a prototype version of a commercial device.

This prototype unit includes a carpet-like surface pad whici carries out the extraction step.

The extraction pad is connected via tubing and power cable bundle to the electrokinetic separation module (ESM). This ESM recycles the liquid electrolyte (which is circulated from the extraction pad). The ESM apparanus carries out an electrodialysis separation of radionuclides from the electrolyte.

Current project planning calls for this equipment to be operated at the DOE's K-25 Site during the months of October and November 1995

\section{Approach:}

The technology for electrically forcing 
contaminants through concrete has a precedent in work carried out under sponsorships of the U.S. Department of Transportation. In this application, an electrical gradient is used to prevent corrosion of steel reinforcing within bridge decks. The mechanism provides a means to remove de-icing salts from concrete, and at the same time, the intense cathodic polarity applied to the rebar prevents subsequent corrosion.

The technology for electrically forcing radioactive contaminants through concrete was studied by Dr. William Bostick and colleagues during 1993-1994 with positive results, however, the early work was designed to favor use of electroosmotic transport of contaminants.

The first phase of ISOTRON"s work focused on study of the fundamentals of dissolution (and subsequent "freeing" of these contaminants from the concrete matrix). Only after the contaminants are solubilized within the concrete matrix, can they be transported.

The development of complexants that could selectively solubilize the "target" contaninant metals was seen to be a strategically vital aspect of this program.

For almost ten years, ISOTRON scientists have worked on electrical migration of radionuclides through soils, groundwater. concrete, and polymeric materials. This experience provided the requisite insight needed to deal with the technological challenges of dissolution kinetics, as well as transport kinetics related to contaminants in concrete.

ISOTRON" scientists are highly focused on this subject of radionuclide desorption from mineral surfaces. This work involves cooperation with recognized experts in USA. including scientists at Oak Ridge National
Laboratory and Los Alamos National Laboratory. The ISOTRON* specialists are also working in close collaboration with Russian scientists who are specialized in this field. Over the past four years, this USA/Russian scientific collaboration regarding this electrokinetic technology involved scientists from the Russian Firm "Radon", Russia's largest processor of radioactive waste materials, Russian Instiute (VNIPIPT), Russia's Institute of Mining and Metallurgy (located in Moscow), Russian Institute of Agricultural Radio-Ecology (located in Obninsk), and the Russian organization ENERGOPOOL which is a nuclear equipment design organization (located in Moscow). This collaboration also involves Former Nuclear Weapons scientists from the installations Chelyabinsk, Mayak, and Arzamas.

The ISOTRON ${ }^{*}$ staff and collaborators have, in general, approached this program with an emphasis on understanding the sorprion mechanisms which are at work within the concrete matrix and which result in the "caprure" of contaminants. Conversely, the technology related to ligand enhanced dissolution has emerged as a significant factor in the efficiency of the process. The selective desorption or dissolution of contaminants is recognized as an important consideration in process optimization.

The optimization of the elecrolyte design has been approached with the following. success criteria:

1. The electrokinetic transport rate of target contaminants (higher is better).

2. Dissolution kinetics - the ISOTRON studies have shown that the cleanup rate is controlled by the kinetics of complexant aided dissolution. (Theoretical analysis reveals that this extraction process may be either transport controlled or dissolution controlled.) 
3. Selectivity for contaminants removing ions that are not necessary for cleanup is undesirabie. Such a condition burdens the process with parasitic power demands, excess electrolyte consumption, and unnecessary waste volume.

4. Environmental (atmospheric) considerations - residual solubilizer components are to be benign.

In general, ISOTRON ${ }^{-1}$ scientists have concluded that one of the more effective electrolytes which can be recommended for this application is carbonate.

\section{Project Description:}

Development of an electrokinetic extraction process for reversing the mechanics of concrete contamination, whereby the contaminants are selectively desorbed from concrete and migrated out of the concrete, and subsequently coilected for disposal.

\section{Results:}

Uranium is the target contaminant which was identified for this demonstration at $\mathrm{K}-25$ Site in Oak Ridige. The ELECTROSORB electrokinetic extraction process has been used to extract uranium from bare concrete floors associated with storage vaults which had been used in various services over a forty-year life span.

The uranium contamination was not uniform. Consequently, removal of uranium was also not uniform. Removal rates range from 0.1 grams per square foot up to a high of 1.1 grams per square foot.

A major success criterion for this process is the efficient recycling of electrolyte.
ISOTRON ${ }^{\circ}$ scientists have deait with this problem by means of its electrokinetic separation module. The following illustration describes its function.

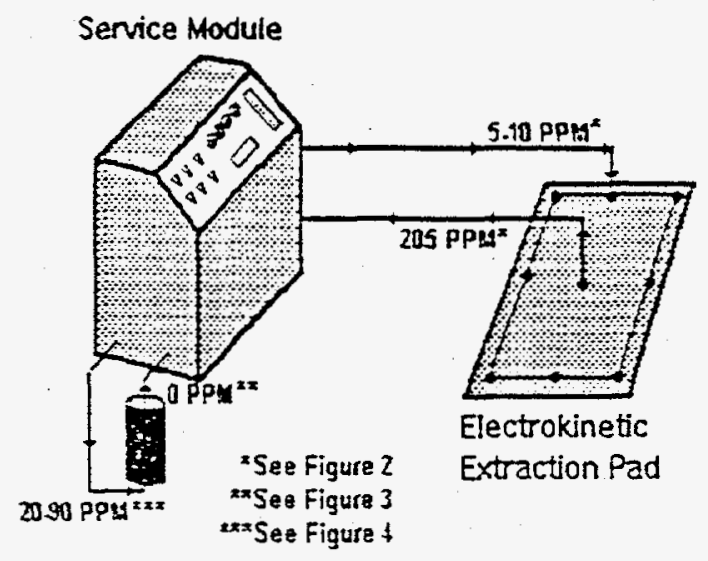

Figure I

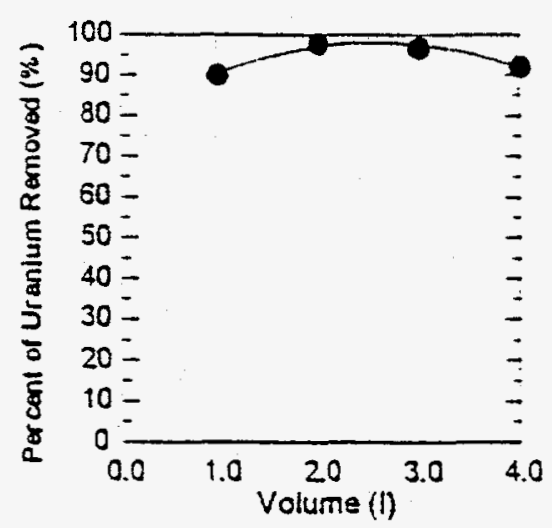

Figure 2

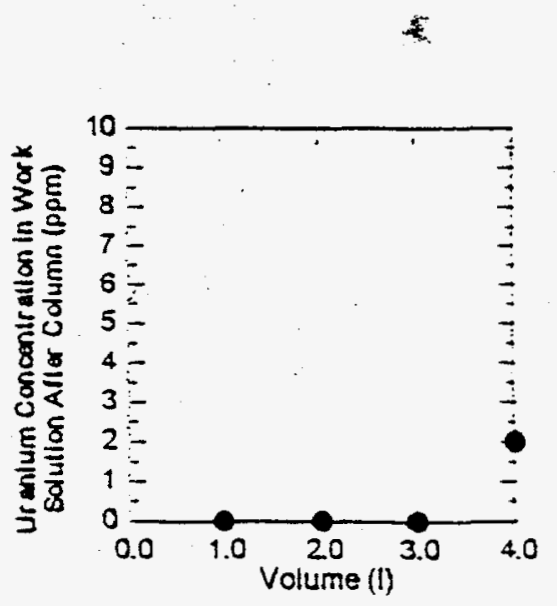

Figure 3 


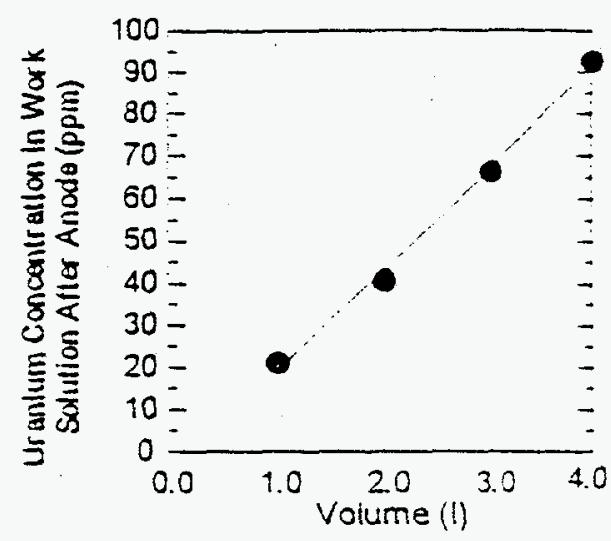

Figure 4

\section{Application:}

This application is designed for use in decontamination and decommissioning activities, wherever an extraction pad can be brought into contact with a contaminated surface.

\section{Future Activities:}

ISOTRON ${ }^{\text {to }}$ staff is preparing for a pilot scale demonstration in October November 1995

An independent third pary contractor will participate. This contractor will be responsible for the characterization of the demo area prior to decon and after decon. This contractor will gather verificarion dara on power consumption, chemical usage, waste volume, and similar related operational information.

Future work is planned to develop more experience with electrolytes for removing radionuclides such as cesium, strontium, plutonium.

Work is anticipated that will investigate the use of high energy pulsed power to enhance overall process efficiency, and at the same time, a shortened cleanup cycle duration.
Work to simplify and to improve the functional controls and automation of the "ESM" is anticipated.

\section{Acknowledgments:}

U.S. Department of Energy, Office of Technology Development, Office of Environmental Management, Germantown, Maryland, Jerry M. Hyde.

\section{U.S. Department of Energy,} Morgantown Energy Technology Center, Morgantown, West Virginia, Dr. Paul Hart, J.T. "Jeet" Malhotra. 